\title{
Polarity establishment, asymmetric division and segregation of fate determinants in early $C$. elegans embryos*
}

\author{
Lesilee Rose $^{1 \S}$ and Pierre Gönczy ${ }^{2 \S}$ \\ ${ }^{1}$ Department of Molecular \& Cellular Biology, University of California, Davis, Davis, CA USA \\ 95616 \\ ${ }^{2}$ Swiss Institute for Experimental Cancer Research (ISREC), School of Life Sciences, Swiss \\ Federal Institute of Technology (EPFL), Lausanne, Switzerland
}

\section{Table of Contents}

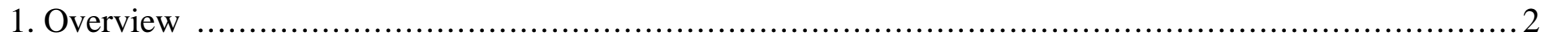

2. Generating the anterior-posterior embryonic axis in the one-cell embryo ...............................

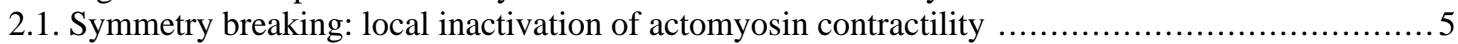

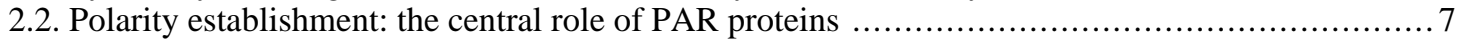

2.3. Polarity maintenance by mutual inhibition of anterior and posterior cortical domains $\ldots \ldots \ldots \ldots \ldots . . . . .9$

2.4. Modeling polarization . .................................................................. 11

3. Centrosome and spindle positioning during the first asymmetric division ............................. 13

3.1. Pulling forces acting on astral microtubules ................................................. 13

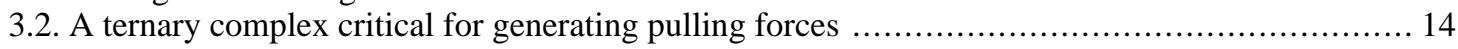

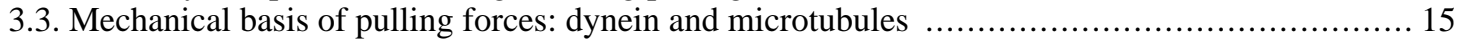

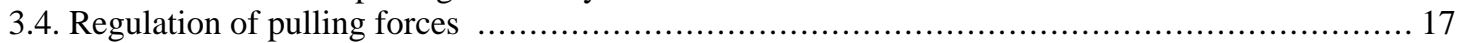

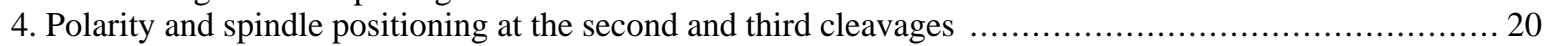

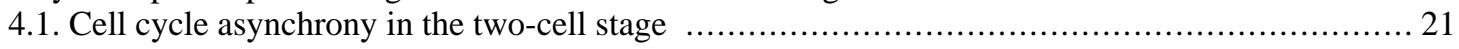

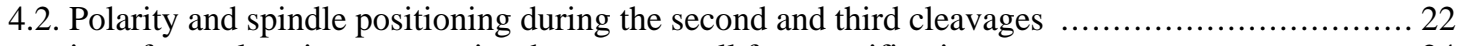

5. Generation of cytoplasmic asymmetries that govern cell fate specification ............................... 24

5.1. PAR-1 kinase activity produces a cytoplasmic gradient of MEX-5 ...............................25

5.2. MEX-5/6 promote the asymmetric localization of multiple factors ................................26

5.3. Polarity mediators interact to generate additional asymmetries of fate regulators $\ldots \ldots \ldots \ldots \ldots \ldots \ldots . \ldots \ldots$

\footnotetext{
*Edited by: Joel H. Rothman and Andrew Singson. Last Revised Nov. 26, 2013. Published December 30, 2014. This chapter should be cited as: Rose L. and Gönczy P. Polarity establishment, asymmetric division and segregation of fate determinants in early C. elegans embryos (December 30, 2014), WormBook, ed. The C. elegans Research Community, WormBook, doi/10.1895/wormbook.1.30.2, http://www.wormbook.org.

Copyright: (C) 2014 Lesilee Rose and Pierre Gönczy. This is an open-access article distributed under the terms of the Creative Commons Attribution License, which permits unrestricted use, distribution, and reproduction in any medium, provided the original author and source are credited.

${ }^{\S}$ To whom correspondence should be addressed. Email: 1srose@ucdavis.edu or Pierre.Gonczy@epfl.ch
} 


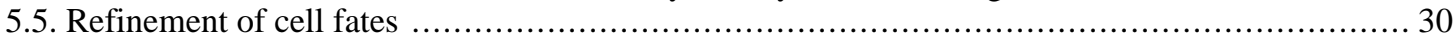

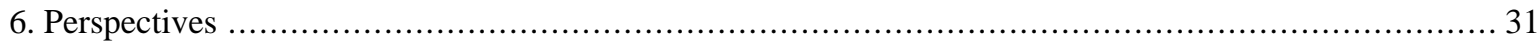

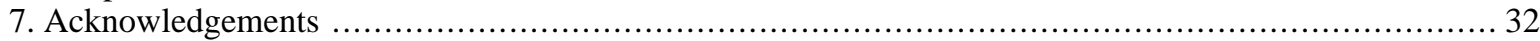

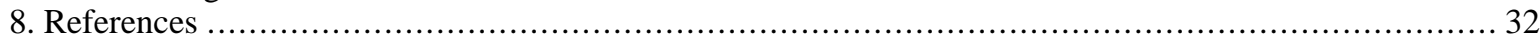

\begin{abstract}
Polarity establishment, asymmetric division, and acquisition of cell fates are critical steps during early development. In this review, we discuss processes that set up the embryonic axes, with an emphasis on polarity establishment and asymmetric division. We begin with the first asymmetric division in the $C$. elegans embryo, where symmetry is broken by the local inactivation of actomyosin cortical contractility. This contributes to establishing a polarized distribution of PAR proteins and associated components on the cell cortex along the longitudinal embryonic axis, which becomes the anterior-posterior (AP) axis. Thereafter, AP polarity is maintained through reciprocal negative interactions between the anterior and posterior cortical domains. We then review the mechanisms that ensure proper positioning of the centrosomes and the mitotic spindle in the one-cell embryo by exerting pulling forces on astral microtubules. We explain how a ternary complex comprised of G $\alpha$ (GOA-1/GPA-16), GPR-1/GPR-2, and LIN-5 is essential for anchoring the motor protein dynein to the cell cortex, where it is thought to exert pulling forces on depolymerizing astral microtubules. We proceed by providing an overview of cell cycle asynchrony in two-cell embryos, as well as the cell signaling and spindle positioning events that underly the subsequent asymmetric divisions, which establish the dorsal-ventral and left-right axes. We then discuss how AP polarity ensures the unequal segregation of cell fate regulators via the cytoplasmic proteins MEX-5/MEX-6 and other polarity mediators, before ending with an overview of how the fates of the early blastomeres are specified by these processes.
\end{abstract}

\title{
1. Overview
}

During development, cells acquire distinct fates, and one prominent mechanism by which this is achieved is asymmetric division. In the early embryo of $C$. elegans, five asymmetric divisions produce six founder cells: AB, MS, E, C, D, and $\mathrm{P}_{4}$ (Figure 1). The first asymmetric division cleaves the one-cell zygote into a larger anterior blastomere, $\mathrm{AB}$, and a smaller posterior blastomere, $\mathrm{P}_{1}$. Thereafter, $\mathrm{P}_{1}$ undergoes an asymmetric division that gives rise to EMS and $\mathrm{P}_{2}$. Subsequent asymmetric divisions of EMS into MS and E, then of $\mathrm{P}_{2}$ into $C$ and $\mathrm{P}_{3}$, and finally of $\mathrm{P}_{3}$ into $\mathrm{D}$ and $\mathrm{P}_{4}$, complete the generation of the six founder cells whose descendants each produce specific cell types (Sulston et al., 1983) (Figure 1).

The three body axes are set up during these early cleavage divisions. First, the anterior-posterior (AP) axis is established in the one-cell embryo, with the sperm-derived centrosome determining the future posterior side. This leads to a series of asymmetries between the anterior and posterior parts of the embryo derived from the $A B$ and $\mathrm{P}_{1}$ cells, respectively. Second, the dorso-ventral (DV) axis is established by the four-cell stage, with EMS dictating the ventral side. Third, the left-right (LR) axis becomes apparent by the six-cell stage, with the ABal and ABpl cells defining the left side. During these early divisions, asymmetries in cellular inheritance combined with cell signaling events act to refine the fates of the founder cells and their daughters. 
This review provides an overview of the mechanisms governing polarity establishment, asymmetric division and segregation of cell fate determinants in early C. elegans embryos. We focus on events taking place in the one-cell embryo, as well as on the generation of cytoplasmic asymmetries in the early embryo. The names and localization within the early embryo of the principal proteins covered in this review are summarized in Tables 1,2, and 3. We refer readers to other publications for detailed coverage of the processes governing cell fate specification (e.g., Wang and Seydoux, 2013; Sawa, 2012; Pohl, 2011; Maduro, 2010; Munro and Bowerman, 2009). This review is related to our 2005 WormBook chapter Asymmetric cell division and axis formation in the embryo, with which it overlaps in part for structure and content, since many of the fundamentals have remained unchanged. Nevertheless, the field witnessed important progress in the past several years, which we attempted to cover in the present rendition. Due to space constraints, some aspects that were covered extensively previously could not be mentioned in detail here; readers should refer to the 2005 contribution and the references therein in those cases.

A
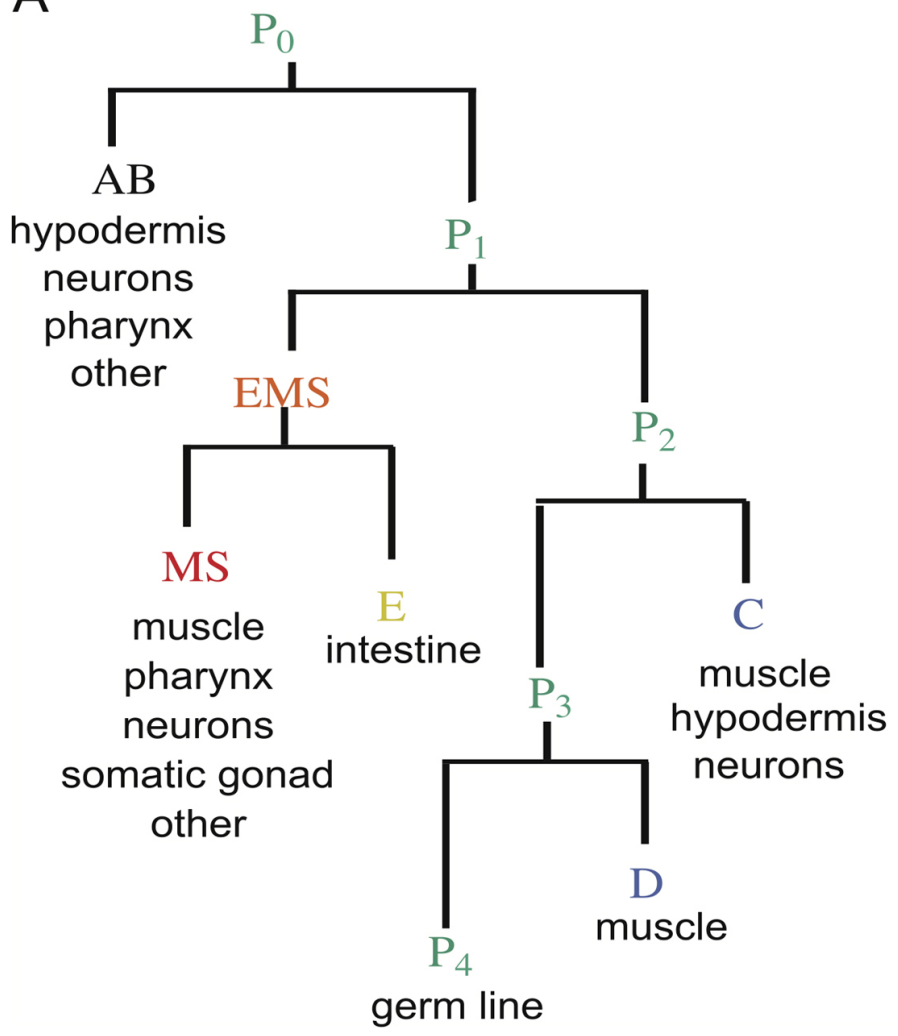

B
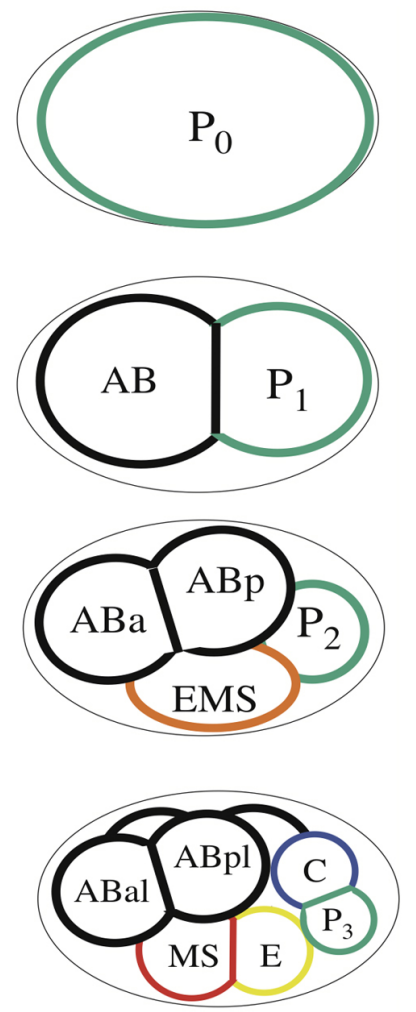

Figure 1. Generation of founder cells in the early embryo. Anterior is to the left, posterior to the right, dorsal is up and ventral down in this and all subsequent figures. (A) Cell lineage of the early embryo. The horizontal lines connect sister cells; the length of the vertical lines indicates the relative cell cycle duration of each founder cell. The major cell types produced from each founder cell are shown. (B) Schematic diagram of cell positions at different stages. The germ-line precursors (P cells) are shown outlined with green, and each of the founder cells generated by asymmetric division are indicated with a different color. The daughters of founder cells are named by their position; e.g., ABa is the anterior daughter of $\mathrm{AB}$, whereas $\mathrm{ABal}$ is the left daughter of $\mathrm{ABa}$. The embryo proper is surrounded by an eggshell, schematized by a black line. 


\section{Generating the anterior-posterior embryonic axis in the one-cell embryo}

The AP embryonic axis is put in place during the first cell cycle and this process can be decomposed into three principal steps: symmetry breaking, establishment of AP polarity, and maintenance of this polarity (Figure 2). These three steps are discussed in turn below and can be viewed with high temporal and spatial resolution using simple time-lapse Differential Interference Contrast (DIC) microscopy (Movie 1).

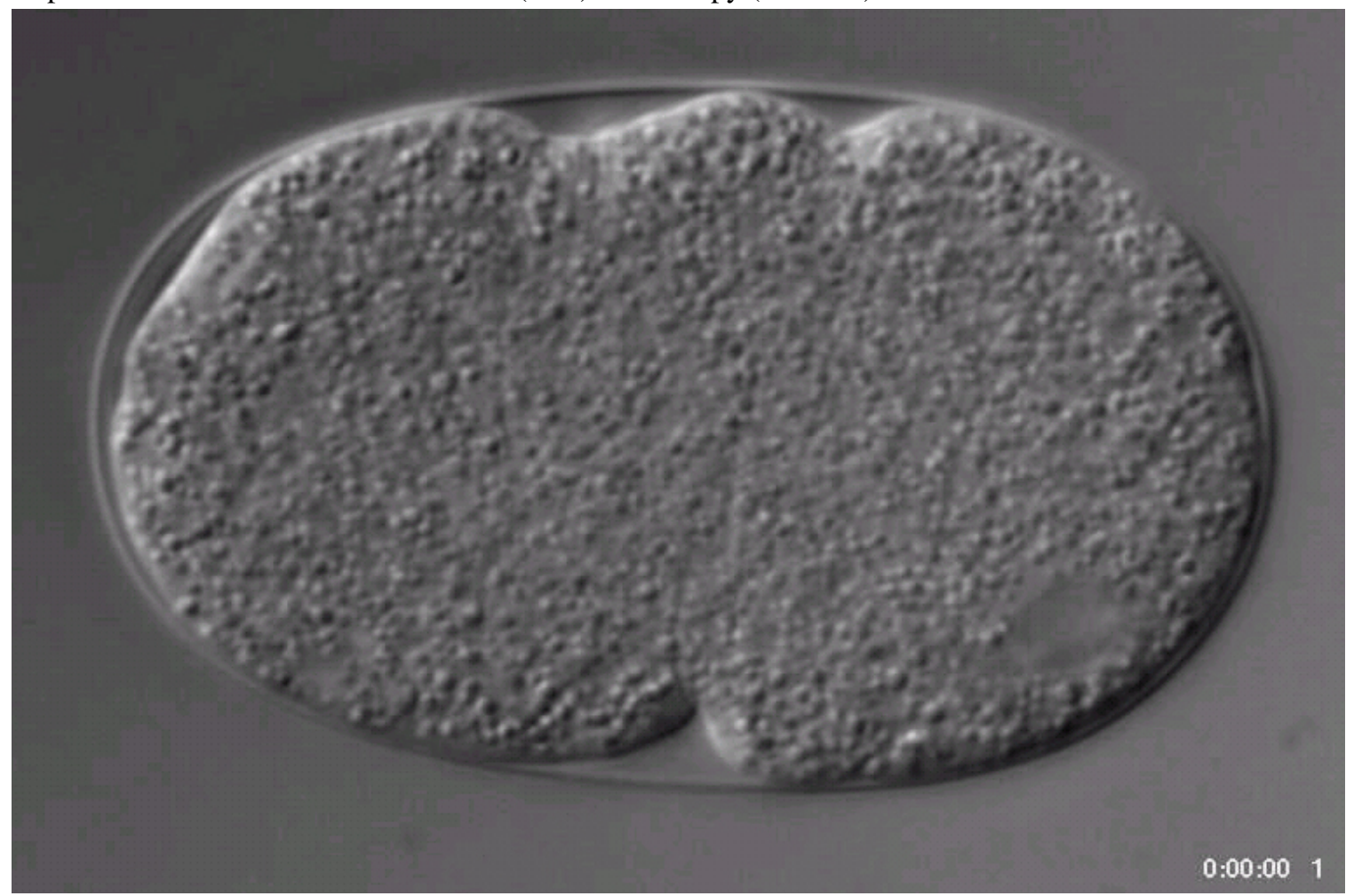

Movie 1. Time-lapse DIC microscopy of one-cell stage embryo from the onset of polarity establishment until the early two-cell stage. In this and the other movies, embryos are approximately $50 \mu \mathrm{m}$ long and oriented with anterior to the left. Time is indicated in minutes and seconds from the beginning of the recording. Courtesy of Zoltán Spiró (Gönczy laboratory). 

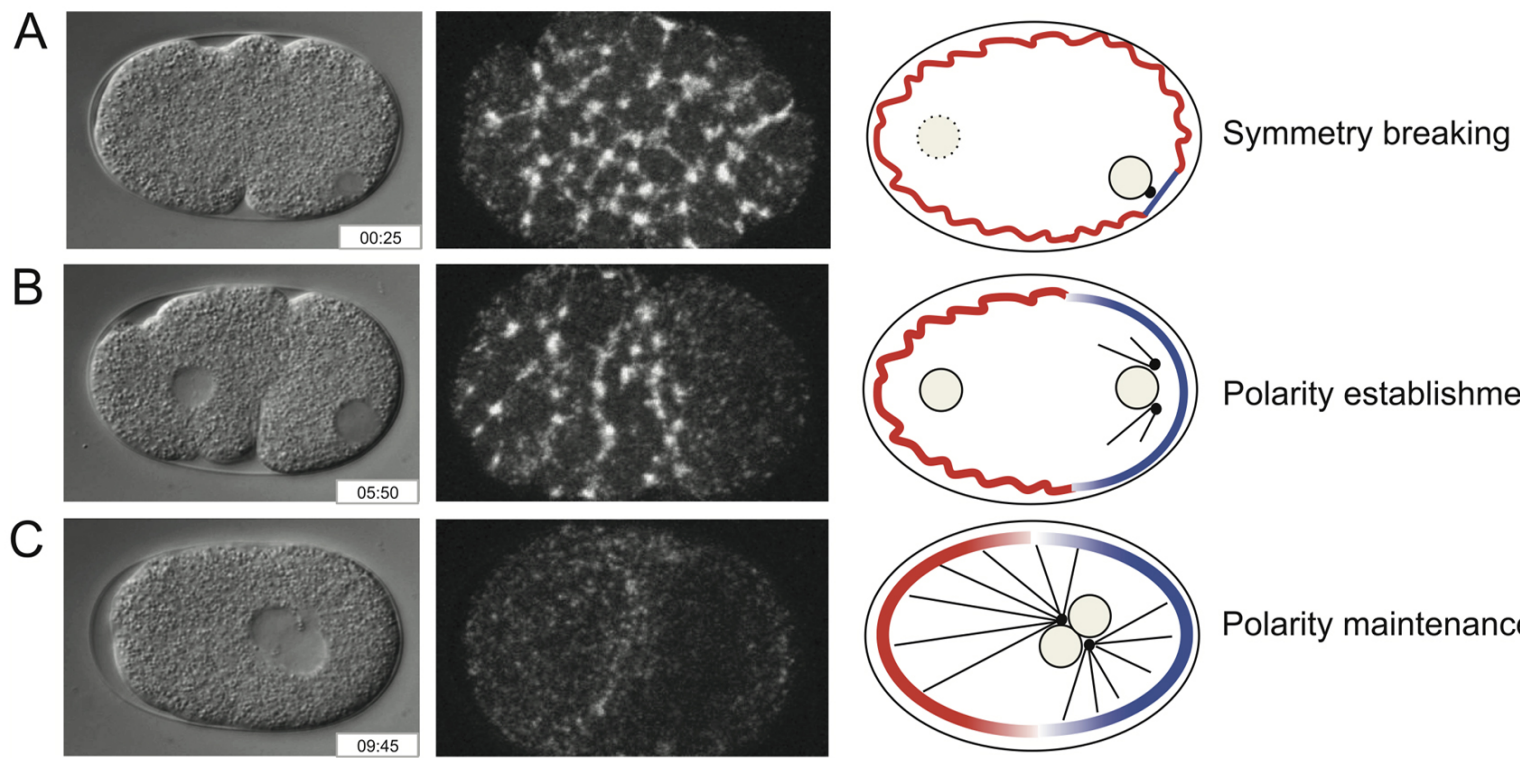

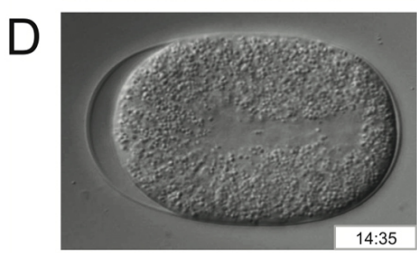

DIC

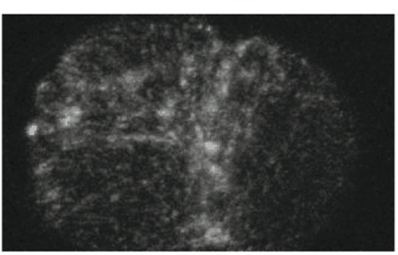

NMY-2-GFP

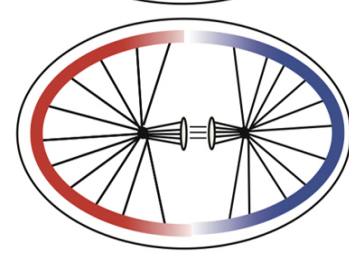

PAR-3/PAR-6/PKC-3 PAR-2/PAR-1
Polarity establishment

Polarity maintenance Mitosis (anaphase)

Nucleus

- Centrosome

Figure 2. Anterior-posterior in one-cell stage embryos. Left: images from time-lapse differential interference contrast (DIC) microscopy (see Movie 1); time is displayed in min:sec from the beginning of the recording. Middle: images from time-lapse fluorescence confocal microscopy at approximately corresponding stages (from Munro et al., 2004). Right: corresponding schematics, illustrating the distribution of the anterior (red) and posterior (blue) PAR proteins. Embryo is approximately $50 \mu \mathrm{m}$ long and is surrounded by an eggshell (visible in A and shown schematically in C). (A) At symmetry breaking, surface contractions of the cortical actomyosin network (red, wiggled line) cease in the vicinity of the centrosome, resulting in the generation of a small smooth cortical domain (blue, smooth line). (B) During polarity establishment, the smooth cortical area expands anteriorly to eventually reach 50\% egg-length. Concomitantly, GFP::PAR-2 expands towards the anterior, whereas GFP::PAR-6 retracts from the posterior. (C, D) During centration/rotation (C) and mitosis (D, anaphase shown here), AP polarity is maintained by the mutual inhibition of the anterior and posterior cortical domains. See also Table 1.

\subsection{Symmetry breaking: local inactivation of actomyosin contractility}

Fertilization occurs in the spermatheca, with the union of a mature oocyte and a sperm cell. The newly fertilized zygote is then displaced into the uterus where meiosis is completed and early embryogenesis takes place. Starting from the time of anaphase of meiosis II, the entire actomyosin network located in the cell cortex that underlies the plasma membrane undergoes contractions that depend on the non-muscle myosin II heavy chain NMY-2 and the associated non-muscle myosin light chain 4 MLC-4 (Munro et al., 2004; Shelton et al., 1999) (Figure 2A). Moreover, such surface contractions require the Rho family GTPase RHO-1 and the Rho-binding kinase LET-502, which together promote NMY-2 activity and contraction of the cortical actomyosin network (Kumfer et al., 2010; Motegi and Sugimoto, 2006; Schonegg and Hyman, 2006). 
Polarity establishment, asymmetric division and segregation of fate determinants in early C. elegans embryos

\begin{tabular}{|c|c|c|c|c|}
\hline & C. elegans & $\begin{array}{l}\text { Drosophilal } \\
\text { Vertebrates }^{\text {a }}\end{array}$ & $\begin{array}{c}\text { Protein } \\
\text { Distribution }^{\mathrm{b}}\end{array}$ & Molecular Nature \& Function \\
\hline \multirow{4}{*}{ 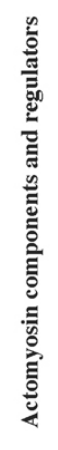 } & CYK-4 & $\begin{array}{l}\text { RacGAP84C/ } \\
\text { MgcRacGAP1 }\end{array}$ & & $\begin{array}{l}\text { Small GTPase activating protein (GAP); protein contributed by sperm } \\
\text { may inactivate RHO-1 at the presumptive posterior pole during } \\
\text { symmetry breaking. }\end{array}$ \\
\hline & ECT-2 & $\begin{array}{l}\mathrm{Pbl} / \\
\mathrm{ECT} 2\end{array}$ & & $\begin{array}{l}\text { Small GTPase exchange factor (GEF) that activates RHO- } 1 \text {; local } \\
\text { removal at the presumptive posterior pole promotes polarity } \\
\text { establishment. }\end{array}$ \\
\hline & NMY-2 & $\begin{array}{l}\text { Mhc/ } \\
\text { Myh3 }\end{array}$ & & $\begin{array}{l}\text { Heavy chain of non-muscle myosin; with light chain (MLC-4), } \\
\text { required for actomyosin cortical flows and establishment of anterior } \\
\text { PAR domain. }\end{array}$ \\
\hline & RHO-1 & $\begin{array}{l}\text { Rho1/ } \\
\text { RhoA }\end{array}$ & & $\begin{array}{l}\text { Small GTPase of the Rho family; promotes actomyosin contractility; } \\
\text { inactivation at the presumptive posterior pole generates asymmetric } \\
\text { NMY- } 2 \text { contractility and thus polarity establishment. }\end{array}$ \\
\hline \multirow{10}{*}{ 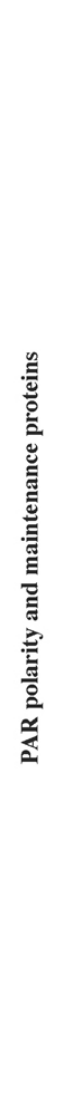 } & CDC-37 & $\begin{array}{l}\text { Cdc37/ } \\
\text { Cdc37 }\end{array}$ & & $\begin{array}{l}\text { Co-chaperone; stabilizes PKC-3 and prevents overlap of anterior and } \\
\text { posterior PAR domains. }\end{array}$ \\
\hline & CDC-42 & $\begin{array}{l}\mathrm{Cdc} 42 / \\
\mathrm{Cdc} 42\end{array}$ & & $\begin{array}{l}\text { Small GTPase of the Cdc } 42 \text { family; maintains polarity via PAR- } 6 \\
\text { binding, regulated by the GEF CGEF-1 and the GAP CHIN-1; CDC- } 42 \\
\text { also contributes to polarity establishment. }\end{array}$ \\
\hline & LGL-1 & $\begin{array}{l}\mathrm{Lgl} / \\
\mathrm{Lgll1}\end{array}$ & & $\begin{array}{l}\text { WD40-repeat protein; maintains polarity in a partially redundant } \\
\text { manner with PAR-2. }\end{array}$ \\
\hline & PAR-1 & $\begin{array}{l}\text { Par-1/ } \\
\text { MARK1 }\end{array}$ & & $\begin{array}{l}\text { Serine/Threonine kinase of the MARK family; regulates cytoplasmic } \\
\text { asymmetry of MEX-5/6. }\end{array}$ \\
\hline & PAR-2 & - & & $\begin{array}{l}\text { Ring-finger protein of E3 ligase class; maintains polarity established by } \\
\text { NMY-2 flows; in absence of flows, establishes polarity through } \\
\text { microtubule-dependent mechanism. }\end{array}$ \\
\hline & PAR-3 & $\begin{array}{l}\text { Baz/ } \\
\text { Pard3 }\end{array}$ & & $\begin{array}{l}\text { Multiple PDZ-domain scaffold protein; recruits PAR- } 6 \text { and PKC-3; } \\
\text { excludes PAR-1 and PAR-2 from the anterior; required for all } \\
\text { downstream asymmetries. }\end{array}$ \\
\hline & PAR-4 & $\begin{array}{l}\text { Lkb1/ } \\
\text { STK11 }\end{array}$ & & $\begin{array}{l}\text { Serine/Threonine kinase; modulates size of anterior/posterior polarity } \\
\text { domains. }\end{array}$ \\
\hline & PAR-5 & $\begin{array}{l}14-3-3 \xi / \\
14-3-3 \varepsilon, \zeta\end{array}$ & & $\begin{array}{l}\text { 14-3-3 protein; modulates size of anterior/posterior polarity domains } \\
\text { and prevents their overlap. }\end{array}$ \\
\hline & PAR-6 & $\begin{array}{l}\text { Par-6/ } \\
\text { Pard6 }\end{array}$ & & $\begin{array}{l}\text { PDZ Domain protein; acts with PAR-3 to exclude PAR-1 and PAR-2 } \\
\text { from the anterior; required for all downstream asymmetries. }\end{array}$ \\
\hline & PKC-3 & $\begin{array}{l}\mathrm{aPKC} / \\
\mathrm{PKC \zeta}\end{array}$ & & $\begin{array}{l}\text { Atypical protein kinase C; acts with PAR- } 3 \text { to exclude PAR-1 and } \\
\text { PAR-2 from the anterior; required for all downstream asymmetries. }\end{array}$ \\
\hline \multicolumn{5}{|c|}{$\begin{array}{l}\text { Polarity proteins and regulators discussed in detail in the text are shown. } \\
\text { aThe orthologs listed for Drosophila melanogaster and vertebrates are based on functional homology where known. In other cases, the protein } \\
\text { listed is the predicted Drosophila or human protein with highest sequence similarity to C. elegans (from WormBase.org release WS234); - } \\
\text { indicates no protein with significant homology was identified. } \\
\text { b Embryos are shown at the stage in which the asymmetry or subcellular enrichment is fully established. Color scheme for PAR proteins } \\
\text { corresponds to that in Fig. 2; positive acto-myosin regulators are shown in green, negative regulators in brown; factors that prevent PAR overlap } \\
\text { are shown in purple. Most protein distributions have been examined by antibody staining and also studied using fluorescently labeled fusion } \\
\text { proteins. However, only fusion proteins have been analyzed for ECT-2, CDC-42, and CDC-37. References for all patterns can be found in the text. }\end{array}$} \\
\hline
\end{tabular}

Table 1. Polarity establishment and maintenance proteins. 
Fertilization initiates a cascade of events that leads to breaking the symmetry of the oocyte, as evidenced by a local cessation of actomyosin contractility. What is the nature of the symmetry-breaking cue? It is not the sperm entry site nor paternal genetic material (Sadler and Shakes, 2000 Goldstein and Hird, 1996). Instead, centrioles are key. As in most metazoan organisms, the sperm contributes the sole pair of centrioles to the zygote. These centrioles recruit pericentriolar material (PCM) from maternal stores and thus assemble centrosomes that nucleate microtubules. After an initial phase during which centrosome maturation is suppressed (McNally et al., 2012), the earliest sign of symmetry-breaking is the local cessation of surface contractions where centrosomes become juxtaposed to the cortex after a random walk that relies on short cortical microtubules (Bienkowska and Cowan, 2012; Cheeks et al., 2004; Cowan and Hyman, 2004b; Munro et al., 2004; Cuenca et al., 2003). Centrosomes can also break symmetry at a slight distance from the cortex, although subsequent AP polarity establishment is delayed in these instances, as is the case when microtubules are lacking and, as a consequence, centrosomes approach the cortex only after a lag time (Bienkowska and Cowan, 2012). This partial reliance on cortical microtubules may help resolve apparent contradictions in the literature concerning the requirement of microtubules for polarization in the one-cell embryo (Tsai and Ahringer, 2007; Cowan and Hyman, 2004b; Sonneville and Gönczy, 2004). Microtubules from the meitoic spindle can also induce polarization in the absence of centrosomes in embryos arrested in metaphase of meiosis I (Wallenfang and Seydoux, 2000). However, during embryogenesis centrosomes, or short microtubules that they nucleate, appear essential for symmetry breaking, as demonstrated by experiments in which centrosomes are ablated with a laser-microbeam (Cowan and Hyman, 2004b). By contrast, removal of most or all microtubules does not prevent polarity establishment (Tsai and Ahringer, 2007; Cowan and Hyman, 2004b; Sonneville and Gönczy, 2004). Compatible with interactions between centrosomes and the cell cortex being critical, symmetry breaking is compromised in embryos carrying mutations in the PAM-1 aminopeptidase, in which centrosomes remain far from the cortex (Fortin et al., 2010; Lyczak et al., 2006). Interestingly, forcing centrosomes to remain at the cortex in pam-1 mutant embryos by depleting the dynein heavy chain DHC-1 rescues symmetry breaking, further indicating the importance of centrosome-cortex interactions in this process (Fortin et al., 2010). Defective interaction between centrosomes and the cell cortex is also observed in embryos depleted of the deubiquitylating enzymes MATH-33 and USP-47, and rescued also in these cases by the additional depletion of DHC-1 (McCloskey and Kemphues, 2012). These observations raise the possibility that MATH-33 and USP-47 contribute to stabilizing one or several components critical for mediating centrosome-cortex interaction.

What are the mechanisms leading to the local cessation of cortical contractions following symmetry breaking? A critical event is the inactivation of RHO-1 in the vicinity of centrosomes. Like other small G proteins, RHO-1 is regulated positively by guanine-nucleotide-exchange factors (GEFs) and negatively by GTPase-activating proteins (GAPs). Thus, the RHO-1 GEF ECT-2 promotes generation of active RHO-1-GTP, and the novel protein NOP-1 is important for ECT-2 activity (Tse et al., 2012). Interestingly, ECT-2 is distributed uniformly on the cortex before symmetry breaking, but removed in the vicinity of centrosomes concomitantly with the appearance of non-contractile cortex (Motegi and Sugimoto, 2006; Schonegg and Hyman, 2006). How the presence of centrosomes results in local ECT-2 removal is not clear. In addition, the GAP CYK-4, which might promote the generation of inactive RHO-1-GDP, has been proposed to play a role (Jenkins et al., 2006). CYK-4 is present in sperm and persists in the newly fertilized zygote on membranous organelles in the vicinity of the centrosome, as well as on the cortex, where it could conceivably contribute to local RHO-1 inactivation. In line with this view, depletion of CYK-4 from sperm compromises symmetry breaking, with the cortical actomyosin network remaining uniformly contractile in a fraction of embryos (Jenkins et al., 2006). However, the mechanisms by which CYK-4 may contribute to polarity establishment remain to be further clarified, and it has been suggested that CYK-4 might be largely inactive during this stage (Tse et al., 2012).

In summary, centrosomes are critical for breaking symmetry of the oocyte and thus for setting into motion the sequence of events that results in establishing polarity along the AP axis. Although RHO-1 inactivation in the vicinity of the centrosome plays a major role in initiating AP polarity establishment, more recent work revealed the existence of a partially redundant mechanism relying on the PAR protein PAR-2, which is discussed in Section 2.3 after the PAR proteins have been introduced just below.

\subsection{Polarity establishment: the central role of PAR proteins}

After symmetry breaking, the non-contractile cortical area expands towards the anterior of the embryo until reaching $~ 50 \%$ egg-length (Hird and White, 1993) (Figure 2B). This anterior movement entails a flow of cortical material away from centrosomes, which is compensated by posterior-directed streaming of cytoplasmic material (Hird and White, 1993). Quantitative analysis and computer simulations confirm that the hydrodynamic properties of the cytoplasm can explain such compensatory streaming (Niwayama et al., 2011). 
What are the properties of the actomyosin network during the anteriorly-directed flow of cortical material? An answer comes from experiments in which the actomyosin network was severed locally with a laser microbeam and the resulting surface movements perpendicular to the cut monitored as a measure of the underlying cortical tension (Mayer et al., 2010). Performing such severing along the longitudinal axis demonstrated that cortical tension orthogonal to the AP axis is twice as high in the anterior, contractile, region than in the posterior, non-contractile, region. By contrast, performing such severing along the shorter axis established that cortical tension along the AP axis is uniform throughout the embryo. Thus, there is an anisotropy in cortical tension in the anterior, being higher orthogonal to the AP axis. Such cortical anisotropy is lacking in embryos that do not have anteriorly-directed cortical flows (for instance, following defective centrosome assembly), compatible with cortical anisotropy being a consequence of such flows (Mayer et al., 2010). A physical model of these phenomena that treats the cortex as a thin film of active viscous fluid demonstrates that local contractions of the actomyosin network can result in long-range movements of the cell cortex towards the embryo anterior (Mayer et al., 2010). Thus, anterior-restricted anisotropy in cortical contractility can be instrumental in polarity establishment.

The partitioning of the cortex into a retracting anterior contractile domain and an expanding posterior non-contractile domain is accompanied by the asymmetric distribution of PAR proteins at the cell cortex. The six par genes (for partitioning defective) were identified amongst maternal-effect mutations as having defective AP polarity, resulting in the generation of daughter cells with altered fate, size, spindle positioning and cell cycle progression (reviewed in Goldstein and Macara, 2007; Asymmetric cell division and axis formation in the embryo; Rose and Kemphues, 1998a; Kemphues and Strome, 1997). PAR-3 and PAR-6 are PDZ-containing proteins that, together with the atypical protein kinase C PKC-3, form the so-called "anterior PAR complex". Both PAR-1 and PAR-4 are Ser/Thr kinases, whereas PAR-2 is a RING-finger protein and PAR-5 a 14-3-3 protein. The anterior PAR complex marked by GFP::PAR-6 is present throughout the cortex initially, but recedes from the posterior following symmetry breaking, concomitant with the anteriorly-directed movement of the contractile cortex (Munro et al., 2004; Cuenca et al., 2003). Conversely, GFP::PAR-2 is first detected on the posterior cortex shortly after the local cessation of cortical contractions and then expands anteriorly to approximately 50\% egg-length (Movie 2) (Bienkowska and Cowan, 2012; Cuenca et al., 2003). PAR-1 is also enriched on the posterior cortex (Figure 2), while PAR-4 and PAR-5 are present uniformly in both cytoplasm and cortex.

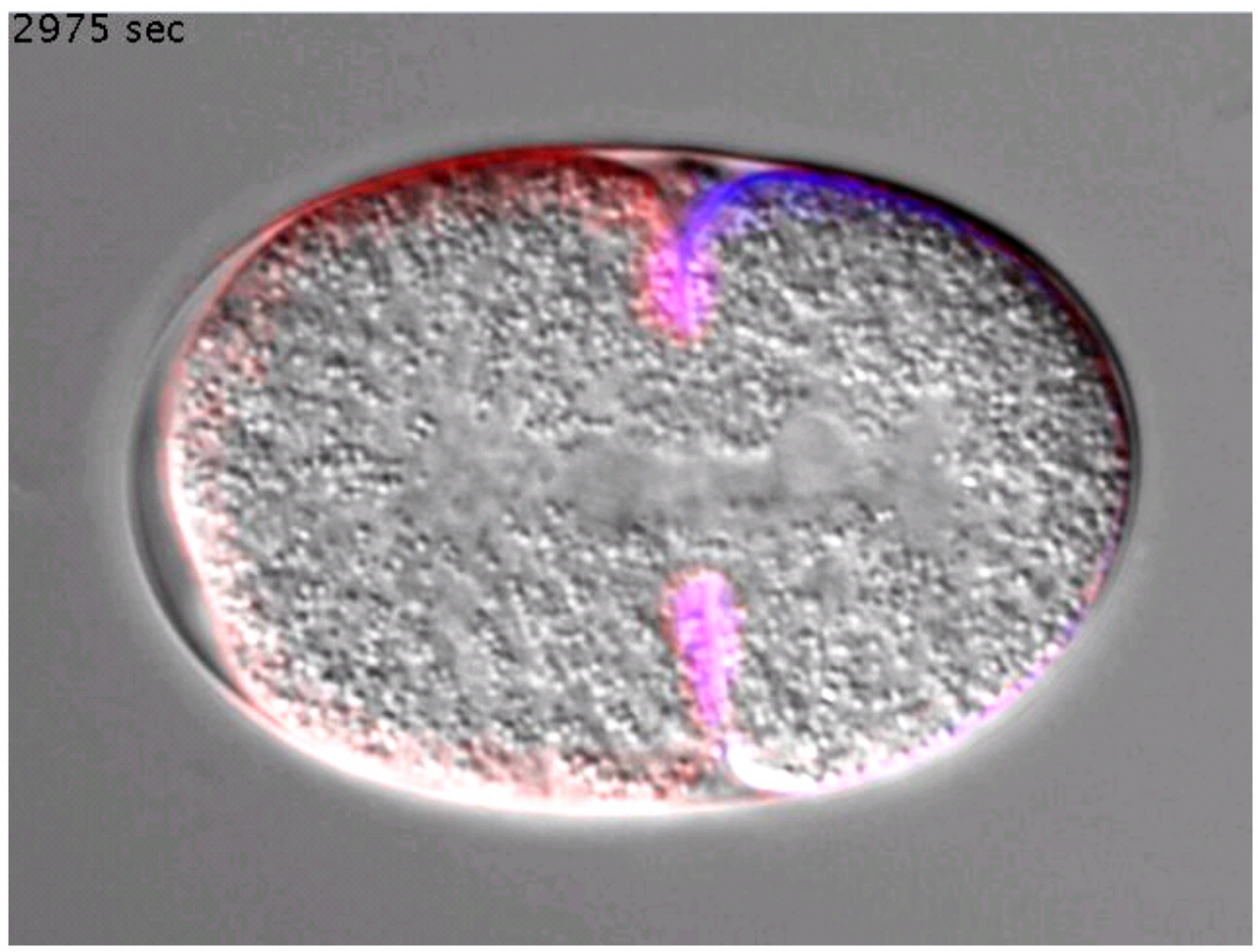

Movie 2. Dual fluorescent and DIC microscopy of one-cell stage embryo carrying mCherry::PAR-6 and GFP::PAR-2 from the onset of polarity establishment until the early two-cell stage. mCherry::PAR-6 is pseudocolored in red; GFP::PAR-2 in blue. Note that, for illustration purposes, only the cortical aspect of the mCherry::PAR-6 and the GFP::PAR-2 signals is shown. Time is indicated in seconds from the beginning of the recording. Courtesy of Simon Blanchoud (Gönczy laboratory). 
Although anteriorly-directed movement of the contractile actomyosin network marked by NMY-2::GFP foci occurs concomitantly with expansion of the posterior domain marked by GFP::PAR-2, the dynamics of these two cortical components differs (Petrasek et al., 2008). Indeed, beam-scanning fluorescence correlation spectroscopy (FCS) experiments revealed that the motility of GFP::PAR-2 is greater than that of NMY-2::GFP (Petrasek et al., 2008). This suggests that PAR-2 distribution is somehow uncoupled from actomyosin dynamics, which is also in line with the finding that PAR-2 can bind phospholipids (Motegi et al., 2011; see below in this section).

The dynamics of anterior and posterior PAR proteins have been investigated using fluorescence recovery after photobleaching (FRAP) (Goehring et al., 2011a; Cheeks et al., 2004). These experiments indicate that exchange between the cytoplasmic and the cortical pool, while occuring (Cheeks et al., 2004), is slow compared to lateral diffusion (Goehring et al., 2011a). In addition, analysis by Total Internal Reflection Fluorescence Microscopy (TIRF) reveals that GFP::PAR-6 resides in puncta that have a limited residency time at the cell cortex (Hyenne et al., 2012). Together, these studies illustrate that PAR proteins constitute a dynamic ensemble, whose kinetics must be taken into consideration when reflecting upon the mechanisms of polarity establishment.

Anteriorly directed movement of the actomyosin network is critical for polarity establishment, as evidenced, for instance, by the fact that movements of cortical GFP::PAR-6 are attenuated in embryos partially depleted of NMY-2 (Munro et al., 2004). Polarity establishment is also altered in other cases in which cortical contractility is compromised, such as in embryos with impaired RHO-1 activity, including those depleted for NOP-1 as mentioned earlier, or of the TAO kinase KIN-18 (Spiga et al., 2013; Tse et al., 2012). Reciprocally, par genes are required for efficient anteriorly-directed cortical flows. Thus, anteriorly-directed movements of NMY-2::GFP are nearly abolished in embryos lacking par-3, par-4, par-5 or par-6 function, as well as in embryos depleted of MEX-5/6, two partially redundant $\mathrm{CCCH}$ finger proteins that contribute to polarity establishment (Cheeks et al., 2004; Munro et al., 2004; Cuenca et al., 2003; Schubert et al., 2000). In par-2(RNAi) embryos, by contrast, cortical flows are normal initially (Cheeks et al., 2004; Munro et al., 2004), in line with the fact that anterior movements of GFP::PAR-6 are not altered during the establishment phase (Cuenca et al., 2003).

In summary, polarity establishment entails contraction of the active actomyosin network towards the embryo anterior, accompanied by the segregation of anterior and posterior PAR proteins into two largely mutually exclusive domains.

Recent work has unveiled a role for PAR-2 during the early steps of polarization that is masked by the principal mechanism discussed above relying on local inactivation of RHO-1 (Motegi et al., 2011; Zonies et al., 2010). Embryos carrying a partial loss-of-function allele of ect-2, ect-2(ax751), exhibit inefficient anteriorly-directed cortical flows and delayed PAR-3 clearance from the posterior cortex, but eventually achieve a polarized distribution of PAR-3 (Zonies et al., 2010). Because par-2 is essential for such delayed polarization in ect-2(ax751) embryos, it was proposed that there is a partially redundant pathway dependent on PAR-2 for polarity initiation that is revealed when the actomyosin network is compromised (Zonies et al., 2010).

What are the mechanisms that enable PAR-2 to exert this function? Live imaging revealed that PAR-2 associates with centrosomes, whereas biochemical experiments established that PAR-2 is a microtubule binding protein (Motegi et al., 2011). Interestingly, microtubule association protects PAR-2 from phosphorylation by PKC-3 in vitro. Thus, in vivo, association of PAR-2 with microtubules emanating from the centrosomes at the posterior would prevent the action of PKC-3, which would otherwise inhibit PAR-2 cortical localization (Motegi et al., 2011). In search of a mechanism underlying this protective effect, it was discovered that PAR-2 binds phospholipids in vitro. This binding is curbed upon phosphorylation of PAR-2 by PKC-3, but this negative regulation does not operate when microtubules are present in addition. Furthermore, membrane-bound PAR-2 recruits more PAR-2, creating a positive feedback loop that promotes expansion of the posterior domain. Whilst important when the principal pathway of polarity establishment is lacking, this PAR-2-dependent pathway is not essential under normal circumstances. Thus, although embryos expressing only a mutant version of PAR-2 that cannot bind microtubules initiate polarity with slower kinetics, they manage to establish it correctly thereafter (Motegi et al., 2011), consistent with the notion that microtubules contribute to but are not essential for polarity establishment (Tsai and Ahringer, 2007; Cowan and Hyman, 2004b; Sonneville and Gönczy, 2004;).

In summary, initiation of polarity establishment in the vicinity of centrosomes is aided by a PAR-2-dependent pathway that relies on the ability of this protein to bind microtubules and thus be shielded from PKC-3-mediated phosphorylation. 


\subsection{Polarity maintenance by mutual inhibition of anterior and posterior cortical domains}

The phase of polarity establishment is followed by a maintenance phase during which centrosome ablation no longer interferes with AP polarity (Cowan and Hyman, 2004b), although microtubules have been suggested to contribute to refining polarity during this phase (Ai et al., 2011). During polarity maintenance, mutual inhibition between the anterior and posterior cortical domains is critical and par-2 is essential to maintain the anterior PAR complex restricted to the embryo anterior. Thus, in par-2 mutants, GFP::PAR-6, which had been restricted to the anterior during the establishment phase, returns to the posterior to occupy the entire cortical circumference (Cuenca et al., 2003), concomitantly with abnormal posterior-directed cortical movements of NMY-2::GFP (Munro et al., 2004). Although it has been proposed that these NMY-2 movements contribute to preventing the maintenance of PAR asymmetries (Munro et al., 2004), more recent evidence indicates that cortical NMY-2 plays a minor role in this phase (Beatty et al., 2013).

FRAP experiments indicate that GFP::PAR-6 and GFP::PAR-2 can diffuse slightly across the boundary during this maintenance phase, highlighting the absence of a strict physical separation between the two domains (Goehring et al., 2011a). What, then, are the mechanisms preventing the spread of anterior PAR proteins to the posterior and reciprocally? Phosphorylation of PAR-2 by PKC-3 is again part of the answer (Hao et al., 2006). Structure/function analysis led to the identification of a PAR-2 fragment that is sufficient for localization to the posterior cortex and which contains 7 predicted PKC-3 phosphorylation sites. Atypical protein kinase C can phosphorylate this PAR-2 fragment in vitro, and mutating these 7 serine/threonine residues to non-phosphorylatable alanine leads to GFP::PAR-2 being present throughout the cortex. Conversely, altering these residues to phosphomimetic glutamic acid prevents GFP::PAR-2 cortical localization (Hao et al., 2006). The RING finger of PAR-2 is critical to counteract the impact of PKC-3, perhaps by making PAR-2 a poorer substrate for the kinase (Hao et al., 2006). In turn, the presence of PAR-2 at the cell cortex promotes the recruitment of PAR-1 through a direct interaction between the two proteins (Motegi et al., 2011), although PAR-1 can localize to the cortex in a PAR-2-independent manner when PAR-3 is lacking (reviewed in Kemphues and Strome, 1997). In addition, PAR-1 can phosphorylate PAR-3 in vitro, and PAR-1 kinase activity is required for the exclusion of the anterior PAR complex from the posterior cortex in embryos that rely solely on the PAR-2-dependent pathway described above (Motegi et al., 2011).

Apart from the actomyosin network and the PAR proteins, other components participate in generating AP polarity in the one-cell embryo. This includes LGL-1, the worm homologue of the Drosophila tumor-suppressor protein Lethal Giant Larvae, which functions redundantly with PAR-2 during polarity maintenance (Beatty et al., 2010; Hoege et al., 2010). LGL-1 is enriched on the posterior cortex, and its depletion, while not resulting in a phenotype on its own, affects the distribution of cortical NMY-2 and enhances the lethality incurred from partial PAR-2 inactivation. Conversely, increasing LGL-1 levels alleviates aspects of the par-2(RNAi) phenotype. Therefore, LGL-1 can be thought of as defining a second pathway that contributes to polarity establishment in the absence of PAR-2. What restricts LGL-1 cortical distribution to the posterior? Phosphorylation by PKC-3 is key here as well. Mutating three PKC-3 predicted phosphorylation sites to non-phosphorylatable residues leads to uniform cortical distribution of GFP::LGL-1, whereas the converse phosphomimetic variant does not localize (Hoege et al., 2010) or localizes less well (Beatty et al., 2010) to the cell cortex. These and other observations suggest that a PAR-6/PAR-3/LGL-1 complex forms initially, but that PKC-3-mediated phosphorylation of LGL-1 prevents its localization on the anterior side during the course of polarity establishment (Beatty et al., 2010; Hoege et al., 2010).

Two other components important for the maintenance of AP polarity are CDC-37, an Hsp90 co-chaperone that in other systems stabilizes kinases, and the small G protein CDC-42. In C. elegans, CDC-37 appears to function primarily by stabilizing PKC-3, such that $c d c-37(R N A i)$ embryos exhibit defective mutual exclusion of the anterior and posterior cortical domains (Beers and Kemphues, 2006). However, slight differences between the $c d c-37(R N A i)$ and the pkc-3(RNAi) phenotypes are suggestive of additional roles for CDC-37 (Beers and Kemphues, 2006). $C$. elegans CDC-42, like its homologue in other organisms, physically interacts with PAR-6 (Gotta et al., 2001), and the two components are mutually dependent for their cortical localization (Aceto et al., 2006). Furthermore, embryos expressing a mutant version that cannot interact with CDC-42 as sole source of PAR-6 exhibit polarity defects mirroring those of partial CDC-42 depletion (Aceto et al., 2006). Where does active CDC-42 GTP localize in one-cell embryos? A transgenic line expressing GFP fused to a binding domain of the Wiskott-Aldrich syndrome protein WSP-1 that specifically interacts with the GTP-bound form of CDC-42 (GFP::GBDWSP-1) has been generated to address this question (Kumfer et al., 2010). This reporter revealed that cortical CDC-42 GTP is enriched initially on the posterior, then on the anterior, before becoming undetectable. A targeted RNAi screen amongst potential GEFs and GAPs using this reporter led to the identification of the GEF CGEF-1 and the GAP 
CHIN-1 as regulators of CDC-42 activity (Kumfer et al., 2010). CGEF-1 depletion results in lower cortical CDC-42 GTP throughout the cell cycle, whereas CHIN-1 depletion affects CDC-42 activity specifically when GFP::GBDWSP-1 is normally present on the anterior cortex. Compatible with antagonistic influences on cortical CDC-42, CGEF-1 depletion leads to reduction of the domain occupied by cortical PAR-6, whereas CHIN-1 depletion leads to an increase in this domain (Beatty et al., 2013). Embryos lacking both PAR-2 and LGL-1 function still exhibit polarized CDC-42 GTP distribution in a CGEF-1- and CHIN-1-dependent manner. Together with other supporting evidence, these results suggests that CHIN-1 and CGEF-1 are part of a third pathway that acts in parallel to the principal PAR-2-dependent pathway and the redundant LGL-1-dependent pathway for polarity maintenance (Beatty et al., 2013). Moreover, the MRCK-1 kinase is needed for CDC-42 GTP cortical enrichment when it is normally present on the anterior (Kumfer et al., 2010). Although $c d c-42(R N A i)$ embryos have been reported to have defects primarily in the maintenance phase of polarization (Gotta et al., 2001; Kay and Hunter, 2001), upon more severe RNAi-mediated depletion, CDC-42 becomes critical for cortical PAR-6 distribution also during polarity establishment (Schonegg and Hyman, 2006). This earlier role appears to be mediated through removal of cortical PAR-2, since PAR-6 remains present at the cell cortex in embryos doubly depleted of CDC-42 and PAR-2 (Schonegg and Hyman, 2006). Overall, these observations indicate that binding of CDC-42 to PAR-6 plays a critical role in setting up and maintaining AP polarity.

Additional components, including ones that are important for basic cellular processes, are harnessed to ensure polarity maintenance. For instance, the dynamin GTPase, a universal modulator of endocytosis, membrane trafficking, and actin dynamics, participates in polarity maintenance in one-cell C. elegans embryos (Nakayama et al., 2009). Embryos partially depleted of DYN-1 exhibit less cortical GFP::PAR-6 on the anterior side during the maintenance phase and, conversely, an expansion of the GFP::PAR-2 domain. Moreover, FRAP analysis reveals that dynamin promotes association of GFP::PAR-6 with the cell cortex during this phase. Compatible with this view, embryos expressing DYN-1::GFP and mCherry::PAR-6 exhibit green and red puncta that are often juxtaposed, raising the possibility that PAR-6 associates in a dynamin-dependent manner with endocytic vesicles (Hyenne et al., 2012; Nakayama et al., 2009). Interestingly, DYN-1::GFP is present initially throughout the cortex as small punctae, but becomes restricted to the anterior cortex during polarity establishment, in a manner analogous to GFP::PAR-6, and this in a PAR-6- and PAR-3-dependent manner (Nakayama et al., 2009). Moreover, the distribution of DYN-1::GFP is altered in embryos depleted of RACK-1, which was identified for its role in cytokinesis, but whose depletion results in polarity phenotypes reminiscent of those observed in dyn-1(RNAi) embryos (Ai et al., 2011). Whereas dynamin contributes to polarity maintenance, conversely, PAR-6, PAR-3, PKC-3, and CDC-42 regulate endocytosis (Balklava et al., 2007), indicative of a mutual interplay between the anterior PAR complex and the trafficking machinery.

Just like dynamin, the early endosomal protein RAB-5 is enriched on the anterior side during the maintenance phase, in a manner that depends on AP polarity cues (Andrews and Ahringer, 2007). RAB-5 depletion results in a slight alteration of the GFP::PAR-6 domain, albeit without an accompanying alteration in the GFP::PAR-2 domain (Hyenne et al., 2012). However, pleiotropic phenotypes often complicate analyzing the consequences of depleting components required for basic cellular processes. For instance, RAB-5 depletion also alters the actin cytoskeleton (Hyenne et al., 2012; Audhya et al., 2007), and it may be that the impact on GFP::PAR-6 is secondary to alterations in actin distribution or dynamics. Overall, whether trafficking events are instructive for directing AP polarity or merely elements that contribute in a more passive manner through their general requirement for cell physiology remains to be clarified.

In summary, the maintenance of AP polarity relies principally on the mutual inhibition of anterior and posterior cortical domains, which, together with associated components, ensures the robust maintenance of polarity along the AP embryonic axis.

\subsection{Modeling polarization}

The wealth of information regarding the relationships between anterior and posterior polarity components, as well as knowledge about their dynamics and that of the underlying actomyosin network, have fueled mathematical modeling of how AP polarity is achieved in one-cell C. elegans embryos. An initial model captured the essence of the behavior of the actomyosin network, as well as of the PAR proteins and of their relationships (Tostevin and Howard, 2008). This model consists of reaction-diffusion equations that rest on the assumption that PAR protein dynamics at the cell cortex result from their diffusion within the cortical plane and from exchange with the cytoplasmic pool. A further assumption is that association of anterior PAR proteins with the contractile actomyosin cortex increases over time. In the output from this model, anterior PAR proteins exclude posterior PAR proteins (and reciprocally), generating effective positive feedback loops that lead to mutually exclusive cortical distributions. 
The molecular tenets of such mutual exclusion remain open in the model, but could correspond for instance to phosphorylation of PAR-2 by PKC-3 in the case of inhibition of the posterior complex by the anterior one. This initial model left open several questions, including how a postulated asymmetry in the distribution of microtubules that is essential in the model to maintain polarity relates to the situation in vivo. Further modeling indicates that mutual inhibition can maintain distinct domains even without a contribution of the actomyosin network, provided oligomerization of the anterior PAR proteins is included (Dawes and Munro, 2011). Interestingly, PAR-3 proteins are known to dimerize in other systems and have thus been postulated to correspond to the molecular basis for such oligomerization. This revised model features a non-linear relationship in mutual cortical exclusion, which predicts that polarity should be lost abruptly below a threshold level of anterior PAR proteins, which is indeed observed experimentally (Dawes and Munro, 2011). A related but more elaborate model incorporating quantitative analysis of parameters that characterize the behavior of GFP::PAR-6 and GFP::PAR-2 has been developed (Goehring et al., 2011b). In this model, the cell cortex is considered as a thin film that transports embedded molecules towards the anterior by advection, much like a river would carry leaves floating on the water surface. Compatible with this model, simulations indicate that advection by such fluid flow can indeed displace anterior PAR proteins transiently and thus be critical for polarization of one-cell C. elegans embryos (Movie 3).

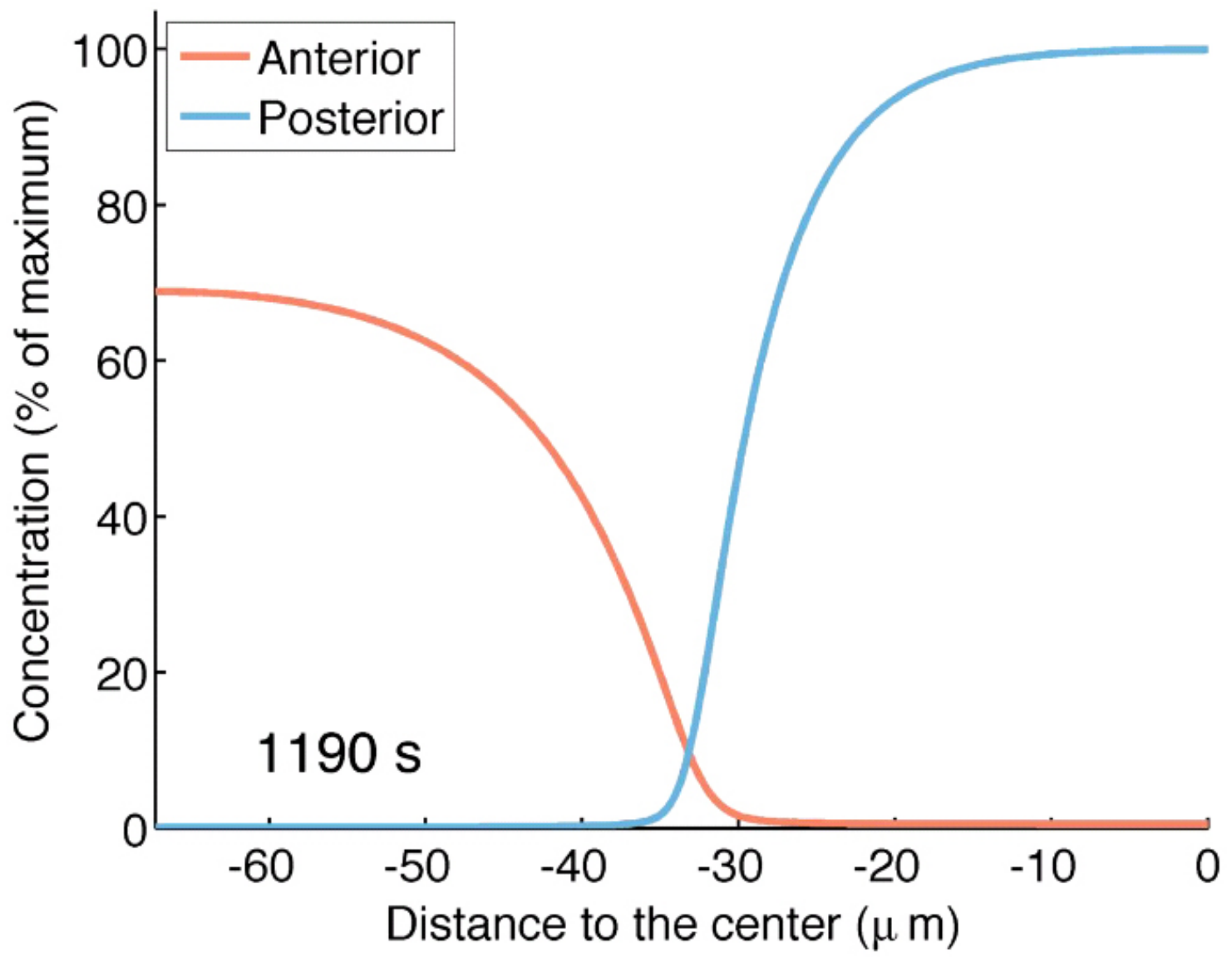

Movie 3. Simulation of a mathematical model of polarity establishment. Model developed by Goehring et al. (2011b). Depicted are the concentrations of the anterior (red) and the posterior (blue) polarity complexes at the cell membrane. The embryo is depicted in 1D, taking advantage of the rotational symmetry of the process, with the anterior pole on the left $(-67.5 \mu \mathrm{m})$ and the posterior pole on the right $(0 \mu \mathrm{m})$. The perturbation of the initial uniform configuration results from an advective force that models the cortical flows observed in vivo. Time is in seconds after simulation onset. Note that the concentrations have been normalized to set their respective maximal value at 100 . Note also that the values of the parameters for this simulation were set as proposed by Goehring et al. (2011b). Courtesy of Simon Blanchoud (Gönczy laboratory). 
In summary, mutual interactions between anterior and posterior PAR proteins have lent themselves to mathematical modeling, and future work in this direction is anticipated to unveil further tenets of the underlying mechanisms of AP polarity.

\section{Centrosome and spindle positioning during the first asymmetric division}

Once properly established and maintained, AP polarity is translated into several processes that contribute to correct asymmetric division of the one-cell embryo, including centrosome and spindle positioning (Figure 3). These processes are crucial for correct asymmetric division because, in animal cells, the cleavage furrow is specified so as to bisect the position of the mitotic spindle at the end of anaphase, thus dictating the relative size and the spatial relationship of daughter cells. Anaphase spindle position is determined by the location of the two centrosomes prior to mitosis, as well as that of the two spindle poles derived from the centrosomes during mitosis. In the one-cell $C$. elegans embryo, both centrosome and spindle positioning are regulated by AP polarity cues, ensuring coordination with the segregation of cell fate determinants (Figure 3) (reviewed in McNally, 2013; Morin and Bellaiche, 2011; Cowan and Hyman, 2007; Galli and van den Heuvel, 2008; Asymmetric cell division and axis formation in the embryo; Betschinger and Knoblich, 2004; Cowan and Hyman, 2004a).

Centrosome and spindle positioning in one-cell $C$. elegans embryos can be readily observed by simple differential interference contrast (DIC) time-lapse microscopy (Movie 1). Centrosomes and the associated male pronucleus are located initially close to the posterior cortex, and then migrate jointly towards the anterior. Concomitantly, the female pronucleus migrates towards the posterior, resulting in the meeting of the two pronuclei in the posterior half of the embryo. Migration of both male and female pronuclei depends on microtubules and microtubule associated proteins, including the minus-end directed motor dynein and members of the dynein complex (reviewed in McNally, 2013; Morin and Bellaiche, 2011; Galli and van den Heuvel, 2008). Dynein present on the surface of the female pronucleus is thought to capture the plus-ends of astral microtubules nucleated by the centrosomes, and thus power migration of the female pronucleus towards the male pronucleus associated with the centrosomes (Gönczy et al., 1999). After pronuclear meeting, the centrosomes and the joined pronuclei move towards the embryo center, while undergoing a $90^{\circ}$ rotation. This process is referred to collectively as centration/rotation and results in the centrosomes becoming aligned along the AP axis in preparation for cell division. Following nuclear envelope breakdown (NEBD), the spindle assembles in the cell center and along the AP axis, but is displaced posteriorly during metaphase and anaphase (reviewed in Asymmetric cell division and axis formation in the embryo). Moreover, the posterior spindle pole exhibits vigorous transverse oscillations during anaphase. As a result of the asymmetric spindle position achieved at the end of mitosis, the first cleavage is unequal and generates the larger anterior blastomere $\mathrm{AB}$ and the smaller posterior blastomere $\mathrm{P}_{1}$.

\subsection{Pulling forces acting on astral microtubules}

What is the nature of forces acting during male pronuclear migration, centration/rotation and spindle positioning? The available evidence indicates that forces pulling on astral microtubules play a major role in all three instances, although the location from which pulling forces are exerted appears to vary. For male pronuclear migration, computer simulations indicate that pulling forces act in a length-dependent manner, with larger forces pulling on longer microtubules (Kimura and Onami, 2005). A related type of mechanism has been proposed to predominate during centration/rotation (Kimura and Kimura, 2011). In a length-dependent type of mechanism, force generators must be distributed throughout the cytoplasm, for instance by being anchored on endomembranes, which could thus generate pulling forces on astral microtubules and associated centrosomes. It has been suggested that small movements of endomembranes towards the minus-end of microtubules could generate a net overall movement of the centrosome in the opposite direction (Kimura and Kimura, 2011). In support of this mechanism, there is a good correlation between centrosome-directed movements of early endosomes marked by GFP::EEA-1 and that of centrosomes in the opposite direction (Kimura and Kimura, 2011). A mathematical model indicates that a combination of microtubule length-dependent forces and the viscous drag of the pronuclei could explain male pronuclear migration as well as centration/rotation (Shinar et al., 2011).

Whereas force generators distributed throughout the cell appear important for force generation during male pronuclear migration and centration/rotation, forces driving posterior spindle displacement seem to be cortically-based. Severing of the spindle or fragmentation of the spindle poles with a UV laser microbeam results in outward movements of the liberated spindle poles or spindle pole fragments (Labbé et al., 2004; Grill et al., 2003; Grill et al., 2001). Because these fragments move all the way to the cortex, the force generators acting during mitosis appear to be cortically-based (Labbé et al., 2004; Grill et al., 2003; Grill et al., 2001). Compatible with this view, 
pulling forces can be observed as invaginations of the plasma membrane following weakening of the actomyosin cytoskeleton (Redemann et al., 2010). The frequency of these invaginations is dramatically reduced when the spindle is severed with a UV laser microbeam or in embryos lacking components required for force generation (see Section 3.2 below). Importantly, the spindle severing and spindle pole fragmentation experiments also establish that the net pulling force acting on the posterior spindle pole is larger than that acting on the anterior one, thus explaining the overall posterior spindle displacement (Grill et al., 2003; Grill et al., 2001). This asymmetry in net pulling forces is under the control of AP polarity cues and serves to couple cell polarity with spindle positioning during the first division (Grill et al., 2001).

In summary, pulling forces acting on astral microtubules are critical for centrosome and spindle positioning in one-cell $C$. elegans embryos. Forces appear to be exerted primarily from the cytoplasm in a length-dependent manner during pronuclear migration and centration/rotation, and from the cell cortex during mitosis. However, there is also evidence indicating that cortical forces contribute to centration/rotation (see Section 3.2 below) and, conversely, length-dependent forces might conceivably also contribute to spindle positioning.

A Centration/rotation

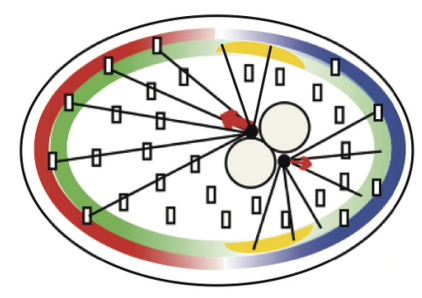

B Spindle positioning

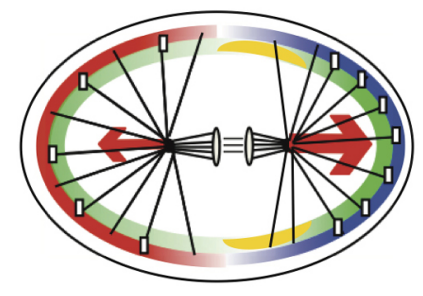

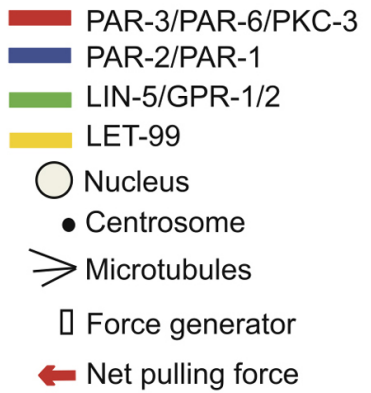

Net pulling force

\section{Cortical force generating complex}
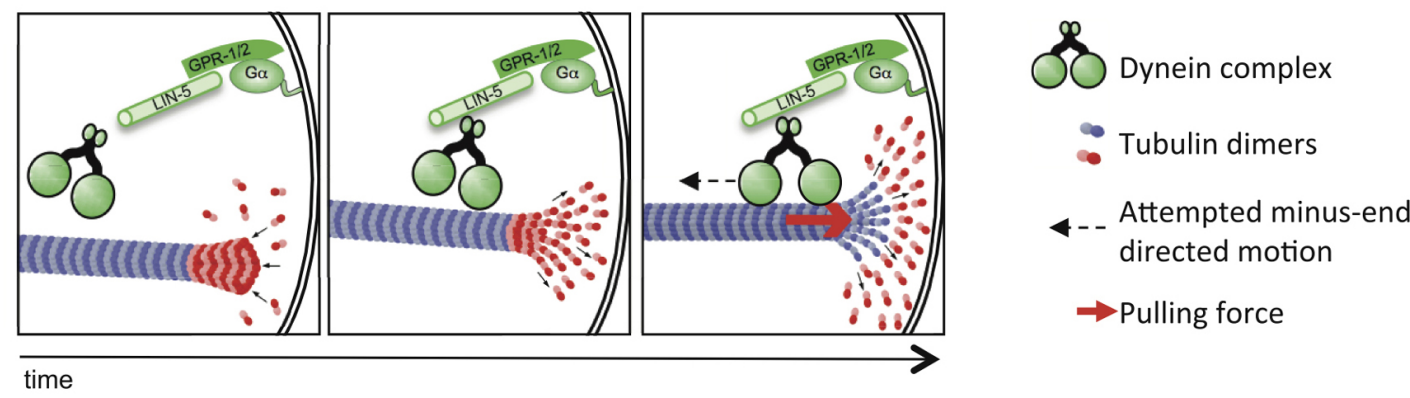

Figure 3. Centrosome and spindle positioning in one-cell stage embryos. (A, B) Schematics of centrosome positioning during centration/rotation (A) and spindle positioning during anaphase (B), with the distribution of GPR-1/2, LIN-5 and LET-99. For simplicity, the LET-99 is shown as a band, but lower levels are present throughout the remaining cortex and in the cytoplasm. GPR-1/2 and LIN-5 are also present throughout the cytoplasm and prominently around the microtubule asters. (A) During centration/rotation, the centrosomes and pronuclei move as a unit towards the cell center, while rotating by $90^{\circ}$ such that centrosomes become aligned with the AP axis. This process appears to be driven by force generators acting both in the cytoplasm and at the cell cortex, as depicted. Note that GPR-1/2 and LIN-5 are present more extensively on the anterior side at this stage. (B) During metaphase/anaphase spindle positioning, unequal net pulling forces act on the two spindle poles, with larger pulling forces acting on the posterior spindle pole. This process is thought to be driven by an imbalance of active cortical force generators. Note that GPR-1/2 and LIN-5 are present more extensively on the posterior side at this stage. (C) Assembly and mechanism of action of cortical force generators. The ternary complex is comprised of a G $\alpha$ protein (GOA-1 or GPA-16), which interacts with the membrane via myristoylation and with the Goloco motif of GPR-1/2. GPR-1/2 in turn interact with LIN-5. LIN-5 associates with the dynein complex, which is thus recruited to the cell cortex below the plasma membrane. Cortical dynein is thought to exert a pull on the plus end of astral microtubules by virtue of attempted minus-end motility and/or by remaining associated with force-generating depolymerizing microtubules (not depicted per se). A related complex may be acting in the cytoplasm. See text for details.

\subsection{A ternary complex critical for generating pulling forces}

What is the molecular nature of the force generators that exert pulling forces on centrosomes and spindle poles? The available evidence indicates that the same components are utilized during male pronuclear migration, centration/rotation and spindle positioning, either at the cell cortex and/or in the cytoplasm. Because most experiments aimed at elucidating the nature and the mechanism of action of these components were focused initially on spindle positioning, this will be discussed first. 
A ternary complex is critical for generating pulling forces on astral microtubules. This ternary complex is comprised of two partially redundant G $\alpha$ subunits, GOA-1 and GPA-16, two essentially identical GoLoco containing proteins, GPR-1 and GPR-2, as well as the large coiled-coil protein LIN-5 (Colombo et al., 2003; Gotta et al., 2003; Srinivasan et al., 2003; Tsou et al., 2003a; Gotta and Ahringer, 2001). The data indicates that LIN-5 binds GPR-1/2, which associate through their GoLoco motif with GOA-1/GPA-16 bound to GDP (Kotak et al., 2012; Park and Rose, 2008; Couwenbergs et al., 2007; Nguyen-Ngoc et al., 2007; Srinivasan et al., 2003). As G $\alpha$ proteins are myristoylated, the entire ternary complex is anchored at the plasma membrane, and perhaps at endomembrane compartments. Spindle severing and spindle pole fragmentation experiments established that the ternary complex, presumably acting at the cell cortex, is required for generating pulling forces during mitosis (Nguyen-Ngoc et al., 2007; Colombo et al., 2003; Grill et al., 2003).

How does the ternary complex result in asymmetric net pulling forces on the two spindle poles? Although the answer to this important question is not entirely clear, the asymmetry in net pulling forces correlates with an asymmetric distribution of some ternary complex components, and this in a PAR-dependent manner. Thus, whereas the cortical distribution of GOA-1 and GPA-16 appears uniform (Park and Rose, 2008; Afshar et al., 2005; Afshar et al., 2004; Gotta and Ahringer, 2001; Miller and Rand, 2000), that of GPR-1/2 is slightly asymmetric during metaphase and thereafter, with more protein present on the posterior side (Colombo et al., 2003; Gotta et al., 2003; Tsou et al., 2003a) (Figure 3). It should be noted also that some mitotic embryos exhibit bipolar asymmetry, in which both anterior and posterior cortices have higher GPR-1/2 levels than the lateral cortex (Park and Rose, 2008). LIN-5 distribution is bipolar in most mitotic embryos, yet all embryos undergo posterior spindle displacement (Park and Rose, 2008), indicating that LIN-5 does not need to be asymmetrically distributed for such displacement to occur (see Section 3.3 below). Importantly, GPR-1/2 asymmetry is under the control of AP polarity cues, indicating that it could be critical for the observed asymmetry in net pulling forces (Colombo et al., 2003; Gotta et al., 2003; Srinivasan et al., 2003; Tsou et al., 2003a; Gotta and Ahringer, 2001). Further support for the levels of GPR-1/2 being key comes from transgenic animals that express YFP-GPR-1 in addition to endogenous GPR-1/2, and which exhibit exaggerated spindle oscillations (Kotak et al., 2012; Redemann et al., 2011). Moreover, during centration/rotation, levels of cortical GPR-1/2 and LIN-5 also correlate with the direction of pulling forces, with more protein present on the anterior cortex (Park and Rose, 2008). This observation supports the notion that cortical force generators play a role also during centration/rotation. A further correlation is observed in embryos depleted of the casein kinase I CSNK-1, which exhibit an increase of cortical GPR-1/2 levels and accompanying exaggerated centration/rotation movements (see also Section 3.4).

In summary, these findings indicate that GPR-1/2 and probably LIN-5 are critical for imparting the proper extent of pulling forces on centrosomes and spindle poles in one-cell C. elegans embryos. The mechanisms that regulate the distribution or function of ternary complex components are described in Section 3.4, after we discuss the mechanical basis of cortical force generators below.

\subsection{Mechanical basis of pulling forces: dynein and microtubules}

How does the ternary complex generate pulling forces on astral microtubules? Dynamic microtubules are an important component. Indeed, spindle severing experiments revealed that pulling forces are lacking when microtubules are stabilized by taxol in wild-type embryos or compromised in $t b b-2(q t 1)$ embryos, which carry a temperature-sensitive mutation in a $\beta$-tubulin gene confering resistance to microtubule depolymerization (Nguyen-Ngoc et al., 2007). In addition, the minus-end directed microtubule dependent motor protein dynein is required. Spindle severing experiments established that pulling forces are compromised in embryos carrying a temperature-sensitive reduction-of-function allele of the dynein heavy chain gene DHC-1 (Nguyen-Ngoc et al., 2007; Schmidt et al., 2005). Similarly, pulling forces are compromised upon depletion of the dynein light chain DYRB-1 or the dynein-interacting protein LIS-1, both of which co-immunoprecipitate with GPR-1/2 and LIN-5 (Couwenbergs et al., 2007; Nguyen-Ngoc et al., 2007).

Importantly, ternary complex components are required for the presence of dynein and of associated proteins at the cell cortex (Nguyen-Ngoc et al., 2007). Given that the LIN-5 homologue NuMA can associate with dynein in vertebrate systems (Kotak et al., 2012; Merdes et al., 1996), a plausible working model is that LIN-5 likewise mediates association with the dynein complex, thus anchoring the motor at the cell cortex (Figure 3B). Dynein could function as a bona fide motor protein, generating force by attempting to move towards the minus end of astral microtubules. With dynein anchored at the cell cortex, this would result in a pull on the astral microtubule. Alternatively, dynein could merely serve as a coupling device to retain interaction with the plus-end of depolymerizing microtubules, which would be generating force in this scenario. Intriguingly, levels of cortical 
YFP-GPR-1 increase locally after mechanical stimulation of the embryo with a glass needle, indicating that GPR-1/2 distribution is modulated by mechanical properties of the cell (Bringmann, 2012). Furthermore, this observation raises the possibility that local increase of GPR-1/2 serves as a positive feedback mechanism to promote dynein anchorage at sites experiencing a cortical pull.

An important step forward came from elegant imaging experiments in which cortical events were visualized with high spatial and temporal resolution (Kozlowski et al., 2007). Microtubule plus-ends in the immediate vicinity of the cortex were imaged using GFP::ßtubulin, which marks both polymerizing and depolymerizing microtubules, as well as with GFP::EB2, which marks strictly the plus-end of growing microtubules (Movie 4). These experiments established that the cortical residency time of microtubule plus-ends is $\sim 1$ second (Kozlowski et al., 2007), significantly lower than previously estimated (Labbé et al., 2003). Interestingly in addition, imaging during spindle oscillations revealed that contacts between microtubules and the cortex are more frequent on the lateral side towards which the spindle pole is moving (Kozlowski et al., 2007). Moreover, the posterior spindle pole moves with a velocity that correlates with the maximal polymerization speed of microtubules over a range of temperatures. These observations led to a 3D model of spindle displacement (Kozlowski et al., 2007). In this model, differences in net pulling forces between the anterior and posterior could be due either to a higher attachment rate of microtubules to cortical force generators on the posterior, to a larger fraction of cortical force generators being active on that side or to differential mechanical properties of the actin cytoskeleton, for instance higher rigidity in the anterior. Each force generator in this model is estimated to exert a pull of $\sim 50 \mathrm{pN}$. Since this value is similar to the force that can be exerted by a single depolymerizing microtubule, but about 7 times higher than that exerted by a single dynein molecule, it was suggested that microtubule depolymerization is more likely to power force generation, with dynein merely serving as a coupling device (Kozlowski et al., 2007).

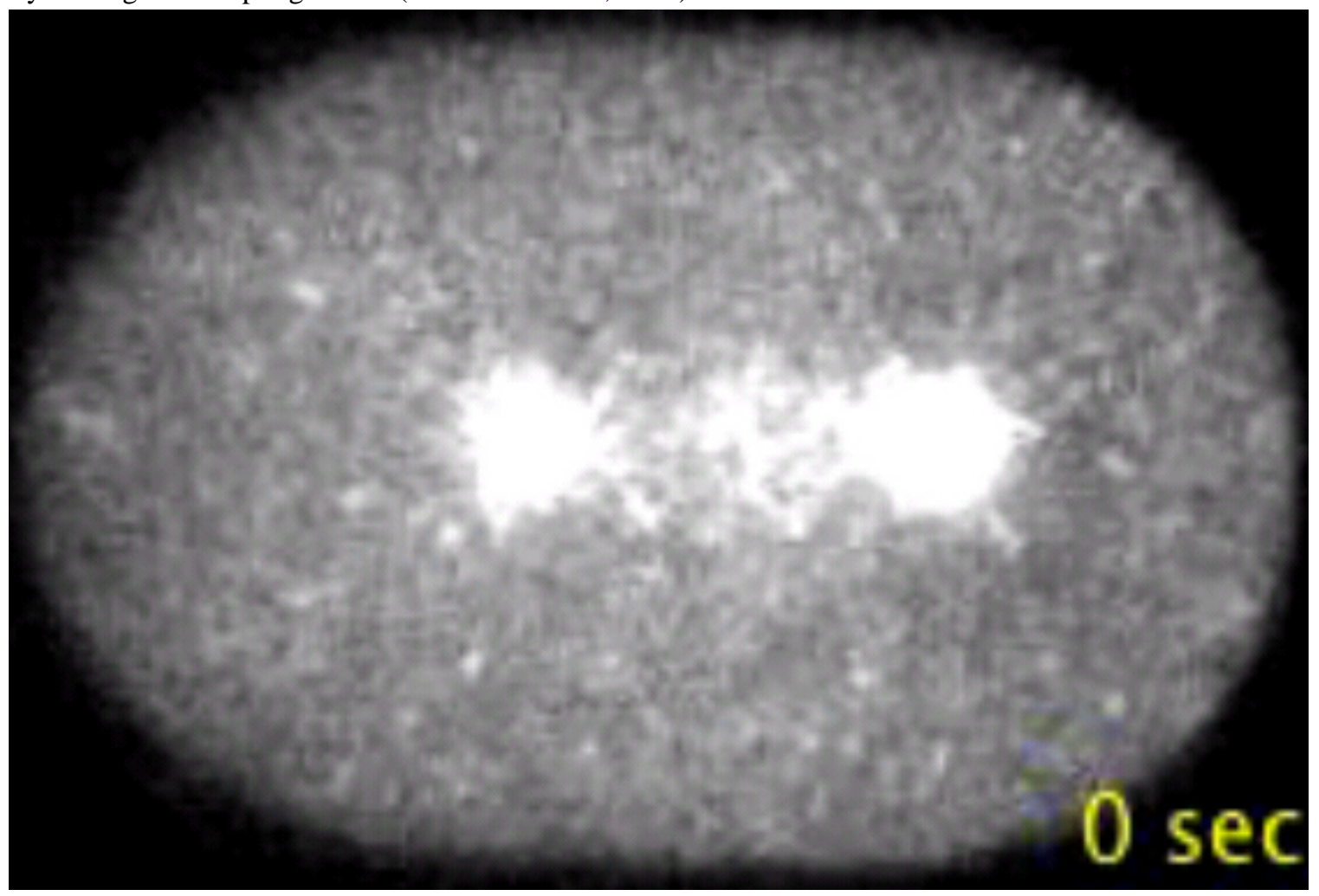

Movie 4. Spinning disc fluorescent microscopy of mitotic one-cell stage embryo carrying EB2::GFP. The initial frames are focused on the middle of the embryo, before the focus is moved to the cell cortex. Filled and empty arrowheads point to examples of arrival and departure, respectively, of EB2::GFP foci at the cell cortex. Courtesy of Zoltán Spiró (Gönczy laboratory).

Another study postulated that modulation of dynein processivity is central for spindle displacement (Pecreaux et al., 2006). It was observed that partial depletion of a dynein light intermediate chain or of GPR-1/2 abolishes oscillations, whereas posterior spindle displacement is nevertheless achieved. These findings indicate that a threshold of force generation must be reached for oscillations to occur (Pecreaux et al., 2006). Modeling suggests that all the features of oscillations in the wild-type, including their onset and their termination, can be accounted for by an increase in the processivity of a motor, for instance dynein. Further analysis of oscillation frequencies lead to 
the proposal that such an increase could, in principle, result from a decrease in the detachment rate of microtubules (Pecreaux et al., 2006).

A major change in cortical residency times of microtubules occurs in embryos depleted of the small G protein of the ARF family EFA-6 (O'Rourke et al., 2010), which was identified as a suppressor of the lethality provoked by conditional dynein inactivation (O'Rourke et al., 2007). efa-6(RNAi) embryos fail to undergo spindle oscillations and exhibit drastic prolongations of microtubule cortical residency times, although the mechanisms by which this occurs remain to be determined (O'Rourke et al., 2010). GFP::EFA-6 is enriched on the anterior cortex, and rescue experiments with truncated fusion proteins indicate that the $\mathrm{N}$-terminal domain and the $\mathrm{PH}$ domain that anchors EFA-6 to the cortex, but not its GTPase activity, are required for spindle oscillations. Other phenotypes observed upon EFA-6 depletion include transient separation of centrosomes from the nuclear envelope and increased pole-to-pole distance during mitosis, suggestive of excess pulling forces (O'Rourke et al., 2010). Whereas it remains to be determined whether this is the case, for instance through spindle severing or spindle pole fragmentation experiments, this raises the possibility that excess and perhaps uniform pulling forces also prevents oscillations.

Interactions between the plus-end of astral microtubules and the cell cortex are numerous, and it is likely that most are not productive for force generation, given that merely $\sim 50$ force generators have been estimated to be active at any given time (Grill et al., 2003). Therefore, changes that are relevant for force generators may be difficult to identify among a large number of unproductive events at the cell cortex. An attempt has been made to monitor the activity of cortical dynein using a so-called EB1 velocity assay (EVA) (Gusnowski and Srayko, 2011). This assay is conducted in mutant embryos in which microtubules are released from the centrosomes due to a dominant mutation in the katanin MEI-1, thus allowing observation of microtubule fragments gliding along the cortex. The fastest amongst such movements are dependent on dynein activity and have been dubbed "dynein dependent microtubule velocities" (ddMTVs). Such ddMTVs are reduced in embryos depleted of LIN-5, but not of GPR-1/2 or of GOA-1/GPA-16. This suggests, first, that LIN-5 can exert some function independently of other ternary complex components, and second, that ddMTVs do not reflect cortical pulling forces responsible for centrosome and spindle displacement. ddMTVs are more numerous during pronuclear migration and centration/rotation (Gusnowski and Srayko, 2011), potentially reflecting the fact that the former type of interaction is more important during these earlier stages.

In summary, the ternary complex serves to anchor dynein to the plasma membrane, and perhaps to endomembranes. Together with microtubule depolymerization, this generates pulling forces on astral microtubules, thus enabling proper centrosome and spindle positioning during the first asymmetric division of C. elegans embryos.

\subsection{Regulation of pulling forces}

Because $\mathrm{G} \alpha$ proteins are an integral part of the ternary complex, modulating their availability has an impact on pulling forces. Depleting the G $\beta$ protein GPB-1 or the G $\gamma$ protein GPC-2, which could normally associate with the $\mathrm{G} \alpha$ proteins in a heterotrimeric configuration, results in excess movements during centration/rotation as well as increased net pulling forces on the anterior spindle pole during mitosis (Afshar et al., 2005; Afshar et al., 2004; Tsou et al., 2003a). These results are compatible with the G $\beta \gamma$ dimer acting as a negative regulator of force generation, presumably by competing with GPR-1/2 for binding to Go-GDP. Consistent with this interpretation, GPR-1/2 distribution in $g p b-1(R N A i)$ embryos increases during centration/rotation and becomes uniform during mitosis (Thyagarajan et al., 2011; Tsou et al., 2003a). Furthermore, the phenotypes generated by depletion of GPB-1 or GPC-2 are suppressed by the concomitant depletion of GOA-1/GPA-16 (Tsou et al., 2003a). The potential for negative regulation offered by the G $\beta \gamma$ dimer appears to be harnessed to ensure appropriate cortical GPR-1/2 distribution in the wild-type (Thyagarajan et al., 2011). Indeed, GPB-1 levels at the cell membrane are lower during mitosis, which correlates with increased cortical GPR-1/2. As in other systems, GPB-1 traffics through the endosomal network in C. elegans (Thyagarajan et al., 2011), and because RAB-5-positive early endosomes are enriched on the anterior in a PAR-dependent manner (Andrews and Ahringer, 2007), GPB-1 trafficking may be more pronounced on the anterior side. Compatible with this view, asymmetric accumulation of GPB-1 is observed inside cells, presumably in the endosomal network, following partial inactivation of intracellular trafficking (Thyagarajan et al., 2011). Overall, these results suggest that modulation of G $\beta \gamma$ trafficking plays a critical role during the first asymmetric division of C. elegans embryos. 
Polarity establishment, asymmetric division and segregation of fate determinants in early C. elegans embryos

\begin{tabular}{|c|c|c|c|c|}
\hline & C.elegans & $\begin{array}{l}\text { Drosophila/ } \\
\text { Vertebrates }^{\text {a }}\end{array}$ & $\begin{array}{c}\text { Protein } \\
\text { Distribution }^{\mathrm{b}}\end{array}$ & Molecular Nature \& Function \\
\hline \multirow{12}{*}{ 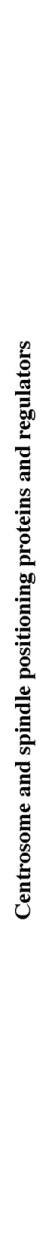 } & CSNK-1 & $\begin{array}{l}\text { Gish/ } \\
\text { CSNK1G }\end{array}$ & & $\begin{array}{l}\text { Casein kinase-like protein; prevents excess GPR-1/2 and LIN- } 5 \text { at the } \\
\text { anterior at prophase; promotes the posterior enrichment of PPK-1 and } \\
\text { thus of GPR-1/2 at metaphase/anaphase. }\end{array}$ \\
\hline & DHC-1 & $\begin{array}{l}\text { Dhc93/ } \\
\text { Dynein }\end{array}$ & & $\begin{array}{l}\text { Dynein heavy chain subunit; with associated subunits/regulators } \\
\text { DRYB-1 and LIS-1, required for cortical pulling forces. }\end{array}$ \\
\hline & GOA-1 & $\begin{array}{c}\mathrm{G} \alpha \mathrm{o} / \\
\mathrm{GnaO} 1\end{array}$ & & $\begin{array}{l}\text { Heterotrimeric G protein } \alpha \text { subunit of } G(0) \text { class; partially redundant } \\
\text { with GPA-16, interacts with GPR-1/2 to form a ternary complex with } \\
\text { LIN-5. }\end{array}$ \\
\hline & GPA-16 & $\begin{array}{l}\text { Gai/ } \\
\text { Goil } 1^{\dagger}\end{array}$ & & $\begin{array}{l}\text { Heterotrimeric G protein } \alpha \text { subunit of G(i) class; partially redundant } \\
\text { with GOA-1, interacts with GPR-1/2 to form a ternary complex with } \\
\text { LIN-5. }\end{array}$ \\
\hline & GPB-1 & $\mathrm{G} \beta$ & & $\begin{array}{l}\text { Heterotrimeric } \mathrm{G} \text { protein } \beta \text { subunit; with } \mathrm{G} \gamma(\mathrm{GPC}-1) \text {, antagonizes } \\
\text { ternary complex by sequestering } \mathrm{G} \alpha \text { subunits in the inactive state. }\end{array}$ \\
\hline & GPR-1/2 & $\begin{array}{l}\text { Pins/ } \\
\text { LGN }\end{array}$ & & $\begin{array}{l}\text { Two highly similar GoLoco motif proteins; associate with Ga and } \\
\text { LIN-5 to form a ternary complex. }\end{array}$ \\
\hline & LET-99 & $-1-$ & & $\begin{array}{l}\text { DEP domain protein; inhibits GPR-1/2 and LIN-5 cortical localization } \\
\text { in a lateral region at prophase and metaphase/anaphase }\end{array}$ \\
\hline & LIN-5 & $\begin{array}{l}\text { Mud/ } \\
\text { NuMA }\end{array}$ & & $\begin{array}{l}\text { Coiled-coil protein; interacts with GPR-1/2 to form a ternary complex } \\
\text { and recruit the dynein complex. }\end{array}$ \\
\hline & PPH-6 & $\begin{array}{l}\mathrm{PpV} / \\
\mathrm{PPP} 6 \mathrm{C}\end{array}$ & & $\begin{array}{l}\text { Serine/threonine phosphatase of PP6 family; with associated partner } \\
\text { SAPS, required for cortical GPR-1/2 localization. }\end{array}$ \\
\hline & PPK-1 & $\begin{array}{l}\text { PIP5K 59B } \\
\text { PIP5K1 }\end{array}$ & & $\begin{array}{l}\text { Phosphatidylinositol-4-phosphate } 5 \text { ' (PIP2) kinase; required for } \\
\text { GPR-1/2 cortical enrichment at posterior during metaphase/anaphase }\end{array}$ \\
\hline & RIC-8 & $\begin{array}{l}\text { Ric8/ } \\
\text { Ric8A }\end{array}$ & & $\begin{array}{l}\text { GTPase exchange factor (GEF) protein; GEF for GOA-1 but promotes } \\
\text { cortical GPA-16; needed for formation of ternary complex and cortical } \\
\text { GPR-1/2. }\end{array}$ \\
\hline & RGS-7 & $\begin{array}{l}\text { CG5036/ } \\
\text { RGS3 }\end{array}$ & & $\begin{array}{l}\text { GTPase activating protein (GAP) for GOA-1; required for } \\
\text { anterior pulling forces. }\end{array}$ \\
\hline \multirow{4}{*}{ 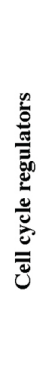 } & ATL-1 & $\begin{array}{l}\text { Mei-41/ } \\
\text { ATR }\end{array}$ & ND & PI-3 like checkpoint kinase; preferentially slows $\mathrm{P}_{1}$ cell cycle. \\
\hline & CDC-25.1 & $\begin{array}{c}\text { Twe/ } \\
\text { Ccdc } 25 \mathrm{~A}\end{array}$ & & Phosphatase; promotes faster AB cell cycle. \\
\hline & PLK-1/2 & $\begin{array}{l}\text { Polo/ } \\
\text { PLK2 }\end{array}$ & & $\begin{array}{l}\text { Polo-like kinase; promotes nuclear import of CDC25.1 and thus faster } \\
\text { AB cell cycle. }\end{array}$ \\
\hline & CHK-1 & $\begin{array}{l}\text { Grp/ } \\
\text { Chk1 }\end{array}$ & ND & $\begin{array}{l}\text { Ser/Thr Kinase; potential target of ATL-1; preferentially slows } P_{1} \text { cell } \\
\text { cycle. }\end{array}$ \\
\hline \multicolumn{5}{|c|}{$\begin{array}{l}\text { The proteins involved in these processes that are discussed in detail in the text are shown. } \\
\text { aThe orthologs listed for Drosophila melanogaster and vertebrates are based on functional homology where known; in other cases, } \\
\text { the protein listed is the predicted Drosophila or human protein with highest sequence similarity to C. elegans (from WormBase.org } \\
\text { release WS234); - indicates no protein with significant homology is known, †Although Drosophila and vertebrates have homologs of } \\
\text { GOA-1, only Gai isoforms have been shown to be involved in spindle positioning. } \\
\text { b Embryos are shown at the stage in which the asymmetry or subcellular enrichment is fully established. In addition, for simplicity } \\
\text { the aster associated localization of DHC-1, GPB-1, GOA-1, GPA-16, GPR-1/2, LIN-5 and RIC-8 is not shown. Color scheme for } \\
\text { spindle positioning proteins corresponds to that in Fig. 3, with additional positive regulators shown in green, negative regulators in } \\
\text { yellow; cell cycle regulators are shown in blue. Protein distributions are based on antibody staining except for CSNK-1 and RGS-7, } \\
\text { which were analyzed using GFP fusion proteins. }\end{array}$} \\
\hline
\end{tabular}

Table 2. Spindle positioning proteins and cell cycle regulators. 
Other components regulate the distribution or function of GOA-1 and GPA-16, thereby modulating pulling forces. Thus, both RIC-8 and RGS-7 are required for proper spindle positioning most likely through an impact on the $\mathrm{G} \alpha$ proteins (Couwenbergs et al., 2007; Afshar et al., 2004; Hess et al., 2004; Miller and Rand, 2000). In vitro, RIC-8 exhibits guanine nucleotide exchange activity (GEF) towards GOA-1, but not GPA-16 (Afshar et al., 2005; Afshar et al., 2004; Hess et al., 2004). Conversely, RIC-8 is needed for cortical enrichment of GPA-16, but not GOA-1 (Afshar et al., 2005; Afshar et al., 2004). As a result of this dual requirement, RIC-8 inactivation severely impairs cortical GPR-1/2 enrichment and leads to a spindle positioning phenotype analogous to that of depleting ternary complex function (Afshar et al., 2004). By contrast, loss of RGS-7, a GTPase activating protein (GAP) for GOA-1, leads to lower net pulling forces on the anterior spindle pole (Hess et al., 2004), perhaps indicative of transit through the $\mathrm{G} \alpha$ cycle being important on that side.

Modulation of LIN-5 provides an interesting link between polarity cues and spindle positioning (Galli et al., 2011). SILAC-based mass spectrometry identified four serine residues of LIN-5 that are phosphorylated in a PKC-3-dependent manner in vivo and that can also be phosphorylated by atypical protein kinase $\mathrm{C}$ in vitro. Phospho-specific antibodies recognizing one of these residues, phospho-S737, label the anterior cortex during centration/rotation and early mitosis, compatible with LIN-5 being phosphorylated by PKC-3 in vivo. Embryos depleted of endogenous LIN-5 by RNAi and expressing RNAi-resistant LIN-5 in which the four PKC-3 phosphorylation sites are mutated to non-phosphorylatable alanine (LIN-5 4A) exhibit exaggerated centration/rotation and a slight increase in net anterior pulling forces during mitosis. Conversely, expression of a quadruple phosphomimetic version (LIN-5 4E) dampens spindle oscillations. Most embryos expressing LIN-5 4A or LIN-5 4E nevertheless undergo posterior spindle pole displacement and unequal division, in contrast to embryos depleted of LIN-5, indicating that PKC-3-mediated inactivation of LIN-5 on the anterior side represents a partially redundant mechanism (Galli et al., 2011).

Components have also been identified that regulate the levels of cortical GPR-1/2 and LIN-5. This is the case for the casein kinase I CSNK-1, whose depletion leads not only to exaggerated centration/rotation, as mentioned above, but also to excess net pulling forces during spindle positioning (Panbianco et al., 2008). These phenotypes correlate with the presence of excess GPR-1/2 and LIN-5 at the cortex. Simultaneous depletion of CSNK-1 and of GPR-1/2 or LIN-5 suppresses the phenotypes observed upon CSNK-1 depletion alone, suggestive of the changes in ternary complex distribution being responsible for the phenotype. Because polarity cues are not affected upon CSNK-1 depletion, this component acts downstream of, or in parallel to, PAR proteins to mediate centrosome and spindle positioning. What is the substrate of CSNK-1 relevant for force generation? An attractive candidate is the phosphatidylinositol-4-phosphate PI(4)P5 (PIP) kinase PPK-1 that converts PIP into PIP $_{2}$ (Panbianco et al., 2008), the homologue of which is phosphorylated by casein kinase I in budding yeast. In C. elegans, PPK-1 is enriched on the posterior cortex in a manner that depends on CSNK-1, as well as on polarity cues. Interestingly, PPK-1 depletion results in decreased cortical GPR-1/2 and lower net pulling forces. These results suggest a model whereby PAR proteins modulate the asymmetric distribution or activity of CSNK-1, which restricts the distribution of cortical PPK-1 to the posterior (Panbianco et al., 2008). Such posterior accumulation might lead to higher levels of PIP ${ }_{2}$ on

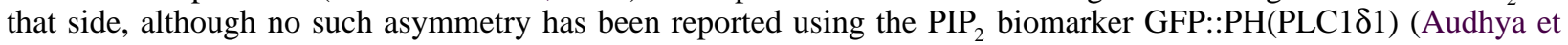
al., 2007). Therefore, how the presence of PPK-1 on the posterior would result in increased cortical GPR-1/2 and LIN-5 remains to be clarified.

Another component that regulates the levels of cortical GPR-1/2 and LIN-5 is the phosphatase PPH-6 and its associated partner SAPS-1 (Afshar et al., 2010). Depletion of PPH-6/SAPS-1 results in phenotypes analogous to those observed following partial depletion of ternary complex components, including decreased net pulling forces on the spindle poles. Accordingly, levels of cortical GPR-1/2 and LIN-5 are decreased in embryos depleted of PPH-6/SAPS-1. Embryos simultaneously depleted of SAPS-1 and CSNK-1 are indistinguishable from those depleted of SAPS-1 alone, indicating that modulation of pulling forces by CSNK-1 depends on PPH-6/SAPS-1 function, although the exact relationship between these components is not yet clear (Afshar et al., 2010). Regardless, these observations indicate that phosphorylation of a given substrate, perhaps of GPR-1/2 or LIN-5, normally restricts force generation. It will be interesting to identify the nature of the responsible kinase and the identity of the substrate that it phosphorylates. One tempting possibility is that PPH-6/SAPS-1 counteracts PKC-3-mediated phosphorylation of LIN-5 (Galli et al., 2011), as the phenotype of embryos expressing LIN-5 4E resembles that of embryos depleted of the PPH-6/SAPS-1 complex. However, there are also differences between the two conditions; for instance, GPR-1/2 distribution does not appear to be altered during mitosis in embryos expressing LIN-5 4E, in contrast to those depleted of PPH-6/SAPS-1 (Galli et al., 2011; Afshar et al., 2010). 
In addition to components that regulate the overall levels of cortical GPR-1/2 and LIN-5, the boundaries of these domains on the cell cortex can also be modulated, as exemplified by the action of the DEP domain protein LET-99 (Tsou et al., 2002; Rose and Kemphues, 1998b). In wild-type embryos, LET-99 is localized asymmetrically in a cortical band at the lateral-posterior cortex and the highest levels of LET-99 correlate with the lowest levels of GPR-1/2 (Figure 3). In embryos lacking let-99 function, GPR-1/2 and LIN-5 are distributed in a uniform manner and, probably as a consequence, centration/rotation and spindle displacement are aberrant (Park and Rose, 2008; Tsou et al., 2002). Indeed, spindle severing and spindle pole fragmentation experiments indicate that in wild-type embryos, forces pulling from the anterior and posterior cortices are stronger than those pulling from the lateral cortex, where LET-99 is located (Krueger et al., 2010). The cortical asymmetry of LET-99 is PAR-dependent. Interestingly, cortical PAR-1 and PAR-3 levels are lowest where LET-99 levels are highest, raising the possibility that these two PAR proteins negatively regulate the presence of cortical LET-99, thus explaining its accumulation in a cortical band in the wild type. Moreover, PAR-1 co-immunoprecipitates with LET-99, and PAR-1 kinase activity is needed for proper LET-99 localization, together suggesting that PAR-1 phosphorylates LET-99 to mediate its restricted cortical localization (Wu and Rose, 2007).

The actomyosin network appears to also modulate force generation. Indeed, partial depletion of NMY-2 to an extent that does not affect AP polarity compromises centration/rotation and can suppress the incomplete centration phenotype in let-99 mutant embryos (Goulding et al., 2007). Conversely, depletion of the myosin phosphatase-targeting subunit MEL-11, a negative regulator of NMY-2, compounds the let-99 centration/rotation phenotype. Cortical NMY-2 particles undergo short-range anterior movements during centration/rotation, which have been suggested to generate anteriorly directed pulling forces on astral microtubules (Goulding et al., 2007). However, whether the role of NMY-2 is mediated entirely through LET-99 and its impact on GPR-1/2 distribution or instead by a separate means remains to be determined. The contribution of the actomyosin network appears to differ during spindle displacement, since acute treatment with the actin-depolymerizing drug latrunculin leads to increased net forces pulling on the anterior side, suggestive of negative regulation on that side during mitosis (Berends et al., 2013; Afshar et al., 2010), compatible with a prediction of the 3D model of spindle displacement (Kozlowski et al., 2007).

In addition to the spatial regulation of pulling forces, temporal regulation is important to ensure coupling with cell cycle progression. Spindle displacement begins shortly after the completion of chromosome congression (McCarthy Campbell et al., 2009; Oegema et al., 2001), and experimental modulation of the master regulator of mitosis Cdk1 leads to corresponding alterations in the timing of spindle displacement (McCarthy Campbell et al., 2009). The available evidence that stems from these experiments supports a model in which spindle displacement is retarded in the wild type until the anaphase promoting complex (APC/C) inactivates Cdk1, thus coupling cell cycle progression and spindle positioning.

In summary, centrosome and spindle positioning rely on the correct levels, distribution and function of the G $\alpha /$ GPR-1/2/LIN-5 ternary complex. Through mechanisms that are becoming increasingly better understood, AP polarity cues ensure that this ternary complex functions appropriately to ensure asymmetric cell division. Interestingly, this relationship is not unidirectional: small alterations in AP polarity that persist after the maintenance phase are corrected prior to cell division, in a manner that depends on the function of the ternary complex (Schenk et al., 2010).

\section{Polarity and spindle positioning at the second and third cleavages}

After the first asymmetric division, the embryo has an $\mathrm{AP}$ axis, with $\mathrm{AB}$ and $\mathrm{P}_{1}$ having inherited different PAR domains (Figure 4A), as well as different cytoplasmic factors that influence cell fate (see Section 5, Figure 5). At second cleavage, the $\mathrm{AB}$ cell undergoes a symmetric division in which the spindle is oriented perpendicular to the previous division axis; however, due to the constraints of the eggshell, one $\mathrm{AB}$ daughter shifts more posteriorly and is thus designated $\mathrm{ABp}$ (Figure $4 \mathrm{C}$ ). In contrast, the $\mathrm{P}_{1}$ cell exhibits polarized domains and divides asymmetrically again on the AP axis to produce EMS and $\mathrm{P}_{2}$; the position of the EMS cell defines the ventral side of the embryo (Figure 1, Figure 4) (reviewed in Maduro, 2010; Schnabel and Priess, 1997). The division of the ABa and $\mathrm{ABp}$ cells at third cleavage results in the left-hand $\mathrm{AB}$ daughter cells being more anterior in position, which ultimately defines the left/right axis of the worm (see Section 5), while the EMS and $\mathrm{P}_{2}$ cells both undergo asymmetric, oriented divisions (Figure 1, Figure 4D). Not only are division orientations during these cleavages highly defined, but also division timing is specific to each blastomere and its progeny. Thus, $A B$ and $P_{1}$ exhibit cell cycle asynchrony, with $\mathrm{P}_{1}$ dividing later than $\mathrm{AB}$; similarly, after the asymmetric division of $\mathrm{P}_{1}$, the $\mathrm{P}_{2}$ daughter divides later than EMS (Figure 4). In this section, we first outline what is known about the molecular basis of cell cycle asynchrony at the two-cell stage and then cover polarity and spindle positioning at the second and third cleavages. 


\subsection{Cell cycle asynchrony in the two-cell stage}

The $\mathrm{P}_{1}$ cell divides approximately 2 minutes after the $\mathrm{AB}$ cell in wild-type animals; this difference depends on AP polarity cues, as par mutants exhibit synchronous divisions. This could reflect a role for the PAR proteins in either directly segregating a cell cycle regulator, or in influencing cell cycle rates through the unequal first cleavage, which could generate cells with different amounts of a uniformly localized cell cycle regulators. The available evidence indicates that both mechanisms play a role.
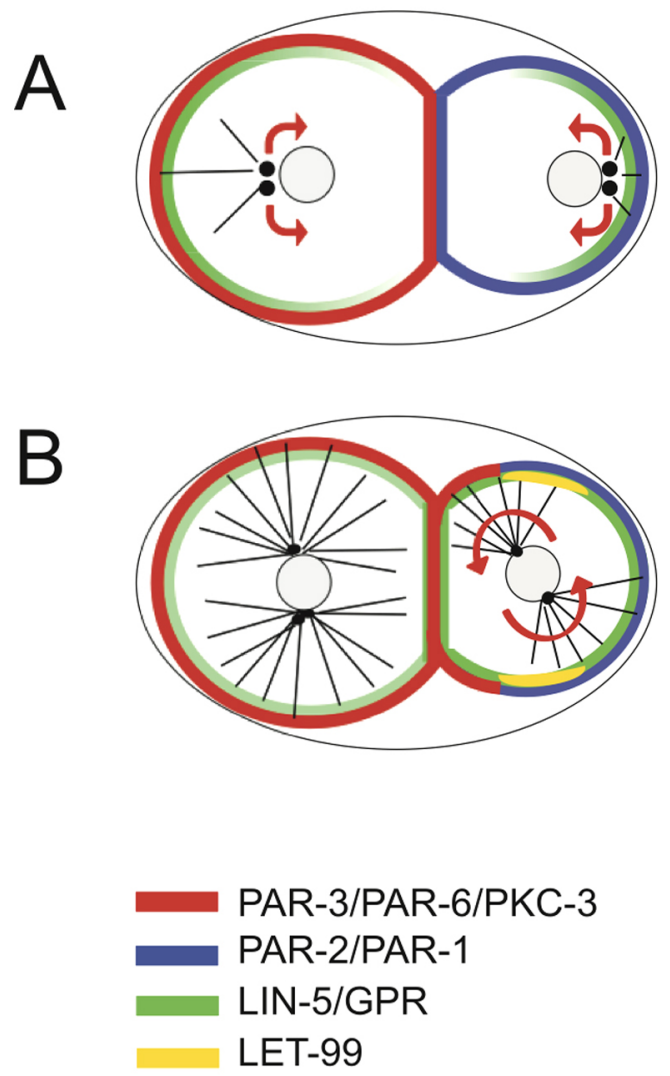
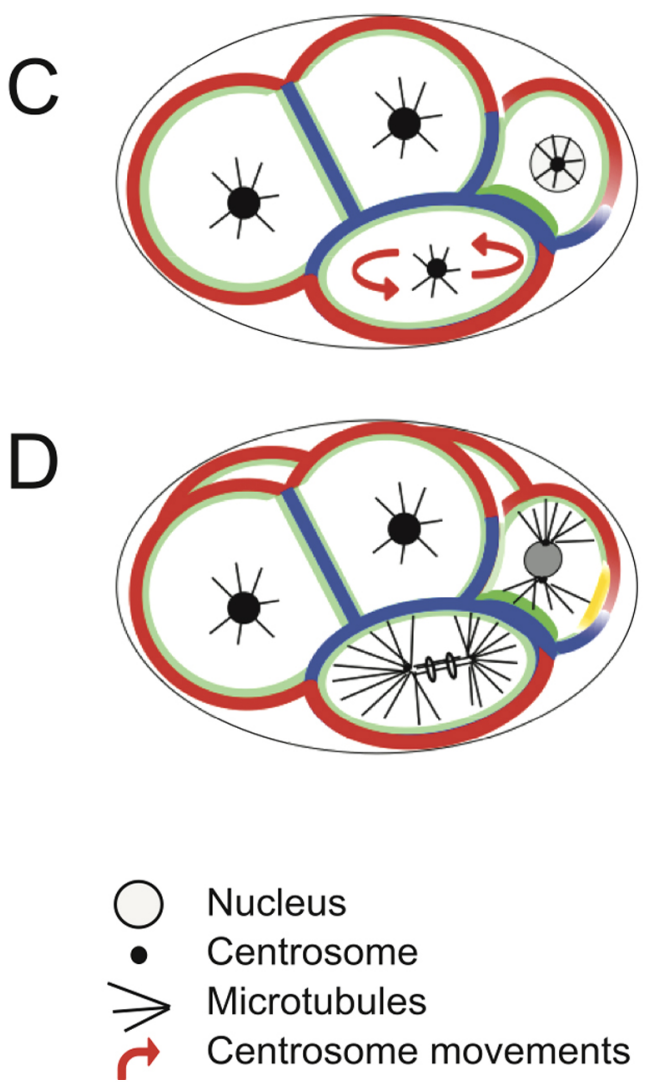

Figure 4. Polarity and spindle positioning in two to six-cell stage embryos. (A) Early two-cell stage. As a result of asymmetric spindle elongation during anaphase, the first division is unequal and generates a larger anterior blastomere $\mathrm{AB}$ and a smaller posterior blastomere $\mathrm{P}_{1}$. PAR-2 and $\mathrm{PAR}-1$ are initially present around the entire cortex of $\mathrm{P}_{1}$ and GPR-1/2 localization is similar to that at the end of the one-cell stage; LET-99 (not shown) is initially present at the cell contact region. (B) After the centrosomes migrate on to a transverse plane, the $\mathrm{P}_{1}$ nucleus rotates $90^{\circ}$ during late prophase, aligning the centrosomes on the AP axis. By this time, asymmetric PAR domains have been reestablished, and a band of cortical LET-99 becomes detectable. For simplicity, LET-99 is shown as a band, but lower levels are present throughout the remaining cortex of both $\mathrm{P}_{1}$ and AB. During mitosis (not shown), higher levels of GPR-1/2 are present at the posterior cortex in $\mathrm{P}_{1}$ and asymmetric spindle elongation occurs. (C) At third cleavage, the spindles in the AB cells initially set up along the left/right plane and the centrosomes in EMS are also on the left/right plane. PAR domains become established in the $\mathrm{P}_{2}$ cell, and GPR-1/2 become enriched at the $\mathrm{P}_{2}$ /EMS cell contact. (D) In the AB cells, the spindles shift slightly anteriorly during telophase, such that the left daughters assume a more anterior position. In EMS, the nucleus rotates to align on the AP axis, and the $\mathrm{P}_{2}$ nucleus rotates so that one centrosome is adjacent to the $\mathrm{P}_{2}$ /EMS cell contact. Cortical LET-99 is present as a lateral band in $\mathrm{P}_{2}$ by this time; LET-99 is also present at all other cell-cell contacts but is reduced at the $\mathrm{P}_{2} /$ EMS cell contact (not shown).

In support of the first mechanism, a candidate approach revealed that PLK-1 and CDC-25, two positive regulators of mitotic entry, are enriched in $\mathrm{AB}$ compared to $\mathrm{P}_{1}$ (Budirahardja and Gönczy, 2008; Nishi et al., 2008; Rivers et al., 2008). Across eukaryotic evolution, polo-like kinases and Cdc25 phosphatases promote entry into mitosis through activation of the cyclin dependent kinase Cdk1. In C. elegans, the polo-like kinase PLK-1 also promotes entry into mitosis and is thought to act by phosphorylating CDC-25.1. PLK-1 is present at higher levels in the cytoplasm of the AB cell than in the $\mathrm{P}_{1}$ cell (Budirahardja and Gönczy, 2008; Nishi et al., 2008; Rivers et al., 2008; Chase et al., 2000). CDC-25.1 is also asymmetrically distributed; the nucleus of AB contains more CDC-25.1, apparently because PLK-1-dependent nuclear import occurs more readily in AB than in $\mathrm{P}_{1}$ (Rivers et al., 2008). Determining the significance of these asymmetries for cell cycle duration in $A B$ versus $P_{1}$ has proven difficult because complete depletion by RNAi results in earlier cell cycle arrest, and partial depletion slows the cell cycles of 
both $\mathrm{AB}$ and $\mathrm{P}_{1}$. Nonetheless, several lines of evidence from partial RNAi experiments support a role for PLK-1 and CDC-25.1 in regulating cell cycle asynchrony (Budirahardja and Gönczy, 2008; Rivers et al., 2008). First, the observed changes in cell cycle rates in various par mutants correlate with PLK-1 and CDC25.1 localization. For example in par-3 mutants, the cell cycle rates of $\mathrm{AB}$ and $\mathrm{P}_{1}$ are like that of a wild-type $\mathrm{P}_{1}$ cell, and the levels of PLK-1 and CDC25.1 in both cells are similar to those in a wild-type $\mathrm{P}_{1}$ cell. Second, although partial depletion of CDC-25.1 and PLK-1 does not abolish asynchrony, it does produce a more profound effect of slowing the $\mathrm{P}_{1}$ cell cycle. This result indicates that $P_{1}$ is more sensitive than AB to reduction of PLK-1 and CDC-25.1, consistent with these proteins being key regulators of cell cycle asynchrony between the two blastomeres in the wild-type.

The second mechanism for cell cycle asynchrony is coupled to the unequal first cleavage. The observation that interference with DNA replication has a stronger effect on delaying entry into mitosis in $\mathrm{P}_{1}$ compared to $\mathrm{AB}$ pointed to a potential role for checkpoint control in influencing cell cycle asynchrony (Brauchle et al., 2003). Such delayed entry into mitosis results from the activation of a DNA replication checkpoint utilizing the conserved ATL and CHK-1 kinases. Importantly, depletion of ATL-1 and/or CHK-1 in wild-type embryos, without interfering with DNA replication, results in the $A B$ and $P_{1}$ cell cycles being closer together (Brauchle et al., 2003). Further, examination of RNAi-treated embryos that have normal polarity but an equal first cleavage revealed a similar decrease in the time difference. These and other results are consistent with the model that DNA replication factors are uniformly distributed in the one-cell and become rate limiting in the $\mathrm{P}_{1}$ cell because of its smaller size after unequal division (Brauchle et al., 2003). This activates the checkpoint and preferentially slows the $\mathrm{P}_{1}$ cell cycle. PLK-1 asymmetry is normal in embryos lacking ATL-1 and/or CHK-1 function, and analysis of embryos simultaneously compromised for the two pathways suggests that they act in parallel (Budirahardja and Gönczy, 2008; Rivers et al., 2008). Thus, the preferential slowing of the $\mathrm{P}_{1}$ cell cycle by checkpoint activity, combined with the preferential acceleration of the AB cell cycle by PLK-1 together contribute to the final cell cycle asynchrony observed in wild-type embryos. Similar mechanisms may contribute to setting the specific cell cycle rates exhibited after subsequent asymmetric divisions.

\subsection{Polarity and spindle positioning during the second and third cleavages}

Asymmetric division of $\mathrm{P}_{1}$ likely depends on the PAR proteins. Although PAR-2 and PAR-1 are initially present around the entire cortex in $\mathrm{P}_{1}$ (Figure 4A), an anterior PAR-3 domain forms during prophase, and PAR-2 and PAR-1 recede to the posterior cortex (Figure 4B) (reviewed in Schubert et al., 2000; Kemphues and Strome, 1997). These observations suggest that polarity is actively reestablished in $P_{1}$ in a manner that mirrors the situation in $\mathrm{P}_{0}$, a view supported by the observation that GFP::PAR-6 localization is coincident with an anteriorly-directed flow of cortical NMY-2::GFP also in $\mathrm{P}_{1}$ (Munro et al., 2004).

Although PAR dynamics during $\mathrm{P}_{1}$ polarization are similar to those in $\mathrm{P}_{0}$, there also appear to be unique requirements for $\mathrm{P}_{1}$ polarity based on the phenotypes of ooc-3 and ooc-5 mutants (Basham and Rose, 2001; Pichler et al., 2000; Basham and Rose, 1999). In embryos derived from ooc mutant mothers, PAR localization is largely normal in the one-cell, but not in $\mathrm{P}_{1}$. The transmembrane protein OOC- 3 and the torsin family member OOC- 5 both localize to the endoplasmic reticulum and contiguous nuclear envelope. In addition, depletion of a subset of nuclear pore complex proteins results in analagous $P_{1}$ polarity defects (Schetter et al., 2006). These observations suggest a link between nuclear envelope biology and polarity that remains to be elucidated.

The movements that determine spindle position in response to PAR polarity domains in $\mathrm{P}_{1}$ are also similar to those described for $\mathrm{P}_{0}$ (reviewed in Asymmetric cell division and axis formation in the embryo; Kemphues and Strome, 1997). The $\mathrm{P}_{1}$ spindle orients on the AP axis via a $90^{\circ}$ rotation of centrosomes and the associated nucleus prior to mitosis (Figure 4B). Mutation or depletion of G $\alpha$, GPR-1/2, LIN-5, and LET-99 show that all these components are required for nuclear rotation in $\mathrm{P}_{1}$ (Colombo et al., 2003; Gotta et al., 2003; Srinivasan et al., 2003; Tsou et al., 2003a). Analysis of temperature sensitive mutations likewise reveals a role for dynein and some of its regulators (Zhang et al., 2008). Embryos with impaired G $\beta \gamma$ function have abnormal centrosome positioning and retarded rotation in $\mathrm{P}_{1}$ (Gotta and Ahringer, 2001), but it remains to be determined if these defects are due to excess $\mathrm{G} \alpha$, as for $\mathrm{P}_{0}$, or whether $\mathrm{G} \beta \gamma$ plays a separate role in $\mathrm{P}_{1}$ spindle positioning. Anaphase spindle positioning has not been analyzed extensively in $\mathrm{P}_{1}$, but the posterior spindle pole oscillates as in $\mathrm{P}_{0}$, and LET-99 and GPR-1/2 are similarly localized (Figure 4). 
There are several other genes required for $\mathrm{P}_{1}$ nuclear rotation, but their precise roles remain to be determined. For example, spn-4 mutant embryos exhibit a $\mathrm{P}_{1}$ spindle orientation perpendicular to the AP axis (Gomes et al., 2001). However, as SPN-4 is known to be involved in translational regulation (see Section 5), this phenotype is likely due to defects in properly translating a yet-to-be identified protein. Regardless, an interesting aspect of the spn-4 phenotype is that PAR domains in $\mathrm{P}_{1}$ are initially normal, but then realign with the transverse spindle later in the cell cycle (Gomes et al., 2001). This suggests the existence of a mechanism that reinforces alignment of the spindle with cell polarity in $\mathrm{P}_{1}$, which could be analogous to the refinement of polarity domains during cytokinesis in the one-cell embryo mentioned earlier (Schenk et al., 2010).

PAR domains are also established prior to the asymmetric divisions of $\mathrm{P}_{2}$ and $\mathrm{P}_{3}$, but their positions are reversed with respect to the earlier divisions, with spindle positioning being similarly reversed (reviewed in Kemphues and Strome, 1997). That is, the PAR-2 domain is located along the ventral side of $\mathrm{P}_{2}$ and the $\mathrm{P}_{2} / \mathrm{EMS}$ contact site, rather than at the posterior of $\mathrm{P}_{2}$ (Figure 4C, D). The $\mathrm{P}_{2}$ nucleus rotates so that one centrosome is associated with the $\mathrm{P}_{2} / \mathrm{EMS}$ cell contact (or the $\mathrm{P}_{3} / \mathrm{E}$ contact) and the spindle sets up with a dorsal/ventral tilt; as a consequence, the smaller P cell is born "anteriorly" and ventrally, adjacent to the E cell (Figure 4, Figure 5). Cell recombination experiments in which wild-type blastomeres were separated and then put back together with different partners revealed that the cue for polarity reversal is contact with the EMS cell (Arata et al., 2010). Polarity reversal requires the activity of the MES-1/SRC-1 pathway. MES-1 has similarity to receptor tyrosine kinases and is enriched at the cell contact region of EMS and $\mathrm{P}_{2}$. MES- 1 is required in both EMS and $\mathrm{P}_{2}$ to induce polarity reversal, while the SRC-1 tyrosine kinase is only required in $\mathrm{P}_{2}$ (Arata et al., 2010; Bei et al., 2002; Berkowitz and Strome, 2000; Kemphues and Strome, 1997).

Spindle positioning in $\mathrm{P}_{2}$ likely utilizes some of the same components as in $\mathrm{P}_{0}$. GPR-1/2 and LIN-5 are enriched at the EMS/ $\mathrm{P}_{2}$ cell contact site prior to division of EMS and $\mathrm{P}_{2}$ (Figure 4C) (Srinivasan et al., 2003; Tsou et al., 2003a). Elegant cell recombination experiments using cells differentially labeled with YFP-GPR-1 and mCherry::GPR-1 revealed that the enrichment at the contact site occurs in $\mathrm{P}_{2}$ rather than in EMS (Werts et al., 2011). Therefore, the asymmetry of GPR- $1 / 2$ and LIN-5 at the cell contact likely reflects PAR dependent pathways for localization of these proteins operating in the $\mathrm{P}_{2}$ cell and needed for $\mathrm{P}_{2}$ spindle orientation. Indeed, MES- 1 and SRC- 1 are required for the localization of GPR-1/2 at the $\mathrm{P}_{2}$ cell contact and for $\mathrm{P}_{2}$ spindle orientation, consistent with their roles in polarity domain reversal.

The EMS cell also undergoes an asymmetric division. A nuclear rotation event positions the spindle on the AP axis of the embryo, and one spindle pole becomes positioned at the EMS $/ \mathrm{P}_{2}$ contact site (Figure $4 \mathrm{C}, \mathrm{D}$ ). These movements coupled with cell polarization result in one daughter, the E cell, being born next to $\mathrm{P}_{2}$ and assuming endodermal fate (see Section 5). PAR domains are not polarized with respect to AP polarity in the EMS cell. Once again, cell isolation and reconstitution experiments illustrated that signals from $\mathrm{P}_{2}$ both polarize EMS for cell fate and induce spindle positioning. Both processes are regulated redundantly by the MES-1/SRC-1 pathway and a Wnt signaling pathway (Sawa, 2012; Werts and Goldstein, 2011; Werts et al., 2011; Bei et al., 2002; Schlesinger et al., 1999; Goldstein, 1995b). Only some of the Wnt pathway components used to specify the E cell (see Section 5) are also used for EMS spindle positioning. For example, upstream components, including the Wnt signal (MOM-2), the Frizzled receptor (MOM-5), and Disheveled family proteins are required. Recent studies determined that the divergent $\beta$-catenin homolog WRM-1 also participates in regulating EMS spindle orientation, although not through transcription as predicted for canonical Wnt signaling. Instead, a WRM-1::GFP reporter becomes asymmetrically depleted from the EMS $/ \mathrm{P}_{2}$ side of the EMS cell in a Wnt pathway-dependent manner (Kim et al., 2013; Takeshita and Sawa, 2005). Genetic analysis indicates that it is the removal of WRM-1 from the posterior $\left(\mathrm{P}_{2}\right.$ interacting cortex) that is key, rather than its presence in the cell (Kim et al., 2013). This explains why previous studies failed to uncover a role for WRM-1 in spindle orientation. Surprisingly however, cell isolation and reconstitution experiments have shown that a Wnt expressing $\mathrm{P}_{2}$ cell can actively orient the spindle (Goldstein et al., 2006). Thus, the Wnt pathway may influence spindle positioning in more than one way, or other factors influence spindle orientation in intact embryos.

Although there is no obvious asymmetry of G protein pathway components in EMS, the analysis of temperature sensitive alleles of LET-99 and GPA-16 indicates that these proteins are nonetheless important for EMS spindle orientation (Zhang et al., 2008; Tsou et al., 2003a). Further, the defects observed in these mutants appear stronger than those observed following single loss of the Wnt or MES-1 pathways. This result could indicate that LET-99 and GPA-16 function in both pathways, or alternatively act in a separate parallel pathway promoting spindle orientation. In addition, analysis of the dynactin components GFP::DNC-1 and GFP::DNC-2 showed that these proteins are enriched at the EMS $/ \mathrm{P}_{2}$ contact site (Zhang et al., 2008). Although cell reconstitution experiments like 
those utilizing tagged-GPR fusions should be conducted to definitively determine if dynactin is asymmetrically localized in the EMS cell, dynactin localization is dependent on both MES and Wnt signaling. Further, $d n c-1(R N A i)$ results in partial failures of EMS rotation. Thus, asymmetric dynactin accumulation may provide a useful tool to further dissect how Wnt signaling regulates spindle movements. For example, it will be of interest to detemine if the removal of WRM-1 is necessary for dynactin accumulation in EMS.

Although the $\mathrm{AB}$ cell and its daughters divide symmetrically, their division pattern is nonetheless tightly regulated. The centrosome migration pattern around the $\mathrm{AB}$ nucleus results in the spindle poles being perpendicular to the AP axis at NEBD, and no rotation events are seen in wild-type embryos. However, in par-3, par-6, and pkc-3 mutant embryos, the $\mathrm{AB}$ nuclear centrosome complex rotates on to the AP axis, as in the $\mathrm{P}_{1}$ cell (reviewed in Kemphues and Strome, 1997). Cell shape manipulations revealed that the nuclear centrosome complex rotates towards flat cell contact areas in par-3 mutants (Tsou et al., 2003b). Thus the anterior PARs act not only to orient spindles onto a specific axis, but to prevent cell shape from affecting division pattern, through an unknown mechanism.

After division of the $\mathrm{AB}$ cell, the centrosomes migrate in $\mathrm{ABa}$ and $\mathrm{ABp}$ so that they are on the future left/right embryonic axis, and the spindles set up in this orientation. However, at telophase, the future left spindle pole shifts anteriorly so that the spindles are skewed $30^{\circ}$ relative to the precise left/right axis (Figure 4) (Pohl, 2011; Bergmann et al., 1998). The only well-characterized component to play a role in this spindle skew is the G $\alpha$ protein GPA-16 (Bergmann et al., 2003). Temperature sensitive gpa-16 mutants raised at semi-permissive temperature can have normal first and second divisions, but variable $\mathrm{ABa}$ and $\mathrm{ABp}$ spindle positions. In some cases, the telophase shift in $\mathrm{ABa}$ and $\mathrm{ABp}$ is reversed, which correlates with the production of adult worms with reversed handedness. It remains to be determined if GPA-16 is part of the cue for left/right handedness, or whether the G protein pathway is acting with GPR-1/2/LIN-5 to orient spindles responding to an asymmetry established earlier during development.

\section{Generation of cytoplasmic asymmetries that govern cell fate specification}

After AP polarity domains have been established in the one-cell embryo, several components act downstream of the PAR proteins to generate cytoplasmic asymmetries (Figure 5), which contribute to specifying the fates of blastomeres or their daughter cells during early embryogenesis (Figure 1). In the following we refer to such components as polarity mediators because they are involved in the asymmetric localization of multiple downstream cell fate regulators and act in many cells. Polarity mediators include several proteins that contain tandem $\mathrm{CCCH}$ zinc-finger domains: MEX-5, MEX-6, MEX-1, and POS-1. In addition, the KH domain protein MEX-3 and the RRM domain protein SPN-4 act as polarity mediators. The $\mathrm{CCCH}$ zinc-finger, $\mathrm{KH}$, and RRM protein domains interact with mRNAs, and most of these polarity mediators have been implicated in translational control (reviewed in RNA-binding proteins; Asymmetric cell division and axis formation in the embryo; Translational control of maternal RNAs). We use the term cell fate regulators for those molecules that directly regulate the fate of one or a few founder cells. These regulators include PIE-1 and NOS-2 (P cell fate), SKN-1 and POP-1 (EMS fates), PAL-1 (C and D fate), as well as GLP-1 and APX-1 (AB fates) (reviewed in Wang and Seydoux, 2013; Sawa, 2012; Maduro, 2010; RNA-binding proteins; Asymmetric cell division and axis formation in the embryo; Notch signaling in the C. elegans embryo; Translational control of maternal RNAs; Wnt signaling; Schnabel and Priess, 1997; Bowerman, 1995). The localization patterns of these regulators are described below in Sections 5.2-5.4, and their developmental activities will be explained in Section 5.5. 
A

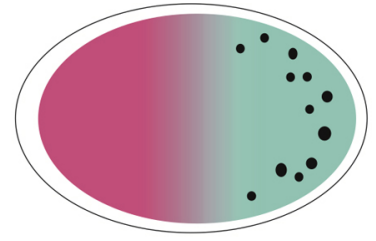

B

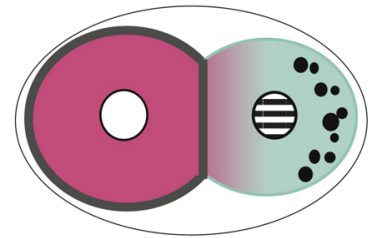

C

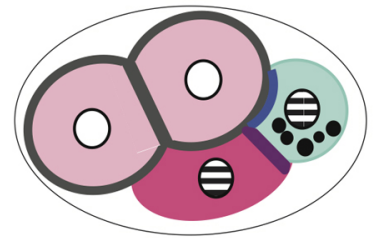

D

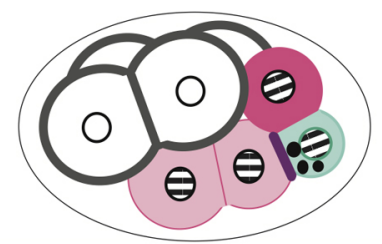

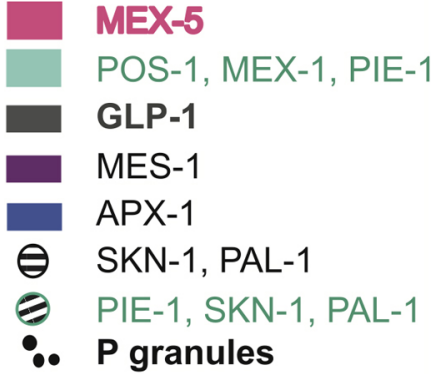

Figure 5. Asymmetric localization of polarity mediators and cell fate regulators in the early embryo. Mediators and cell fate regulators are localized to the cytoplasm (boxes and dots in legend), the membrane (thick lines) or nuclei (circles). In addition, all the polarity mediators and PIE-1 are localized on $\mathrm{P}$ granules during the early divisions. MEX-5, MEX-3, MEX-1, PIE-1, POS-1, and P granules are uniformly present in the cytoplasm just after fertilization, but become asymmetrically localized during the one-cell stage (A) and two-cell (B) stages. In addition to cytoplasmic localization, PIE-1 and SKN-1 enter the nucleus. As the cell cycle proceeds at the two-cell stage, MEX-5 becomes distributed in an anterior to posterior gradient in $\mathrm{P}_{1}$ (not shown) and thus more MEX-5 is inherited by EMS. At the four-cell stage, MEX-5 begins to disappear (light pink) from the AB cells, but is still present in the EMS; MEX-5 is similarly lost from the other somatic daughters as divisions proceed. MEX-3 shows a similar distribution to MEX-5 but presists in the AB cells. The levels of SKN-1 begin to decrease at the 8-cell stage, while PAL-1 is not detectable until the four-cell stage but persists through the 12-cell stage. SPN-4 is uniformly expressed at the one and two-cell stages but becomes restricted to the posterior cells beginning at the four-cell stage. See also Table 3 .

\subsection{PAR-1 kinase activity produces a cytoplasmic gradient of MEX-5}

MEX-5 and MEX-6 are almost identical proteins that act partially redundantly and thus will be referred to as MEX-5/6, unless studies were carried out on one protein only. MEX-5/6 are required to generate asymmetric localization of the other polarity mediators in addition to downstream cell fate determinants, and thus can be considered primary polarity mediators.

MEX-5 is localized at higher levels in the anterior cytoplasm by the end of the one-cell stage, and thus is inherited primarily by the AB daughter cell upon division (Figure 5A, B) (Cuenca et al., 2003; Schubert et al., 2000). Analysis of the dynamics of GFP::MEX-5 fusions gave no evidence for directed transport to the anterior, but revealed that the cytoplasmic mobility of MEX-5 is faster in the posterior compared to the anterior (Daniels et al., 2010; Tenlen et al., 2008). Examination of a photoconvertible Dendra::MEX-5 fusion, which allows proteins to be marked and then monitored over time, yielded similar results and further showed that neither degradation nor synthesis promotes MEX-5 asymmetry (Griffin et al., 2011). Several sites in MEX-5 are phosphorylated in vivo in a PAR-4- and PAR-1-dependent manner and are needed for normal MEX-5 asymmetry and function (Griffin et al., 2011; Tenlen et al., 2008). PAR-1 is likely to be the direct regulator of MEX-5 asymmetry. PAR-1 is present in a cortical and cytoplasmic gradient that correlates with the gradient of increased diffusivity of MEX-5 in wild type. Although it remains to be determined how the cytoplasmic PAR-1 gradient is produced, this kinase can phosphorylate MEX-5 at serine residue 404 (S404) in vitro. Further, mutation of S404 in Dendra::MEX-5 results in slower mobility and loss of asymmetry, similar to what is observed for unaltered Dendra::MEX-5 in par-1 mutant embryos. Conversely, knockdown of the catalytic subunit of PP2A phosphatase, which is uniformly distributed in the cytoplasm, results in increased MEX-5 mobility (Griffin et al., 2011). Mutations in the tandem zinc-finger domains of MEX-5, including ones that alter the affinity of MEX-5 for RNA, also cause an increase in MEX-5 mobility and loss of asymmetry (Griffin et al., 2011; Tenlen et al., 2008; Pagano et al., 2007). Finally, FCS experiments and biochemical analyses indicate that multiple MEX-5 complexes exist in vivo (Griffin et al., 2011; Daniels et al., 2010). These results, along with mathematical modeling, lead to the proposal that phosphorylation by a gradient of cytoplasmic PAR-1 promotes the release of MEX-5 from RNA-containing complexes in the posterior (Griffin et al., 2011). The resulting increased mobility of MEX-5 allows it to diffuse to the anterior where the lower levels of PAR-1 are insufficient to counteract dephosphorylation of MEX-5 by PP2A. Dephosphorylated MEX-5 associates with RNP complexes and cannot redistribute into the posterior as readily, generating a stable anterior to posterior gradient of MEX-5.

In summary, by the end of the one-cell stage, anterior-posterior polarity of cortical PAR proteins has been translated into opposing cytoplasmic gradients of PAR-1 and MEX-5. MEX-5/6 then regulate further downstream asymmetries as outlined below. 


\subsection{MEX-5/6 promote the asymmetric localization of multiple factors}

The mechanism by which MEX-5/6 restrict the localization of the polarity mediators POS- 1 and MEX-1, as well as the cell fate regulator PIE-1, to the germ cell precursors is well understood (Figure 5). Live imaging of PIE-1::GFP showed that the fusion protein is localized in two steps (Movie 5) (Reese et al., 2000). First, PIE-1::GFP becomes enriched in the posterior cytoplasm of the one-cell embryo before division. Second, any protein remaining in the $\mathrm{AB}$ cell is degraded, and a similar degradation occurs in the somatic daughter cell of subsequent $\mathrm{P}$ cell divisions. The degradation events are dependent on MEX-5/6. PIE-1 contains tandem CCCH finger domains, as do POS-1 and MEX-1, even though the overall sequence of these proteins is distinct. A structure/function analysis of PIE-1::GFP revealed that the first zinc finger ZF1 is necessary and sufficient for degradation in the anterior cell. ZF1 binds to ZIF-1, a SOCS box protein that is a substrate recruitment factor for the CUL-2 E3 Ubiquitin ligase complex (DeRenzo et al., 2003). The ZF1 of POS-1 and MEX-1 are likewise necessary for their degradation in somatic cells (Reese et al., 2000).

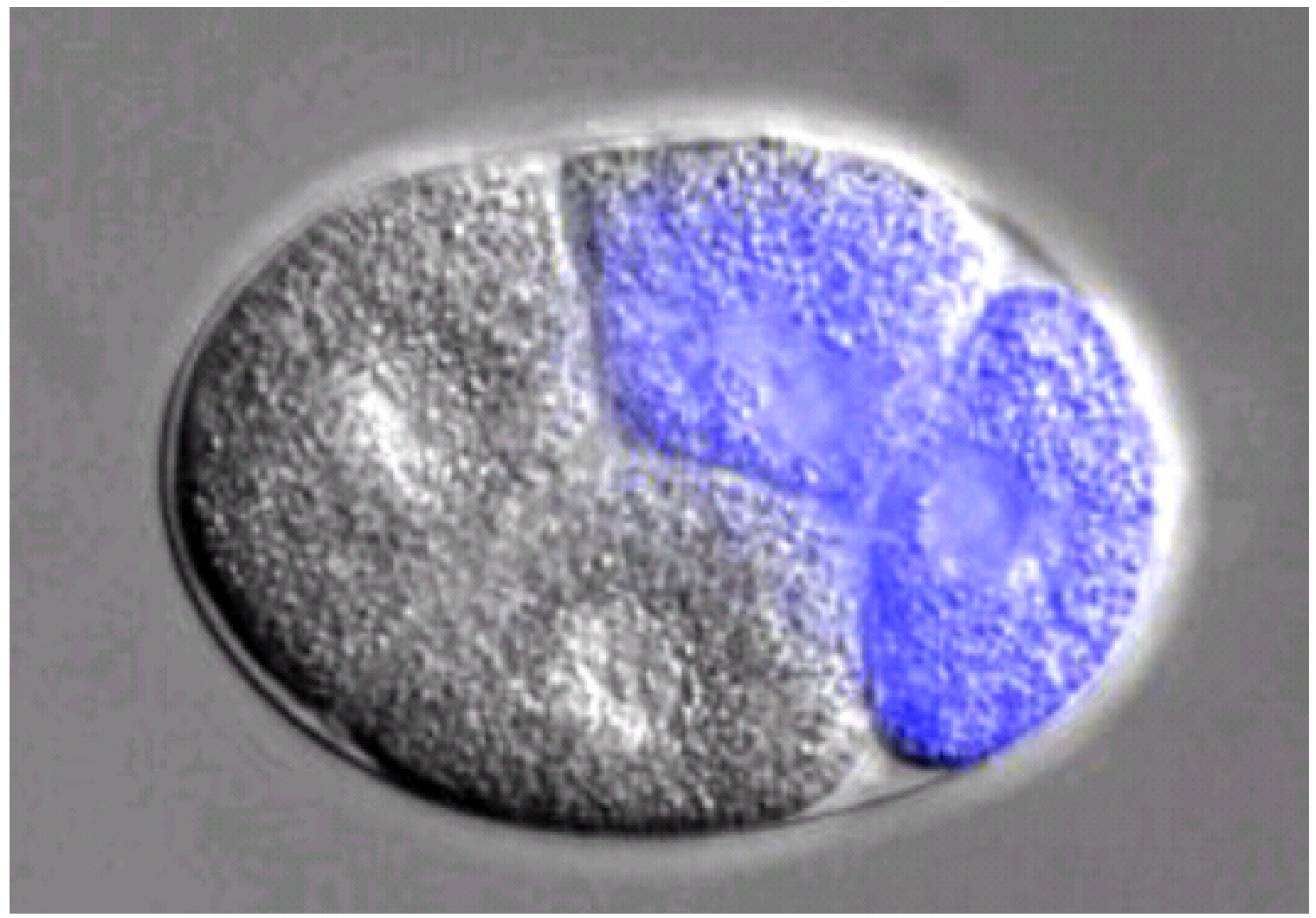

Movie 5. Dual fluorescent and DIC microscopy of embryo carrying GFP::PIE-1 from the one-cell stage until the four-cell stage. GFP::PIE-1 is pseudocolored in blue. One image was captured every ten seconds, and the movie is played back at 10 frames per second. Courtesy of the Gönczy laboratory.

How do MEX-5/6 activate protein degradation in somatic cells? Regulation of ZIF-1 by MEX-5 at the translational level is key. The zif-1 mRNA appears uniformly distributed, but the expression of a reporter transgene bearing only the zif-1 3'UTR is repressed during oogenesis and then in the P lineage of embryos (Oldenbroek et al., 2012; Guven-Ozkan et al., 2010). Analysis of reporter gene expression in different mutant backgrounds indicates that MEX-3, SPN-4, and POS-1 all act negatively on zif-1 mRNA translation in the embryo, while MEX-5/6 act positively. All of these factors bind to the zif-1 3'UTR in vitro. MEX-5/6 and POS-1 bind to the same region of the 3'UTR, with MEX-5/6 binding being preferred. These and other data suggest that in vivo, high levels of MEX-5/6 antagonize translational repression of the zif- 1 mRNA, allowing its expression in $\mathrm{AB}$ and other somatic cells (Oldenbroek et al., 2012). Because ZIF-1 also promotes POS-1 degradation in AB, this further relieves zif-1 mRNA translational repression in somatic cells, whereas the high levels of POS-1 in the germ line precursors keep zif- 1 expression off (Reese et al., 2000). Moreover, POS-1 has been suggested to repress MEX-6 translation based on in vitro binding to the mex-6 3'UTR and genetic analysis (Tenlen et al., 2006). Such mutual antagonism of MEX-5/6 and POS-1 would reinforce their asymmetric localization patterns and thus those of their downstream targets. 
While the studies above suggest a role in translational regulation, other work indicates that MEX-5/6 can also mediate asymmetry through interactions at the protein level. MEX-5/6 are required for the anterior cytoplasmic enrichment in the one-cell embryo of the polo-like kinases PLK-1 and PLK-2, which are important for cell cycle asynchrony at the two-cell stage as described earlier (Budirahardja and Gönczy, 2008; Nishi et al., 2008; Rivers et al., 2008). Both PLK-1 and PLK-2 bind to MEX-5 and MEX-6 in yeast two hybrid assays via their polo box domains (PBD), and a PBD::GFP fusion protein is anteriorly enriched in embryos. These and other results suggest that physical association with MEX-5/6 generates the asymmetric localization of PLK-1/2. Conversely, mutations that affect the ability of MEX-5 to bind to PLK-1/2 do not affect MEX-5 asymmetry, but do affect MEX-5 activity, including its ability to promote PIE-1 degradation (Nishi et al., 2008).

MEX-5/6 also appear to regulate the anterior distribution of the polarity mediator MEX-3 at the protein level. Based on quantitative analysis of MEX-3 levels, the activity of MEX-5/6 stabilizes MEX-3 in the AB lineage, potentially protecting it from degradation. MEX-6 can physically associate with MEX-3 in yeast two-hybrid assays and this interaction could promote MEX-3 stability (Huang et al., 2002). For example, the association of MEX-3 with MEX-6, and thus PLK-1/2, could modify MEX-3 stability through phosphorylation. Alternatively, because MEX-3 and MEX-5/6 both bind to zif-1 mRNA (Oldenbroek et al., 2012), the MEX-3/MEX-6 protein interaction could instead reflect a transient association that is part of the mechanism for zif- 1 regulation.

\subsection{Polarity mediators interact to generate additional asymmetries of fate regulators}

By the end of the two-cell stage, the polarity mediators POS-1, MEX-1, and MEX-3 are asymmetrically localized (Figure 5), while SPN-4 is still uniform at this stage. In addition to their role in repressing zif-1 translation discussed above, these polarity mediators determine the protein localization patterns of several cell fate regulators (Figure 5) (Ogura et al., 2003; Gomes et al., 2001; Tabara et al., 1999; Guedes and Priess, 1997; Draper et al., 1996). The best characterized examples involve translational repression by MEX-3 and POS-1. 
Polarity establishment, asymmetric division and segregation of fate determinants in early C. elegans embryos

\begin{tabular}{|c|c|c|c|c|}
\hline & C. elegans & $\begin{array}{l}\text { Drosophilal } \\
\text { Vertebrates }^{\text {a }}\end{array}$ & $\begin{array}{c}\text { Protein } \\
\text { Distribution }\end{array}$ & Molecular Nature \& Function \\
\hline \multirow{5}{*}{ 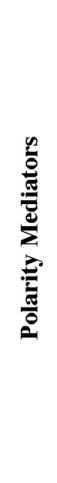 } & MEX-1 & $\begin{array}{l}\text { Tis11/ } \\
\text { Tis11* }\end{array}$ & & $\begin{array}{l}\text { Tandem CCCH-type zinc-finger (ZF) protein; required for } \mathrm{P} \\
\text { granule segregation and SKN-1 localization. }\end{array}$ \\
\hline & MEX-3 & $\begin{array}{l}\text { CG11360 } \\
\text { MEX3A }\end{array}$ & & $\begin{array}{l}\text { KH-domain RNA binding protein; represses expression of PAL-1, } \\
\text { ZIF-1 and NOS-2. }\end{array}$ \\
\hline & MEX-5/6 & $\begin{array}{l}\text { Tis11/ } \\
\text { Tis11* }\end{array}$ & & $\begin{array}{l}\text { Partially redundant tandem } \mathrm{CCCH} \text {-type } \mathrm{ZF} \text { proteins; required for } \\
\text { localization of all other polarity mediators and cell fate regulators. }\end{array}$ \\
\hline & POS-1 & $\begin{array}{l}\text { Tis11/ } \\
\text { Tis11* }\end{array}$ & & $\begin{array}{l}\text { Tandem CCCH-type ZF protein; represses GLP- } 1 \text { and ZIF-1 } \\
\text { translation, but required for APX-1 and NOS- } 2 \text { expression. }\end{array}$ \\
\hline & SPN-4 & $\begin{array}{l}\text { A2bp1/ } \\
\text { RBFOX1 }\end{array}$ & & $\begin{array}{l}\text { RRM-domain RNA binding protein; represses translation of ZIF-1 } \\
\text { and NOS-2. }\end{array}$ \\
\hline \multirow{12}{*}{ 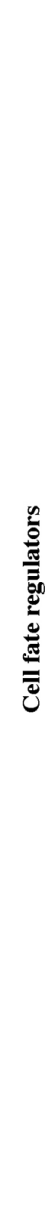 } & APX-1 & $\begin{array}{c}\mathrm{D} 1 / \\
\mathrm{DLK} 2\end{array}$ & & $\begin{array}{l}\text { Delta family ligand; activates GLP-1 signaling in ABp to generate } \\
\text { dorsal fates. }\end{array}$ \\
\hline & GLP-1 & $\begin{array}{c}\mathrm{N} / \\
\mathrm{NOTCH} 1\end{array}$ & & $\begin{array}{l}\text { Notch receptor protein; required for } \mathrm{ABp} \text { to generate dorsal fates } \\
\text { and for } \mathrm{ABa} \text { descendants to produce left/right lineage differences. }\end{array}$ \\
\hline & MES-1 & $\stackrel{-1}{\text { TYK}^{-1} *}$ & & $\begin{array}{l}\text { Receptor tyrosine kinase-like; induces E cell fate by decreasing } \\
\text { POP-1 levels in parallel to Wnt signaling; required for EMS and } \mathrm{P}_{2} \\
\text { spindle positioning. }\end{array}$ \\
\hline & MOM-2 & $\mathrm{Wg} / \mathrm{Int}$ & ND & $\begin{array}{l}\text { Wnt ligand; with Frizzled receptor (MOM-5) induces E cell fate by } \\
\text { decreasing POP-1 levels; required for EMS spindle positioning by } \\
\text { inhibiting cortical WRM-1. }\end{array}$ \\
\hline & NOS-2 & $\begin{array}{l}\text { Nanos/ } \\
\text { Nanos2 }\end{array}$ & & $\begin{array}{l}\text { Nanos family RNA-binding protein; required for germ-line } \\
\text { development. }\end{array}$ \\
\hline & PAL-1 & $\begin{array}{c}\mathrm{Cad} / \\
\mathrm{Cdx}-4\end{array}$ & & $\begin{array}{l}\text { Homeodomain transcription factor of the Caudal family; activates } \\
\text { transcription of genes in C and D. }\end{array}$ \\
\hline & PIE-1 & $\begin{array}{l}\text { Tis11/ } \\
\text { Tis11* }\end{array}$ & & $\begin{array}{l}\text { Tandem CCCH-type ZF protein; inhibits all transcription and } \\
\text { promotes translation of NOS-2 in germ-line precursors. }\end{array}$ \\
\hline & POP-1 & $\begin{array}{l}\text { Pan/ } \\
\text { TCF7L2 }\end{array}$ & & $\begin{array}{l}\text { TCF family transcription factor; high levels repress transcription } \\
\text { of endoderm genes; low levels activate transcription of endoderm } \\
\text { genes in presence of SYS- } 1 \text {. }\end{array}$ \\
\hline & SKN-1 & $-/ \mathrm{Nrf} 2$ & & $\begin{array}{l}\text { bZIP-like transcription factor; activates transcription of genes in } \\
\text { EMS, MS and E. }\end{array}$ \\
\hline & SRC-1 & $\begin{array}{l}\text { Src42A/ } \\
\text { FYN }\end{array}$ & & $\begin{array}{l}\text { Non-receptor tyrosine kinase; required for induction of the E cell } \\
\text { fate and for spindle positioning in EMS and } \mathrm{P}_{2} \text {. }\end{array}$ \\
\hline & SYS-1 & $\begin{array}{c}\text { Arm/ } \\
\beta \text {-catenin* }\end{array}$ & 0 & $\begin{array}{l}\text { Divergent } \beta \text {-catenin; co-activator with POP-1 for transcription of } \\
\text { endoderm genes. }\end{array}$ \\
\hline & WRM-1 & $\underset{\beta-\text { catenin* }}{\text { Arm/ }}$ & & $\begin{array}{l}\text { Divergent } \beta \text {-catenin; promotes nuclear export of POP- } 1 \text { to promote } \\
\text { E cell fate; cortical removal necessary for EMS spindle } \\
\text { positioning. }\end{array}$ \\
\hline \multicolumn{5}{|c|}{$\begin{array}{l}\text { The proteins involved in these processes that are described in detail in the text are shown. } \\
\text { aThe orthologs listed for Drosophila melanogaster and vertebrates are based on functional homology where known; in other cases, } \\
\text { the protein listed is the predicted Drosophila or human protein with highest sequence similarity to C. elegans (from WormBase.org } \\
\text { release WS234); * indicates the protein is one of several sequence homologs in a protein family; ; - indicates no protein with } \\
\text { significant homology is known. } \\
\text { b For simplicity, only asymmetric enrichment is illustrated, although many proteins are also present at lower levels in the cytoplasm } \\
\text { or nuclei of other cells, as described in the text or the references therein. The stage at which the asymmetry is fully established is } \\
\text { shown for most proteins. For APX-1 and GLP-1, asymmetry is present in 2-cells embryos but these proteins appear to affect cell } \\
\text { fate starting at the 4-cell stage shown. The pattern shown for SRC-1 is the phosphorylated form. Protein distributions are based on } \\
\text { antibody staining except for WRM-1, which was analyzed using GFP fusion proteins. }\end{array}$} \\
\hline
\end{tabular}

Table 3. Polarity mediators and cell fate regulators. 
MEX-3 negatively regulates PAL-1, a caudal family transcription factor needed for C and D fates. PAL-1 protein is first observed at the 4-cell stage in $\mathrm{P}_{2}$ and EMS, and then is present in their descendants through the 12-cell stage (Figure 5) (Hunter and Kenyon, 1996). The absence of PAL-1 in the AB lineage is due to translational repression by MEX-3, which is present at high levels in the AB cell and binds the pal-1 3'UTR in vitro (Pagano et al., 2009; Hunter and Kenyon, 1996). Similarly, MEX-3 is needed for the restricted localization of NOS-2, a translational factor required for P cell fate (Pagano et al., 2009; Jadhav et al., 2008; Subramaniam and Seydoux, 1999). MEX-3 binds the nos-2 3'UTR and the expression of a nos-2 3'UTR reporter in mex-3 mutants is consistent with MEX-3 negatively regulating nos-2 mRNA translation. However, in contrast to PAL-1, NOS-2 protein is repressed throughout the embryo until the 28-cell stage when it appears in the $\mathrm{P}_{4}$ cell only, indicating that other factors cooperate with MEX-3. SPN-4 appears to be one such factor, because NOS-2 is ectopically present in somatic cells in spn-4 mutant embryos (Jadhav et al., 2008).

POS-1 plays a role in repressing translation of the $g l p-1$ mRNA in the $\mathrm{P}_{1}$ lineage. GLP-1, a Notch family receptor important for diversifying $\mathrm{AB}$ cell fates, is only present on plasma membranes of the $\mathrm{AB}$ lineage cells (Figure 5B-D) (reviewed in Notch signaling in the C. elegans embryo; Translational control of maternal RNAs; Schnabel and Priess, 1997). This restricted localization is mediated through specific sequences in the glp-1 3'UTR, which can bind to POS-1 in vitro (Ogura et al., 2003). An adjacent region of the 3'UTR also binds GLD-1, a KH domain protein enriched in the $\mathrm{P}_{1}$ cell, which was originally characterized for its role in repressing germ line expression of $g l p-1$. Interestingly, POS-1 is also required for the restricted pattern of APX-1, which is the ligand for GLP-1 in the four-cell embryo (Figure 5C). However, in this case, loss of pos-1 results in the absence of APX-1 (Tabara et al., 1999). Similarly, pos- 1 mutants fail to express NOS-2 in the germ line precursor cell $\mathrm{P}_{4}$ (Tabara et al., 1999). Given the role of POS-1 in repression outlined above, POS-1 may therefore act indirectly through other proteins to positively regulate APX-1 and NOS-2. Surprisingly however, POS-1 directly binds the nos-2 3'UTR and competition experiments combined with genetic data suggested that POS-1 antagonizes the repressive effects of SPN-4 on translation of NOS-2 in the P cells (Jadhav et al., 2008). These and related findings highlight the complexities of translational regulation and suggest that unique combinations of proteins interacting with the 3 'UTR or other modifications can change the ultimate effect of RNA binding proteins like POS- 1 .

\subsection{Additional mechanisms contribute to the asymmetry of cell fate regulators}

Although the mechanisms described above can account for many of the asymmetric protein localizations in the early embryo, interesting variations on these themes contribute to the segregation of other components.

For instance, the pre-divisional posterior enrichment of PIE-1 has been linked to its diffusional mobility, reminiscent of the studies of the MEX-5 gradient, but in this case with diffusion of PIE-1::GFP being slower in the posterior. Pre-division enrichment is separable from somatic degradation and involves a region of the PIE-1 protein that includes the second CCCH-finger (ZF2) (Daniels et al., 2009; Reese et al., 2000). It has been postulated that the formation of complexes of PIE-1 with P granules and/or RNA could slow PIE-1 diffusion in the posterior and prevent its redistribution (Daniels et al., 2009); however, an asymmetric distribution of P granules is not needed for proper PIE-1 localization (Gallo et al., 2010; Wallenfang and Seydoux, 2000). Although in theory PAR-1 could phosphorylate PIE-1 to regulate diffusion, this seems unlikely given that MEX-5/6 act downstream of PAR-1 and are required for the pre-division enrichment of PIE-1, in addition to regulating PIE-1 after division (Cuenca et al., 2003; Schubert et al., 2000).

Mobility regulated by the state of assembly may also play a role in the localization of $\mathrm{P}$ granules to the germ cells (Gallo et al., 2010; Brangwynne et al., 2009; Cheeks et al., 2004). P granules were initially thought to move towards the posterior with the internal cytoplasmic flow in the early one-cell embryo, with $\mathrm{P}$ granules left in the anterior postulated to be degraded (reviewed in Asymmetric cell division and axis formation in the embryo). However, more recent studies show that $\mathrm{P}$ granules also travel anteriorly with subcortical flow, such that flow per se would not provide an efficient localization mechanism (Gallo et al., 2010; Brangwynne et al., 2009; Cheeks et al., 2004). Further, detailed quantitative analysis of fluorescent $P$ granule reporters showed that the major mechanism for posterior enrichment involves regulated assembly and disassembly (Gallo et al., 2010; Cheeks et al., 2004), which can be modeled as a system of condensing versus dissolving liquid droplets (Brangwynne et al., 2009). In particular, P granule grow and shrink throughout the cell cycle, with the portions of the cell destined to the P lineage showing a higher degree of assembly. Mutations in the pptr-1 gene (protein phosphatase 2a regulatory subunit) prevent $\mathrm{P}$ granules assembly during mitosis and lead to a lack of their enrichment in the $\mathrm{P}$ cells (Gallo et al., 2010). However, pptr-1 mutants exhibit normal posterior enrichment of several other germ line proteins. In addition, although MEX-5/6 act to promote $\mathrm{P}$ granule disassembly in the anterior cytoplasm in wild-type embryos, double 
mutant analysis indicates that this effect is separable from that of PPTR-1 in the posterior (Gallo et al., 2010). These and other results suggest that this assembly mechanism is distinct from the other MEX-5/6 dependent posterior localization mechanisms described earlier.

Another mechanism ensures the segregation of SKN-1, a bZip-like transcription factor needed for the fates of EMS and its daughter blastomeres (Bowerman et al., 1993; reviewed in Maduro, 2010; Maduro, 2006, Schnabel and Priess, 1997). SKN-1 protein is enriched in the nucleus of the $P_{1}$ cell and its daughters, due to enrichment in the $P_{1}$ cell combined with degradation in the AB cell. Although its posterior localization depends on MEX-5, SKN-1 does not have a CCCH-type finger that could mediate its degradation via the ZIF-1 pathway. Instead, reduction of SKN-1 in the AB cells is regulated in part by a different E3 ligase, EEL-1 (Page et al., 2007). The polarity mediator MEX-1 is also needed for proper SKN-1 distribution. However whether MEX-5 and MEX-1 are involved in the degradation or posterior enrichment of SKN-1 remains to be determined.

In contrast to some organisms, the localization of mRNAs to specific cells does not appear to play a major role in the restricted localization of most proteins in C. elegans (Tranlational control of maternal RNAs; Schnabel and Priess, 1997). Although the pos- 1 and mex- 1 mRNAs are enriched in the $\mathrm{P}_{1}$ cell, the corresponding proteins are also subjected to regulation at the level of degradation as described earlier. In addition, a number of mRNAs are localized specifically to the germ cell precursor $\mathrm{P}_{4}$ by the 28 cell stage, but this is due to degradation in the somatic blastomeres beginning at the 4-cell stage. MEX-5/6 are required for this degradation via a mechanism that appears distinct from their role in localizing PIE-1 and POS-1 to the $\mathrm{P}_{4}$ cell (D'Agostino et al., 2006; Tenenhaus et al., 2001). In addition, germ-line restricted mRNAs are likely regulated at the level of translation as well, as illustrated above for $n o s-2$.

In summary, although the details regarding the mechanisms underlying some of these interactions remain to be elucidated, their existence adds to the diversity of means to localize proteins in the early embryo. Further, for many of the proteins described here and earlier, localization patterns are generated through more than one of these mechanisms, presumably conferring robustness to the system.

\subsection{Refinement of cell fates}

The division pattern of the embryo leads to a specific arrangement of cells, which, combined with cytoplasmic asymmetries, results in spatially restricted cell signaling events that further refine the fates of the early blastomeres. As mentioned earlier, contact with the $\mathrm{P}_{2}$ cell induces EMS to divide asymmetrically to produce $\mathrm{E}$, the precursor of all intestinal tissue, and MS, a major muscle precursor (Figure 1, Figure 5) (reviewed in Sawa, 2012; Munro and Bowerman, 2009; Notch signaling in the C. elegans embryo; Wnt signaling; Schnabel and Priess, 1997). Additional asymmetric divisions in the $\mathrm{P}$ lineage produce $\mathrm{C}$, a muscle and hypodermis precursor, $\mathrm{D}$, a muscle precursor and $\mathrm{P}_{4}$, the germ-line precursor (Figure 1D). Concurrently, signals from $\mathrm{P}_{2}$ influence ABp so that it generates a different set of cell types than those produced by its more ventral sister $\mathrm{ABa}$. In addition, the specific cell contacts generated by the skew in the division of the $\mathrm{ABa}$ and $\mathrm{ABp}$ cells at third cleavage leads to cell-signaling events that determine the left/right axis of the embryo (reviewed in Pohl, 2011; Schnabel and Priess, 1997).

How does contact with the $\mathrm{P}_{2}$ cell result in such different outputs in the $A B$ descendants versus the EMS descendants? The answer is that the signaling pathways involved are distinct. The specification of $\mathrm{ABa}$ and $\mathrm{ABp}$ will be discussed below, together with the establishment of left/right differences, as both involve the Notch signaling pathway. In contrast, the specification of $\mathrm{E}$ versus MS depends on an asymmetric division induced by Wnt and MES-1/SRC-1 signaling pathways introduced earlier. Cell isolation and reconstitution experiments using wild-type and mutant cells indicated that the Wnt signal (MOM-2) is required in $\mathrm{P}_{2}$, while the Frizzled receptor (MOM-5) and other downstream components are needed in EMS for endoderm specification (Goldstein and Hird, 1996; Goldstein, 1995a; Goldstein, 1995b; reviewed in Werts and Goldstein, 2011; Schnabel and Priess, 1997). MES-1, on the other hand, is required in both $\mathrm{P}_{2}$ and EMS for proper specification of endoderm (Bei et al., 2002; Schlesinger et al., 1999). It remains to be determined how early polarity cues localize Wnt and MES-1 activity.

The outcome of both Wnt and MES-1/SRC-1 signaling is that the EMS daughter cell closest to $\mathrm{P}_{2}$, the E cell, exhibits lower nuclear levels of the TCF family transcription factor POP-1 (Sugioka et al., 2011; Sumiyoshi et al., 2011; Lin et al., 1998; Thorpe et al., 1997; Lin et al., 1995; reviewed in Sawa, 2012; Munro and Bowerman, 2009). The most progress has been made in determining how Wnt signals polarize POP-1 levels. In particular, the E cell has higher nuclear levels of WRM-1, which correlates with the loss of cortical WRM-1 prior to the EMS division (Kim et al., 2013). WRM-1 is important for the nuclear export of POP-1 in the E nucleus. Another $\beta$-catenin family protein, SYS-1, is also enriched in the E cell nucleus. SYS-1 acts as a transcriptional co-activator with POP-1, 
similar to $\beta$-catenin in other systems. The POP-1 remaining in the E cell nucleus appears to complex with SYS-1 and thus activate endodermal (E cells) gene targets. In contrast, the high levels of nuclear POP-1 in MS, where only low levels of the SYS-1 co-activator are present, results in repression of endoderm genes; body wall and pharyngeal muscle gene targets are expressed in MS instead (Sugioka et al., 2011; Huang et al., 2007; Phillips et al., 2007; Rocheleau et al., 1999; Shin et al., 1999). SKN-1 is required for activation of gene targets in both E and MS, and thus it is the specific combination of activators and repressors that leads to differential gene expression and determines their respective fates.

The fates of the somatic daughters of $\mathrm{P}_{2}$ and $\mathrm{P}_{3}$ appear to result mainly from the presence of PAL-1, a caudal domain transcription factor that activates genes required for the production of muscle cell types (reviewed in Maduro, 2010; Schnabel and Priess, 1997). As described in Section 5.3, PAL-1 protein is restricted to the nuclei in the posterior half of the embryo, but it is not specific for C and D (Hunter and Kenyon, 1996). Given the overlap in posterior localization of SKN-1 and PAL-1, why do the C and D cells activate different targets than the EMS daughters? The timing of SKN-1 protein availability is thought to be the reason, since SKN-1 is present from the 2-cell stage but remains at only low levels by the 12-cell stage (Bowerman et al., 1993). By contrast, PAL-1 is present at similar levels from the 4- to the 12-cell stage, and thus remains at high levels when the $\mathrm{C}$ and $\mathrm{D}$ founders are generated.

Although present, neither SKN-1 nor PAL-1 activates gene expression in the P cells. This is because the germ line precursors are protected from activating somatic programs of gene expression by PIE-1, which is restricted to the P cell at each asymmetric division (Figure 5) (Mello et al., 1996). Germ-line precursors in C. elegans, as in many organisms, are transcriptionally quiescent. Inhibition of transcription correlates with the failure to phosphorylate the C-terminal domain of RNA polymerase on Serine-5 (Ser-5) and Ser-2, which are needed for transcription initiation and elongation, respectively. These phophorylation events are inhibited by PIE-1 in the P cells of early C. elegans embryos (Tenenhaus et al., 1998). In vitro studies indicate that PIE-1 directly binds to, and inhibits, the kinase needed for Ser-2 phosphorylation (Batchelder et al., 1999). Altered forms of PIE-1 that do not bind the kinase fail to inhibit Ser-2 phosphorylation in vivo, but can still suppress transcription and promote germ-line fate through effects on Ser-5 phosphorylation (Ghosh and Seydoux, 2008). Inhibition of transcription is thought to prevent SKN-1, PAL-1 and other transcription factors from activating gene expression in the P cells. However, after asymmetric division of $\mathrm{P}_{2}$, the degradation of PIE-1 from the somatic daughter via the MEX-5/ZIF-1 pathway described above relieves transcriptional repression, allowing SKN-1 activation of target genes in EMS. Similarly, after the $\mathrm{P}_{2}$ and $\mathrm{P}_{3}$ divisions, disappearance of PIE-1 allows PAL-1 activation of target genes to commence. PIE-1 is also important for activating the translation of NOS-2 in the $\mathrm{P}_{4}$ cell; although the mechanism is unknown, this function of PIE-1 is separable from its role in preventing transcription (D'Agostino et al., 2006; Tenenhaus et al., 2001).

At the same time that signals from $\mathrm{P}_{2}$ induce the asymmetry of EMS, $\mathrm{P}_{2}$ contact influences the fate of ABp via a separate signaling pathway involving GLP-1, a Notch family receptor (reviewed in Notch signaling in the $C$. elegans embryo; Translational control of maternal RNAs; Schnabel and Priess, 1997). Only the AB daughters express the GLP-1 receptor (Figure 5; see Section 5.3) due to the repressive actions of polarity mediators in the posterior (Crittenden et al., 1997; Evans et al., 1994). Conversely, only $\mathrm{P}_{2}$ has the ligand for the GLP-1 receptor, APX-1 (Figure 5C) (Mickey et al., 1996). Thus, GLP-1 signaling can only be stimulated in the AB cells, and it is asymmetrically activated because only $\mathrm{ABp}$ makes contact with $\mathrm{P}_{2}$. This signaling interaction induces ABp's descendants to produce dorsal cell types (Mickey et al., 1996; Shelton and Bowerman, 1996; Mango et al., 1994).

The formation of the left/right (LR) body axis also requires Notch signaling (reviewed in Pohl, 2011; Notch signaling in the C. elegans embryo; Schnabel and Priess, 1997). Although C. elegans is overtly bilaterally symmetric, there are specific left/right differences in cell types and organ positioning, which are virtually invariant in wild-type worms. The mechanism that establishes left/right handedness begins at the third cleavage (see Section 4); the initial anterior shift in position of the left-hand $\mathrm{AB}$ daughter cells is amplified by coordinated cell movements that ultimately result in specific cell contacts between certain AB descendants and the MS cell (Pohl and Bao, 2010; Bergmann et al., 2003; Bergmann et al., 1998). Physical manipulation during the third cleavage such that the right $\mathrm{AB}$ daughters are more anteriorly positioned results in a reversal of cell arrangements and produces viable worms with reversed left/right handedness. These observations and the lack of any asymmetric localization of cell fate regulators within the $\mathrm{AB}$ lineage suggest that most aspects of the left-right axis are specified by cell-cell signaling events. Indeed, the use of a temperature sensitive $g l p-l$ allele and cell ablations revealed that the GLP- 1 receptor and the MS cell are required for the distinct lineages on the left and right sides; however the ligand in this case is not APX-1 and remains to be identified (reviewed in Pohl, 2011; Notch signaling in the C. elegans embryo; Schnabel and Priess, 1997). 


\section{Perspectives}

The early $C$. elegans embryo has emerged as a major model for the study of asymmetric division. In addition to the usual benefits of $C$. elegans, such as excellent genetic and genomic tools, the transparency of the worm embryo has allowed for major advances in imaging subcellular processes with utmost spatial and temporal resolution, through the use of countless fusion proteins. Combined with laser manipulations to test biophysical aspects of these process, as well as mathematical modeling and computational simulations, this has translated into a comprehensive approach to tackle fundamental biological questions during polarization and asymmetric division of the one-cell $C$. elegans embryo. In addition to elucidating the mechanisms that transform an initially isotropic system into a polarized one in the first cell cycle, studies of the subsequent early divisions have yielded insights into how cell-signaling events build upon the initial polarity to further refine cell fates. Comparative studies will be of particular interest to investigate how subtle variations on these themes may explain the fascinating diversity among early nematode embryos (Schulze and Schierenberg, 2011; Brauchle et al., 2009).

Many findings made in the $C$. elegans embryo system have had an important impact on understanding related processes in other organisms. Since the discovery of the PAR proteins in C. elegans over 20 years ago, homologs have been identified in numerous vertebrates, in other invertebrates such as Drosophila and even sponges (reviewed in Morin and Bellaiche, 2011; Fahey and Degnan, 2010; St Johnston and Ahringer, 2010; Galli and van den Heuvel, 2008; Betschinger and Knoblich, 2004). PAR proteins are localized in reciprocal cortical domains not only in asymmetrically dividing cells during development, but also after differentiation in polarized epithelial cells and neurons. Where examined, the PAR proteins have been shown to play important roles in establishing or maintaining polarity in these diverse cell types. Similarly, the use of heterotrimeric G proteins to link PAR polarity cues to spindle positioning is conserved in many organisms and cell types. Finally, the principles underlying the formation of cytoplasmic asymmetries and refinement of cell fates by signaling events in the early embryo have parallels in other systems. At the same time, the work in $C$. elegans is yielding new paradigms such as asymmetric cytoplasmic localization generated by regulated diffusion. Further analysis in C. elegans as well as studies in various other organisms are likely to continue to synergize in the future to further our knowledge of universal polarity mechanisms.

\section{Acknowledgements}

We are grateful to Eugenel Espiritu, Sachin Kotak, Zoltán Spiró, Michael VanGompel, and the reviewers for critical reading of the manuscript. We thank Eugenel Espiritu for help with the tables, Simon Blanchoud and Zoltán Spiró for contributing Movies 1-4, as well as Ed Munro for providing the images of NMY-2::GFP in Figure 1. Research on asymmetric division in the Gönczy laboratory is supported by the Swiss National Science Foundation (grants 3100A0-102087 and 3100A0-122500/1), that in the Rose laboratory by the NIH (R01GM068744).

\section{References}

Aceto, D., Beers, M., and Kemphues, K.J. (2006). Interaction of PAR-6 with CDC-42 is required for maintenance but not establishment of PAR asymmetry in C. elegans. Dev. Biol. 299, 386-397. Abstract Article

Afshar, K., Werner, M.E., Tse, Y.C., Glotzer, M., and Gönczy, P. (2010). Regulation of cortical contractility and spindle positioning by the protein phosphatase 6 PPH-6 in one-cell stage C. elegans embryos. Development 137 , 237-247. Abstract Article

Afshar, K., Willard, F.S., Colombo, K., Johnston, C.A., McCudden, C.R., Siderovski, D.P., and Gönczy, P. (2004). RIC-8 is required for GPR-1/2-dependent G $\alpha$ function during asymmetric division of C. elegans embryos. Cell 119, 219-230. Abstract Article

Afshar, K., Willard, F.S., Colombo, K., Siderovski, D.P., and Gönczy, P. (2005). Cortical localization of the G $\alpha$ protein GPA-16 requires RIC-8 function during C. elegans asymmetric cell division. Development 132, 4449-4459. Abstract Article

Ai, E., Poole, D.S., and Skop, A.R. (2011). Long astral microtubules and RACK-1 stabilize polarity domains during maintenance phase in Caenorhabditis elegans embryos. PLoS One 6, e19020. Abstract Article 
Andrews, R., and Ahringer, J. (2007). Asymmetry of early endosome distribution in C. elegans embryos. PLoS One 2, e493. Abstract Article

Arata, Y., Lee, J.Y., Goldstein, B., and Sawa, H. (2010). Extracellular control of PAR protein localization during asymmetric cell division in the C. elegans embryo. Development 137, 3337-3345. Abstract Article

Audhya, A., Desai, A., and Oegema, K. (2007). A role for Rab5 in structuring the endoplasmic reticulum. J. Cell Biol. 178, 43-56. Abstract Article

Balklava, Z., Pant, S., Fares, H., and Grant, B.D. (2007). Genome-wide analysis identifies a general requirement for polarity proteins in endocytic traffic. Nat. Cell Biol. 9, 1066-1073. Abstract Article

Basham, S.E., and Rose, L.S. (1999). Mutations in ooc-5 and ooc-3 disrupt oocyte formation and the reestablishment of asymmetric PAR protein localization in two-cell Caenorhabditis elegans embryos. Dev. Biol. 215, 253-263. Abstract Article

Basham, S.E., and Rose, L.S. (2001). The Caenorhabditis elegans polarity gene ooc-5 encodes a Torsin-related protein of the AAA ATPase superfamily. Development 128, 4645-4656. Abstract

Batchelder, C., Dunn, M.A., Choy, B., Suh, Y., Cassie, C., Shim, E.Y., Shin, T.H., Mello, C., Seydoux, G., and Blackwell, T.K. (1999). Transcriptional repression by the Caenorhabditis elegans germ-line protein PIE-1. Genes Dev. 13, 202-212. Abstract Article

Beatty, A., Morton, D., and Kemphues, K. (2010). The C. elegans homolog of Drosophila Lethal giant larvae functions redundantly with PAR-2 to maintain polarity in the early embryo. Development $137,3995-4004$. Abstract Article

Beatty, A., Morton, D.G., and Kemphues, K. (2013). PAR-2, LGL-1 and the CDC-42 GAP CHIN-1 act in distinct pathways to maintain polarity in the C. elegans embryo. Development 140, 2005-2014. Abstract Article

Beers, M., and Kemphues, K. (2006). Depletion of the co-chaperone CDC-37 reveals two modes of PAR-6 cortical association in C. elegans embryos. Development 133, 3745-3754. Abstract Article

Bei, Y., Hogan, J., Berkowitz, L.A., Soto, M., Rocheleau, C.E., Pang, K.M., Collins, J., and Mello, C.C. (2002). SRC-1 and Wnt signaling act together to specify endoderm and to control cleavage orientation in early $C$. elegans embryos. Dev. Cell 3, 113-125. Abstract Article

Berends, C.W., Munoz, J., Portegijs, V., Schmidt, R., Grigoriev, I., Boxem, M., Akhmanova, A., Heck, A.J., and van den Heuvel, S. (2013). F-actin asymmetry and the endoplasmic reticulum-associated TCC-1 protein contribute to stereotypic spindle movements in the Caenorhabditis elegans embryo. Mol. Biol. Cell 24, 2201-2215. Abstract Article

Bergmann, D.C., Crew, J.R., Kramer, J.M., and Wood, W.B. (1998). Cuticle chirality and body handedness in Caenorhabditis elegans. Dev. Genet. 23, 164-174. Abstract Article

Bergmann, D.C., Lee, M., Robertson, B., Tsou, M.F., Rose, L.S., and Wood, W.B. (2003). Embryonic handedness choice in C. elegans involves the G $\alpha$ protein GPA-16. Development 130, 5731-5740. Abstract Article

Berkowitz, L.A., and Strome, S. (2000). MES-1, a protein required for unequal divisions of the germline in early $C$. elegans embryos, resembles receptor tyrosine kinases and is localized to the boundary between the germline and gut cells. Development 127, 4419-4431. Abstract

Betschinger, J., and Knoblich, J.A. (2004). Dare to be different: asymmetric cell division in Drosophila, C. elegans and vertebrates. Curr. Biol. 14, R674-685. Abstract Article

Bienkowska, D., and Cowan, C.R. (2012). Centrosomes can initiate a polarity axis from any position within one-cell C. elegans embryos. Curr. Biol. 22, 583-589. Abstract Article 
Bowerman, B. (1995). Determinants of blastomere identity in the early C. elegans embryo. Bioessays 17, $405-414$. Abstract Article

Bowerman, B., Draper, B.W., Mello, C.C., and Priess, J.R. (1993). The maternal gene skn-1 encodes a protein that is distributed unequally in early C. elegans embryos. Cell 74, 443-452. Abstract Article

Brangwynne, C.P., Eckmann, C.R., Courson, D.S., Rybarska, A., Hoege, C., Gharakhani, J., Julicher, F., and Hyman, A.A. (2009). Germline P granules are liquid droplets that localize by controlled dissolution/condensation. Science 324, 1729-1732. Abstract Article

Brauchle, M., Baumer, K., and Gönczy, P. (2003). Differential activation of the DNA replication checkpoint contributes to asynchrony of cell division in C. elegans embryos. Curr. Biol. 13, 819-827. Abstract Article

Brauchle, M., Kiontke, K., MacMenamin, P., Fitch, D.H., and Piano, F. (2009). Evolution of early embryogenesis in rhabditid nematodes. Dev. Biol. 335, 253-262. Abstract Article

Bringmann, H. (2012). G protein regulator 1 (GPR-1) localizes to cortical sites of artificial mechanical indentation in Caenorhabditis elegans zygotes. Cytoskeleton 69, 819-825. Abstract Article

Budirahardja, Y., and Gönczy, P. (2008). PLK-1 asymmetry contributes to asynchronous cell division of C. elegans embryos. Development 135, 1303-1313. Abstract Article

Chase, D., Serafinas, C., Ashcroft, N., Kosinski, M., Longo, D., Ferris, D.K., and Golden, A. (2000). The polo-like kinase PLK-1 is required for nuclear envelope breakdown and the completion of meiosis in Caenorhabditis elegans. Genesis 26, 26-41. Abstract Article

Cheeks, R.J., Canman, J.C., Gabriel, W.N., Meyer, N., Strome, S., and Goldstein, B. (2004). C. elegans PAR proteins function by mobilizing and stabilizing asymmetrically localized protein complexes. Curr. Biol. 14, 851-862. Abstract Article

Colombo, K., Grill, S.W., Kimple, R.J., Willard, F.S., Siderovski, D.P., and Gönczy, P. (2003). Translation of polarity cues into asymmetric spindle positioning in Caenorhabditis elegans embryos. Science 300, 1957-1961. Abstract Article

Couwenbergs, C., Labbe, J.C., Goulding, M., Marty, T., Bowerman, B., and Gotta, M. (2007). Heterotrimeric G protein signaling functions with dynein to promote spindle positioning in C. elegans. J. Cell Biol. 179, $15-22$. Abstract Article

Cowan, C.R., and Hyman, A.A. (2004a). Asymmetric cell division in C. elegans: cortical polarity and spindle positioning. Annu. Rev. Cell Dev. Biol. 20, 427-453. Abstract Article

Cowan, C.R., and Hyman, A.A. (2004b). Centrosomes direct cell polarity independently of microtubule assembly in C. elegans embryos. Nature 431,92-96. Abstract Article

Cowan, C.R., and Hyman, A.A. (2007). Acto-myosin reorganization and PAR polarity in C. elegans. Development 134, 1035-1043. Abstract Article

Crittenden, S.L., Rudel, D., Binder, J., Evans, T.C., and Kimble, J. (1997). Genes required for GLP-1 asymmetry in the early Caenorhabditis elegans embryo. Dev. Biol. 181, 36-46. Abstract Article

Cuenca, A.A., Schetter, A., Aceto, D., Kemphues, K., and Seydoux, G. (2003). Polarization of the C. elegans zygote proceeds via distinct establishment and maintenance phases. Development 130, 1255-1265. Abstract Article

D'Agostino, I., Merritt, C., Chen, P.L., Seydoux, G., and Subramaniam, K. (2006). Translational repression restricts expression of the C. elegans Nanos homolog NOS-2 to the embryonic germline. Dev. Biol. 292, 244-252. Abstract Article

Daniels, B.R., Dobrowsky, T.M., Perkins, E.M., Sun, S.X., and Wirtz, D. (2010). MEX-5 enrichment in the $C$. elegans early embryo mediated by differential diffusion. Development 137, 2579-2585. Abstract Article 
Daniels, B.R., Perkins, E.M., Dobrowsky, T.M., Sun, S.X., and Wirtz, D. (2009). Asymmetric enrichment of PIE-1 in the Caenorhabditis elegans zygote mediated by binary counterdiffusion. J. Cell Biol. 184, 473-479. Abstract Article

Dawes, A.T., and Munro, E.M. (2011). PAR-3 oligomerization may provide an actin-independent mechanism to maintain distinct PAR protein domains in the early Caenorhabditis elegans embryo. Biophys. J. 101, 1412-1422. Abstract Article

DeRenzo, C., Reese, K.J., and Seydoux, G. (2003). Exclusion of germ plasm proteins from somatic lineages by cullin-dependent degradation. Nature 424, 685-689. Abstract Article

Draper, B.W., Mello, C.C., Bowerman, B., Hardin, J., and Priess, J.R. (1996). MEX-3 is a KH domain protein that regulates blastomere identity in early C. elegans embryos. Cell 87, 205-216. Abstract Article

Eisenmann, D.M. (2005). Wnt signaling. WormBook, ed. The C. elegans Research Community, WormBook, doi/10.1895/wormbook.1.7.1, http://www.wormbook.org.

Encalada, S.E., Martin, P.R., Phillips, J.B., Lyczak, R., Hamill, D.R., Swan, K.A., and Bowerman, B. (2000). DNA replication defects delay cell division and disrupt cell polarity in early Caenorhabditis elegans embryos. Dev. Biol. 228, 225-238. Abstract Article

Evans, T.C., Crittenden, S.L., Kodoyianni, V., and Kimble, J. (1994). Translational control of maternal $g l p-1$ mRNA establishes an asymmetry in the C. elegans embryo. Cell 77, 183-194. Abstract Article

Evans, T.C., and Hunter, C.P. (2005). Translational control of maternal RNAs. WormBook, ed. The C. elegans Research Community, WormBook, doi/10.1895/wormbook.1.34.1, http://www.wormbook.org.

Fahey, B., and Degnan, B.M. (2010). Origin of animal epithelia: insights from the sponge genome. Evol. Devel. 12, 601-617. Abstract Article

Fortin, S.M., Marshall, S.L., Jaeger, E.C., Greene, P.E., Brady, L.K., Isaac, R.E., Schrandt, J.C., Brooks, D.R., and Lyczak, R. (2010). The PAM-1 aminopeptidase regulates centrosome positioning to ensure anterior-posterior axis specification in one-cell C. elegans embryos. Dev. Biol. 344, 992-1000. Abstract Article

Galli, M., Munoz, J., Portegijs, V., Boxem, M., Grill, S.W., Heck, A.J., and van den Heuvel, S. (2011). aPKC phosphorylates NuMA-related LIN-5 to position the mitotic spindle during asymmetric division. Nat. Cell Biol. 13, 1132-1138. Abstract Article

Galli, M., and van den Heuvel, S. (2008). Determination of the cleavage plane in early C. elegans embryos. Annu. Rev. Genet. 42, 389-411. Abstract Article

Gallo, C.M., Wang, J.T., Motegi, F., and Seydoux, G. (2010). Cytoplasmic partitioning of P granule components is not required to specify the germline in C. elegans. Science 330, 1685-1689. Abstract Article

Ghosh, D., and Seydoux, G. (2008). Inhibition of transcription by the Caenorhabditis elegans germline protein PIE-1: genetic evidence for distinct mechanisms targeting initiation and elongation. Genetics 178, 235-243. Abstract Article

Goehring, N.W., Hoege, C., Grill, S.W., and Hyman, A.A. (2011a). PAR proteins diffuse freely across the anterior-posterior boundary in polarized C. elegans embryos. J. Cell Biol. 193, 583-594. Abstract Article

Goehring, N.W., Trong, P.K., Bois, J.S., Chowdhury, D., Nicola, E.M., Hyman, A.A., and Grill, S.W. (2011b). Polarization of PAR proteins by advective triggering of a pattern-forming system. Science 334, 1137-1141. Abstract Article

Goldstein, B. (1995a). An analysis of the response to gut induction in the C. elegans embryo. Development 121 , 1227-1236. Abstract 
Goldstein, B. (1995b). Cell contacts orient some cell division axes in the Caenorhabditis elegans embryo. J. Cell Biol. 129, 1071-1080. Abstract Article

Goldstein, B., and Hird, S.N. (1996). Specification of the anteroposterior axis in Caenorhabditis elegans. Development 122, 1467-1474. Abstract

Goldstein, B., and Macara, I.G. (2007). The PAR proteins: fundamental players in animal cell polarization. Dev. Cell 13, 609-622. Abstract Article

Goldstein, B., Takeshita, H., Mizumoto, K., and Sawa, H. (2006). Wnt signals can function as positional cues in establishing cell polarity. Dev. Cell 10,391-396. Abstract Article

Gomes, J.E., Encalada, S.E., Swan, K.A., Shelton, C.A., Carter, J.C., and Bowerman, B. (2001). The maternal gene $s p n-4$ encodes a predicted RRM protein required for mitotic spindle orientation and cell fate patterning in early $C$. elegans embryos. Development 128, 4301-4314. Abstract

Gönczy, P., Pichler, S., Kirkham, M., and Hyman, A.A. (1999). Cytoplasmic dynein is required for distinct aspects of MTOC positioning, including centrosome separation, in the one cell stage Caenorhabditis elegans embryo. J. Cell Biol. 147, 135-150. Abstract

Gönczy, P., and Rose, L.S. (2005). Asymmetric cell division and axis formation in the embryo. WormBook, ed. The C. elegans Research Community, WormBook, doi/10.1895/wormbook.1.30.1, http://www.wormbook.org

Gotta, M., Abraham, M.C., and Ahringer, J. (2001). CDC-42 controls early cell polarity and spindle orientation in $C$. elegans. Curr. Biol. 11, 482-488. Abstract Article

Gotta, M., and Ahringer, J. (2001). Distinct roles for G $\alpha$ and G $\beta \gamma$ in regulating spindle position and orientation in Caenorhabditis elegans embryos. Nat. Cell Biol. 3, 297-300. Abstract Article

Gotta, M., Dong, Y., Peterson, Y.K., Lanier, S.M., and Ahringer, J. (2003). Asymmetrically distributed C. elegans homologs of AGS3/PINS control spindle position in the early embryo. Curr. Biol. 13, 1029-1037. Abstract Article

Goulding, M.B., Canman, J.C., Senning, E.N., Marcus, A.H., and Bowerman, B. (2007). Control of nuclear centration in the $C$. elegans zygote by receptor-independent $\mathrm{G} \alpha$ signaling and myosin II. J. Cell Biol. 178, 1177-1191. Abstract Article

Griffin, E.E., Odde, D.J., and Seydoux, G. (2011). Regulation of the MEX-5 gradient by a spatially segregated kinase/phosphatase cycle. Cell 146, 955-968. Abstract Article

Grill, S.W., Gönczy, P., Stelzer, E.H., and Hyman, A.A. (2001). Polarity controls forces governing asymmetric spindle positioning in the Caenorhabditis elegans embryo. Nature 409, 630-633. Abstract Article

Grill, S.W., Howard, J., Schaffer, E., Stelzer, E.H., and Hyman, A.A. (2003). The distribution of active force generators controls mitotic spindle position. Science 301, 518-521. Abstract Article

Guedes, S., and Priess, J.R. (1997). The C. elegans MEX-1 protein is present in germline blastomeres and is a P granule component. Development 124, 731-739. Abstract

Gusnowski, E.M., and Srayko, M. (2011). Visualization of dynein-dependent microtubule gliding at the cell cortex: implications for spindle positioning. J. Cell Biol. 194, 377-386. Abstract Article

Guven-Ozkan, T., Robertson, S.M., Nishi, Y., and Lin, R. (2010). zif-1 translational repression defines a second, mutually exclusive OMA function in germline transcriptional repression. Development 137, 3373-3382. Abstract Article

Hao, Y., Boyd, L., and Seydoux, G. (2006). Stabilization of cell polarity by the C. elegans RING protein PAR-2. Dev. Cell 10, 199-208. Abstract Article 
Hess, H.A., Roper, J.C., Grill, S.W., and Koelle, M.R. (2004). RGS-7 completes a receptor-independent heterotrimeric $\mathrm{G}$ protein cycle to asymmetrically regulate mitotic spindle positioning in C. elegans. Cell 119, 209-218. Abstract Article

Hird, S.N., and White, J.G. (1993). Cortical and cytoplasmic flow polarity in early embryonic cells of Caenorhabditis elegans. J. Cell Biol. 121, 1343-1355. Abstract Article

Hoege, C., Constantinescu, A.T., Schwager, A., Goehring, N.W., Kumar, P., and Hyman, A.A. (2010). LGL can partition the cortex of one-cell Caenorhabditis elegans embryos into two domains. Curr. Biol. 20 , $1296-1303$. Abstract Article

Huang, N.N., Mootz, D.E., Walhout, A.J., Vidal, M., and Hunter, C.P. (2002). MEX-3 C. elegans interacting proteins link cell polarity to asymmetric gene expression in Caenorhabditis elegans. Development 129, $747-759$. Abstract

Huang, S., Shetty, P., Robertson, S.M., and Lin, R. (2007). Binary cell fate specification during C. elegans embryogenesis driven by reiterated reciprocal asymmetry of TCF POP-1 and its coactivator $\beta$-catenin SYS-1. Development 134, 2685-2695. Abstract Article

Hunter, C.P., and Kenyon, C. (1996). Spatial and temporal controls target pal-1 blastomere-specification activity to a single blastomere lineage in C. elegans embryos. Cell 87, 217-226. Abstract Article

Hyenne, V., Tremblay-Boudreault, T., Velmurugan, R., Grant, B.D., Loerke, D., and Labbe, J.C. (2012). RAB-5 controls the cortical organization and dynamics of PAR proteins to maintain C. elegans early embryonic polarity. PLoS One 7, e35286. Abstract Article

Jadhav, S., Rana, M., and Subramaniam, K. (2008). Multiple maternal proteins coordinate to restrict the translation of C. elegans nanos-2 to primordial germ cells. Development 135, 1803-1812. Abstract Article

Jenkins, N., Saam, J.R., and Mango, S.E. (2006). CYK-4/GAP provides a localized cue to initiate anteroposterior polarity upon fertilization. Science 313, 1298-1301. Abstract Article

Kay, A.J., and Hunter, C.P. (2001). CDC-42 regulates PAR protein localization and function to control cellular and embryonic polarity in C. elegans. Curr. Biol. 11, 474-481. Abstract Article

Kemphues, K.J., and Strome, S. (1997). Fertilization and establishment of polarity in the embryo. In C. elegans II, D.L. Riddle, T. Blumenthal, B.J. Meyer, and J.R. Priess, eds. (Cold Spring Harbor, NY: Cold Spring Harbor Laboratory Press), pp. 335-359. Abstract

Kim, S., Ishidate, T., Sharma, R., Soto, M.C., Conte, D., Jr., Mello, C.C., and Shirayama, M. (2013). Wnt and CDK-1 regulate cortical release of WRM-1/ $\beta$-catenin to control cell division orientation in early Caenorhabditis elegans embryos. Proc. Natl. Acad. Sci. U. S. A. 110, E918-927. Abstract

Kimura, A., and Onami, S. (2005). Computer simulations and image processing reveal length-dependent pulling force as the primary mechanism for C. elegans male pronuclear migration. Dev. Cell 8, 765-775. Abstract Article

Kimura, K., and Kimura, A. (2011). Intracellular organelles mediate cytoplasmic pulling force for centrosome centration in the Caenorhabditis elegans early embryo. Proc. Natl. Acad. Sci. U. S. A. 108, 137-142. Abstract Article

Kotak, S., Busso, C., and Gönczy, P. (2012). Cortical dynein is critical for proper spindle positioning in human cells. J. Cell Biol. 199, 97-110. Abstract Article

Kozlowski, C., Srayko, M., and Nédélec, F. (2007). Cortical microtubule contacts position the spindle in C. elegans embryos. Cell 129, 499-510. Abstract Article

Krueger, L.E., Wu, J.C., Tsou, M.F., and Rose, L.S. (2010). LET-99 inhibits lateral posterior pulling forces during asymmetric spindle elongation in C. elegans embryos. J. Cell Biol. 189, 481-495. Abstract Article 
Kumfer, K.T., Cook, S.J., Squirrell, J.M., Eliceiri, K.W., Peel, N., O'Connell, K.F., and White, J.G. (2010). CGEF-1 and CHIN-1 regulate CDC-42 activity during asymmetric division in the Caenorhabditis elegans embryo. Mol. Biol. Cell 21, 266-277. Abstract Article

Labbé, J.C., Maddox, P.S., Salmon, E.D., and Goldstein, B. (2003). PAR proteins regulate microtubule dynamics at the cell cortex in C. elegans. Curr. Biol. 13, 707-714. Abstract Article

Labbé, J.C., McCarthy, E.K., and Goldstein, B. (2004). The forces that position a mitotic spindle asymmetrically are tethered until after the time of spindle assembly. J. Cell Biol. 167, 245-256 Epub 2004 Oct 2018. Abstract Article

Lee, M.H., and Schedl, T. (2006). RNA-binding proteins. WormBook, ed. The C. elegans Research Community, WormBook, doi/10.1895/wormbook.1.79.1, http://www.wormbook.org.

Lin, R., Hill, R.J., and Priess, J.R. (1998). POP-1 and anterior-posterior fate decisions in C. elegans embryos. Cell 92, 229-239. Abstract Article

Lin, R., Thompson, S., and Priess, J.R. (1995). pop-1 encodes an HMG box protein required for the specification of a mesoderm precursor in early C. elegans embryos. Cell 83, 599-609. Abstract Article

Lyczak, R., Zweier, L., Group, T., Murrow, M.A., Snyder, C., Kulovitz, L., Beatty, A., Smith, K., and Bowerman, B. (2006). The puromycin-sensitive aminopeptidase PAM-1 is required for meiotic exit and anteroposterior polarity in the one-cell Caenorhabditis elegans embryo. Development 133, 4281-4892. Abstract Article

Maduro, M.F. (2006). Endomesoderm specification in Caenorhabditis elegans and other nematodes. BioEssays 28, 1010-1022. Abstract Article

Maduro, M.F. (2010). Cell fate specification in the C. elegans embryo. Dev. Dyn. 239, 1315-1329. Abstract Article

Mango, S.E., Thorpe, C.J., Martin, P.R., Chamberlain, S.H., and Bowerman, B. (1994). Two maternal genes, apx-1 and pie-1, are required to distinguish the fates of equivalent blastomeres in the early Caenorhabditis elegans embryo. Development 120, 2305-2315. Abstract

Mayer, M., Depken, M., Bois, J.S., Julicher, F., and Grill, S.W. (2010). Anisotropies in cortical tension reveal the physical basis of polarizing cortical flows. Nature 467, 617-621. Abstract Article

McCarthy Campbell, E.K., Werts, A.D., and Goldstein, B. (2009). A cell cycle timer for asymmetric spindle positioning. PLoS Biol 7, e1000088. Abstract Article

McCloskey, R.J., and Kemphues, K.J. (2012). Deubiquitylation machinery is required for embryonic polarity in Caenorhabditis elegans. PLoS Genet 8, e1003092. Abstract Article

McNally, F.J. (2013). Mechanisms of spindle positioning. J. Cell Biol. 200, 131-140. Abstract Article

McNally, K.L., Fabritius, A.S., Ellefson, M.L., Flynn, J.R., Milan, J.A., and McNally, F.J. (2012). Kinesin-1 prevents capture of the oocyte meiotic spindle by the sperm aster. Dev. Cell 22, 788-798. Abstract Article

Mello, C.C., Schubert, C., Draper, B., Zhang, W., Lobel, R., and Priess, J.R. (1996). The PIE-1 protein and germline specification in C. elegans embryos. Nature 382, 710-712. Abstract Article

Merdes, A., Ramyar, K., Vechio, J.D., and Cleveland, D.W. (1996). A complex of NuMA and cytoplasmic dynein is essential for mitotic spindle assembly. Cell 87, 447-458. Abstract Article

Mickey, K.M., Mello, C.C., Montgomery, M.K., Fire, A., and Priess, J.R. (1996). An inductive interaction in 4-cell stage C. elegans embryos involves APX-1 expression in the signalling cell. Development 122, 1791-1798. Abstract

Miller, K.G., and Rand, J.B. (2000). A role for RIC-8 (Synembryn) and GOA-1 $\left(\mathrm{G}_{0} \alpha\right)$ in regulating a subset of centrosome movements during early embryogenesis in Caenorhabditis elegans. Genetics 156, 1649-1660. Abstract 
Morin, X., and Bellaiche, Y. (2011). Mitotic spindle orientation in asymmetric and symmetric cell divisions during animal development. Dev. Cell 21, 102-119. Abstract Article

Motegi, F., and Sugimoto, A. (2006). Sequential functioning of the ECT-2 RhoGEF, RHO-1 and CDC-42 establishes cell polarity in Caenorhabditis elegans embryos. Nat. Cell Biol. 8, 978-985. Abstract Article

Motegi, F., Zonies, S., Hao, Y., Cuenca, A.A., Griffin, E., and Seydoux, G. (2011). Microtubules induce self-organization of polarized PAR domains in Caenorhabditis elegans zygotes. Nat. Cell Biol. 13, $1361-1367$. Abstract Article

Munro, E., and Bowerman, B. (2009). Cellular symmetry breaking during Caenorhabditis elegans development. Cold Spring Harb. Perspect. Biol. 1, a003400. Abstract Article

Munro, E., Nance, J., and Priess, J.R. (2004). Cortical flows powered by asymmetrical contraction transport PAR proteins to establish and maintain anterior-posterior polarity in the early C. elegans embryo. Dev. Cell 7, $413-424$. Abstract Article

Nakayama, Y., Shivas, J.M., Poole, D.S., Squirrell, J.M., Kulkoski, J.M., Schleede, J.B., and Skop, A.R. (2009). Dynamin participates in the maintenance of anterior polarity in the Caenorhabditis elegans embryo. Dev. Cell 16, 889-900. Abstract Article

Nguyen-Ngoc, T., Afshar, K., and Gönczy, P. (2007). Coupling of cortical dynein and G $\alpha$ proteins mediates spindle positioning in Caenorhabditis elegans. Nat. Cell Biol. 9, 294-302. Abstract Article

Nishi, Y., Rogers, E., Robertson, S.M., and Lin, R. (2008). Polo kinases regulate C. elegans embryonic polarity via binding to DYRK2-primed MEX-5 and MEX-6. Development 135, 687-697. Abstract Article

Niwayama, R., Shinohara, K., and Kimura, A. (2011). Hydrodynamic property of the cytoplasm is sufficient to mediate cytoplasmic streaming in the Caenorhabditis elegans embryo. Proc. Natl. Acad. Sci. U. S. A. 108, 11900-11905. Abstract Article

O'Rourke, S.M., Christensen, S.N., and Bowerman, B. (2010). Caenorhabditis elegans EFA-6 limits microtubule growth at the cell cortex. Nat. Cell Biol. 12, 1235-1241. Abstract Article

O'Rourke, S.M., Dorfman, M.D., Carter, J.C., and Bowerman, B. (2007). Dynein modifiers in C. elegans: light chains suppress conditional heavy chain mutants. PLoS Genet 3, e128. Abstract Article

Oegema, K., Desai, A., Rybina, S., Kirkham, M., and Hyman, A.A. (2001). Functional analysis of kinetochore assembly in Caenorhabditis elegans. J. Cell Biol. 153, 1209-1226. Abstract Article

Ogura, K., Kishimoto, N., Mitani, S., Gengyo-Ando, K., and Kohara, Y. (2003). Translational control of maternal glp-1 mRNA by POS-1 and its interacting protein SPN-4 in Caenorhabditis elegans. Development 130, $2495-2503$. Abstract Article

Oldenbroek, M., Robertson, S.M., Guven-Ozkan, T., Gore, S., Nishi, Y., and Lin, R. (2012). Multiple RNA-binding proteins function combinatorially to control the soma-restricted expression pattern of the E3 ligase subunit ZIF-1. Dev. Biol. 363, 388-398. Abstract Article

Pagano, J.M., Farley, B.M., Essien, K.I., and Ryder, S.P. (2009). RNA recognition by the embryonic cell fate determinant and germline totipotency factor MEX-3. Proc. Natl. Acad. Sci. U. S. A. 106, 20252-20257. Abstract Article

Pagano, J.M., Farley, B.M., McCoig, L.M., and Ryder, S.P. (2007). Molecular basis of RNA recognition by the embryonic polarity determinant MEX-5. J. Biol. Chem. 282, 8883-8894. Abstract Article

Page, B.D., Diede, S.J., Tenlen, J.R., and Ferguson, E.L. (2007). EEL-1, a Hect E3 ubiquitin ligase, controls asymmetry and persistence of the SKN-1 transcription factor in the early C. elegans embryo. Development 134 , 2303-2314. Abstract Article 
Panbianco, C., Weinkove, D., Zanin, E., Jones, D., Divecha, N., Gotta, M., and Ahringer, J. (2008). A casein kinase 1 and PAR proteins regulate asymmetry of a PIP ${ }_{2}$ synthesis enzyme for asymmetric spindle positioning. Dev. Cell 15, 198-208. Abstract Article

Park, D.H., and Rose, L.S. (2008). Dynamic localization of LIN-5 and GPR-1/2 to cortical force generation domains during spindle positioning. Dev. Biol. 315, 42-54. Abstract Article

Pecreaux, J., Roper, J.C., Kruse, K., Julicher, F., Hyman, A.A., Grill, S.W., and Howard, J. (2006). Spindle oscillations during asymmetric cell division require a threshold number of active cortical force generators. Curr. Biol. 16, 2111-2122. Abstract Article

Petrasek, Z., Hoege, C., Mashaghi, A., Ohrt, T., Hyman, A.A., and Schwille, P. (2008). Characterization of protein dynamics in asymmetric cell division by scanning fluorescence correlation spectroscopy. Biophys. J. 95, 5476-5486. Abstract Article

Phillips, B.T., Kidd, A.R., 3rd, King, R., Hardin, J., and Kimble, J. (2007). Reciprocal asymmetry of SYS-1/ $\beta$-catenin and POP-1/TCF controls asymmetric divisions in Caenorhabditis elegans. Proc. Natl. Acad. Sci. U. S. A. 104, 3231-3236. Abstract Article

Pichler, S., Gönczy, P., Schnabel, H., Pozniakowski, A., Ashford, A., Schnabel, R., and Hyman, A.A. (2000). OOC-3, a novel putative transmembrane protein required for establishment of cortical domains and spindle orientation in the $\mathrm{P}_{1}$ blastomere of C. elegans embryos. Development 127, 2063-2073. Abstract

Pohl, C. (2011). Left-right patterning in the C. elegans embryo: Unique mechanisms and common principles. Commun. Integr. Biol. 4, 34-40. Abstract Article

Pohl, C., and Bao, Z. (2010). Chiral forces organize left-right patterning in C. elegans by uncoupling midline and anteroposterior axis. Dev. Cell 19, 402-412. Abstract Article

Priess, J.R. (2005). Notch signaling in the C. elegans embryo. WormBook, ed. The C. elegans Research Community, WormBook, doi/10.1895/wormbook.1.10.2, http://www.wormbook.org.

Redemann, S., Pecreaux, J., Goehring, N.W., Khairy, K., Stelzer, E.H., Hyman, A.A., and Howard, J. (2010). Membrane invaginations reveal cortical sites that pull on mitotic spindles in one-cell C. elegans embryos. PLoS One 5, e12301. Abstract Article

Redemann, S., Schloissnig, S., Ernst, S., Pozniakowsky, A., Ayloo, S., Hyman, A.A., and Bringmann, H. (2011). Codon adaptation-based control of protein expression in C. elegans. Nat. Methods 8, 250-252. Abstract Article

Reese, K.J., Dunn, M.A., Waddle, J.A., and Seydoux, G. (2000). Asymmetric segregation of PIE-1 in C. elegans is mediated by two complementary mechanisms that act through separate PIE-1 protein domains. Mol. Cell 6, 445-455. Abstract Article

Rivers, D.M., Moreno, S., Abraham, M., and Ahringer, J. (2008). PAR proteins direct asymmetry of the cell cycle regulators Polo-like kinase and Cdc25. J. Cell Biol. 180, 877-885. Abstract Article

Rocheleau, C.E., Yasuda, J., Shin, T.H., Lin, R., Sawa, H., Okano, H., Priess, J.R., Davis, R.J., and Mello, C.C. (1999). WRM-1 activates the LIT-1 protein kinase to transduce anterior/posterior polarity signals in C. elegans. Cell 97, 717-726. Abstract Article

Rose, L.S., and Kemphues, K.J. (1998a). Early patterning of the C. elegans embryo. Annu. Rev. Genet. 32, 521-545. Abstract Article

Rose, L.S., and Kemphues, K. (1998b). The let-99 gene is required for proper spindle orientation during cleavage of the C. elegans embryo. Development 125, 1337-1346. Abstract

Sadler, P.L., and Shakes, D.C. (2000). Anucleate Caenorhabditis elegans sperm can crawl, fertilize oocytes and direct anterior-posterior polarization of the 1-cell embryo. Development 127, 355-366. Abstract 
Sawa, H. (2012). Control of cell polarity and asymmetric division in C. elegans. Curr. Top. Dev. Biol. 101, 55-76. Abstract Article

Schenk, C., Bringmann, H., Hyman, A.A., and Cowan, C.R. (2010). Cortical domain correction repositions the polarity boundary to match the cytokinesis furrow in C. elegans embryos. Development 137, 1743-1753. Abstract Article

Schetter, A., Askjaer, P., Piano, F., Mattaj, I., and Kemphues, K. (2006). Nucleoporins NPP-1, NPP-3, NPP-4, NPP-11 and NPP-13 are required for proper spindle orientation in C. elegans. Dev. Biol. 289, 360-371. Abstract Article

Schlesinger, A., Shelton, C.A., Maloof, J.N., Meneghini, M., and Bowerman, B. (1999). Wnt pathway components orient a mitotic spindle in the early Caenorhabditis elegans embryo without requiring gene transcription in the responding cell. Genes Dev. 13, 2028-2038. Abstract Article

Schmidt, D.J., Rose, D.J., Saxton, W.M., and Strome, S. (2005). Functional analysis of cytoplasmic dynein heavy chain in Caenorhabditis elegans with fast-acting temperature-sensitive mutations. Mol. Biol. Cell 16, $1200-1212$. Abstract Article

Schnabel, R., and Priess, J.R. (1997). Specification of cell fates in the early embryo. In C. elegans II, D.L. Riddle, T. Blumenthal, B.J. Meyer, and J.R. Priess, eds. (Cold Spring Harbor, NY: Cold Spring Harbor Laboratory Press), pp. 361-382. Abstract

Schonegg, S., and Hyman, A.A. (2006). CDC-42 and RHO-1 coordinate acto-myosin contractility and PAR protein localization during polarity establishment in C. elegans embryos. Development 133, 3507-3516. Abstract Article

Schubert, C.M., Lin, R., de Vries, C.J., Plasterk, R.H., and Priess, J.R. (2000). MEX-5 and MEX-6 function to establish soma/germline asymmetry in early C. elegans embryos. Mol. Cell 5, 671-682. Abstract Article

Schulze, J., and Schierenberg, E. (2011). Evolution of embryonic development in nematodes. EvoDevo 2 , 18. Abstract Article

Shelton, C.A., and Bowerman, B. (1996). Time-dependent responses to $g l p$ - 1 -mediated inductions in early $C$. elegans embryos. Development 122, 2043-2050. Abstract

Shelton, C.A., Carter, J.C., Ellis, G.C., and Bowerman, B. (1999). The nonmuscle myosin regulatory light chain gene $m l c-4$ is required for cytokinesis, anterior-posterior polarity, and body morphology during Caenorhabditis elegans embryogenesis. J. Cell Biol. 146, 439-451. Abstract Article

Shin, T.H., Yasuda, J., Rocheleau, C.E., Lin, R., Soto, M., Bei, Y., Davis, R.J., and Mello, C.C. (1999). MOM-4, a MAP kinase kinase kinase-related protein, activates WRM-1/LIT-1 kinase to transduce anterior/posterior polarity signals in C. elegans. Mol. Cell 4, 275-280. Abstract Article

Shinar, T., Mana, M., Piano, F., and Shelley, M.J. (2011). A model of cytoplasmically driven microtubule-based motion in the single-celled Caenorhabditis elegans embryo. Proc. Natl. Acad. Sci. U. S. A. 108, 10508-10513. Abstract Article

Sonneville, R., and Gönczy, P. (2004). zyg-11 and cul-2 regulate progression through meiosis II and polarity establishment in C. elegans. Development 131, 3527-3535 3543. Abstract Article

Spiga, F.M., Prouteau, M., and Gotta, M. (2013). The TAO kinase KIN-18 regulates contractility and establishment of polarity in the C. elegans embryo. Dev. Biol. 373, 26-38. Abstract Article

Srinivasan, D.G., Fisk, R.M., Xu, H., and van den Heuvel, S. (2003). A complex of LIN-5 and GPR proteins regulates $\mathrm{G}$ protein signaling and spindle function in C. elegans. Genes Dev. 17, 1225-1239. Epub 2003 May 1222. Abstract Article

St Johnston, D., and Ahringer, J. (2010). Cell polarity in eggs and epithelia: parallels and diversity. Cell 141, 757-774. Abstract Article 
Subramaniam, K., and Seydoux, G. (1999). nos-1 and nos-2, two genes related to Drosophila nanos, regulate primordial germ cell development and survival in Caenorhabditis elegans. Development 126, 4861-4871. Abstract

Sugioka, K., Mizumoto, K., and Sawa, H. (2011). Wnt regulates spindle asymmetry to generate asymmetric nuclear $\beta$-catenin in C. elegans. Cell 146, 942-954. Abstract Article

Sulston, J.E., Schierenberg, E., White, J.G., and Thomson, J.N. (1983). The embryonic cell lineage of the nematode Caenorhabditis elegans. Dev. Biol. 100, 64-119. Abstract Article

Sumiyoshi, E., Takahashi, S., Obata, H., Sugimoto, A., and Kohara, Y. (2011). The $\beta$-catenin HMP-2 functions downstream of Src in parallel with the Wnt pathway in early embryogenesis of C. elegans. Dev. Biol. 355, $302-312$. Abstract Article

Tabara, H., Hill, R.J., Mello, C.C., Priess, J.R., and Kohara, Y. (1999). pos-1 encodes a cytoplasmic zinc-finger protein essential for germline specification in C. elegans. Development 126,1-11. Abstract

Takeshita, H., and Sawa, H. (2005). Asymmetric cortical and nuclear localizations of WRM-1/beta-catenin during asymmetric cell division in C. elegans. Genes Dev. 19, 1743-1748. Abstract Article

Tenenhaus, C., Schubert, C., and Seydoux, G. (1998). Genetic requirements for PIE-1 localization and inhibition of gene expression in the embryonic germ lineage of Caenorhabditis elegans. Dev. Biol. 200, 212-224. Abstract Article

Tenenhaus, C., Subramaniam, K., Dunn, M.A., and Seydoux, G. (2001). PIE-1 is a bifunctional protein that regulates maternal and zygotic gene expression in the embryonic germ line of Caenorhabditis elegans. Genes Dev. 15, 1031-1040. Abstract Article

Tenlen, J.R., Molk, J.N., London, N., Page, B.D., and Priess, J.R. (2008). MEX-5 asymmetry in one-cell C. elegans embryos requires PAR-4- and PAR-1-dependent phosphorylation. Development 135, 3665-3675. Abstract Article

Tenlen, J.R., Schisa, J.A., Diede, S.J., and Page, B.D. (2006). Reduced dosage of pos-1 suppresses Mex mutants and reveals complex interactions among $\mathrm{CCCH}$ zinc-finger proteins during Caenorhabditis elegans embryogenesis. Genetics 174, 1933-1945. Abstract Article

Thorpe, C.J., Schlesinger, A., Carter, J.C., and Bowerman, B. (1997). Wnt signaling polarizes an early C. elegans blastomere to distinguish endoderm from mesoderm. Cell 90, 695-705. Abstract Article

Thyagarajan, K., Afshar, K., and Gönczy, P. (2011). Polarity mediates asymmetric trafficking of the G $\beta$ heterotrimeric G-protein subunit GPB-1 in C. elegans embryos. Development 138, 2773-2782. Abstract Article

Tostevin, F., and Howard, M. (2008). Modeling the establishment of PAR protein polarity in the one-cell C. elegans embryo. Biophys. J. 95, 4512-4522. Abstract Article

Tsai, M.C., and Ahringer, J. (2007). Microtubules are involved in anterior-posterior axis formation in C. elegans embryos. J. Cell Biol. 179, 397-402. Abstract Article

Tse, Y.C., Werner, M., Longhini, K.M., Labbe, J.C., Goldstein, B., and Glotzer, M. (2012). RhoA activation during polarization and cytokinesis of the early Caenorhabditis elegans embryo is differentially dependent on NOP-1 and CYK-4. Mol. Biol. Cell 23, 4020-4031. Abstract Article

Tsou, M.F., Hayashi, A., DeBella, L.R., McGrath, G., and Rose, L.S. (2002). LET-99 determines spindle position and is asymmetrically enriched in response to PAR polarity cues in C. elegans embryos. Development 129 , 4469-4481. Abstract

Tsou, M.F., Hayashi, A., and Rose, L.S. (2003a). LET-99 opposes G $\alpha /$ GPR signaling to generate asymmetry for spindle positioning in response to PAR and MES-1/SRC-1 signaling. Development 130, 5717-5730. Abstract Article 
Tsou, M.F., Ku, W., Hayashi, A., and Rose, L.S. (2003b). PAR-dependent and geometry-dependent mechanisms of spindle positioning. J. Cell Biol. 160, 845-855. Abstract Article

Wallenfang, M.R., and Seydoux, G. (2000). Polarization of the anterior-posterior axis of C. elegans is a microtubule-directed process. Nature 408, 89-92. Abstract Article

Wang, J.T., and Seydoux, G. (2013). Germ cell specification. Adv. Exp. Med. Biol. 757, 17-39. Abstract Article

Werts, A.D., and Goldstein, B. (2011). How signaling between cells can orient a mitotic spindle. Semin. Cell Dev. Biol. 22, 842-849. Abstract Article

Werts, A.D., Roh-Johnson, M., and Goldstein, B. (2011). Dynamic localization of C. elegans TPR-GoLoco proteins mediates mitotic spindle orientation by extrinsic signaling. Development 138, 4411-4422. Abstract Article

Wu, J.C., and Rose, L.S. (2007). PAR-3 and PAR-1 inhibit LET-99 localization to generate a cortical band important for spindle positioning in Caenorhabditis elegans embryos. Mol. Biol. Cell 18, 4470-4482. Abstract Article

Zhang, H., Skop, A.R., and White, J.G. (2008). Src and Wnt signaling regulate dynactin accumulation to the P2-EMS cell border in C. elegans embryos. J. Cell Sci. 121, 155-161. Abstract Article

Zonies, S., Motegi, F., Hao, Y., and Seydoux, G. (2010). Symmetry breaking and polarization of the C. elegans zygote by the polarity protein PAR-2. Development 137, 1669-1677. Abstract Article

All WormBook content, except where otherwise noted, is licensed under a Creative Commons Attribution License. 